\title{
Organizing the Un-Organized ? Evidence from Indian Diamond Industry
}

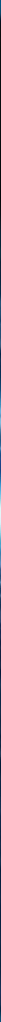




\section{ORGANIZING THE UN-ORGANIZED? EVIDENCE FROM INDIAN DIAMOND INDUSTRY}

K. Indu Rao 


\section{Thesis committee members:}

Prof. dr. ir. A.J. Mouthaan (chairman)

Prof. dr. Kuldeep Kumar (promotor)

Prof. dr. Jos van Hillegersberg (promotor)

Prof. dr. L.J.M. Nieuwenhuis

Prof. dr. Tanya Bondarouk

Prof. dr. H.G. van Dissel

Prof. dr. Slawek Magala
University of Twente

University of Twente \&

Florida International University

University of Twente

University of Twente

University of Twente

University of Amsterdam

Erasmus University

The work described in this thesis was performed at the IEBIS group, Faculty of Behavioral, Management and Social Sciences, University of Twente, PO Box 217, 7500 AE Enschede, the Netherlands.

Ph.D. thesis, University of Twente, Enschede, the Netherlands Printed at Ipskamp Drukkers B.V. Enschede CK. Indu Rao, Enschede. 2014.

All rights reserved. No part of this publication may be reproduced, stored in a retrieval system or transmitted in any form or by any means, electronic or mechanical, including uploading, downloading, printing, decompiling, recording or otherwise without the prior written permission of the author.

ISBN:- 978-90-365-3724-7

doi :- 10.3990/1.9789036537247.

url :- http://dx.doi.org/10.3990/1.9789036537247 


\title{
ORGANIZING THE UN-ORGANIZED? EVIDENCE FROM INDIAN DIAMOND INDUSTRY
}

\author{
DISSERTATION
}

to obtain

the degree of doctor at the University of Twente, on the authority of the rector magnificus, prof. dr. H. Brinksma,

on account of the decision of the graduation committee,

to be publicly defended

on day the 24th of October, 2014 at $1245 \mathrm{hrs}$

by

\section{K. Indu Rao}

Born on the $2^{\text {nd }}$ October, 1971

at Udaipur, India 
This dissertation has been approved by my promotores:

Prof dr. Kuldeep Kumar

Prof dr. Jos van Hillegersberg 


\section{ACKNOWLEDGEMENTS}

First, I express sincere thanks to my promotores Prof Kuldeep Kumar and Prof Jos van Hillegersberg for accepting me as a $\mathrm{PhD}$ candidate at the University of Twente and for their invaluable support and guidance in this work. $\mathrm{A} \mathrm{PhD}$ candidate can only have ideas, but without encouragement and support from the promotores, ideas never get channelized into a thesis. I am lucky and honored to have had exchange of ideas through a series of discussions with my promotores. They helped me work with countless number of drafts of this thesis before it has reached this stage.

I thank Prof A.J. Mouthaan and Prof P.B. Boorsma for the inspiration and help. I am grateful to the committee members, Prof Han van Dissel, Prof Slawek Magala, Prof Bart Nieuwenhuis and Prof Tanya Bondarouk for their time and expertise which has improve the quality of my thesis. I thank all members of IEBIS department of Faculty of Behavioral, Management and Social Sciences at the University of Twente for the learning received as part of the group. I specially thank Prof Jos for providing me with a visiting scholar position, office space and support facilities at the Twente campus. It helped me focus and complete the dissertation. I feel blessed to get valuable feedback from Prof Celeste P.M. Wilderom on this thesis and humbly express my thanks to her.

Prof Marianne and Hans, Prof Chintan Amrit and Simi were great friends in Enschede, Netherlands, your emotional support kept me going while I was away from my kids and family in India. Elke, Hilde, Brenda, Astrid, Evelien, I thank you for the friendly smiles, lively talks over coffee and for your office support during the writing up of thesis. Love you ladies, for making this enjoyable ! Patricia, the friendly representative from the printers at Enschede, I admire you for your timely, professional response.

The support of people working in the Indian diamond industry forms the basis of this work. I would like to mention Mr Sevanthibhai Shah and Mr Rahul Pandey for kindly allowing me to collect data from workers of their diamond factory, sometimes, at the expense of stopping production for hours. I owe gratitude to the hundreds of workers, artisans and owners of the small, medium and large units engaged in cutting and polishing of diamonds in Surat and Surendranagar, in the state of Gujarat, India, for their time, willingness and enthusiasm in sharing their knowledge and helping me understand.

Although it is not possible to mention here all the names, but it is these people who gave me a first hand experience of the culture and working of the Indian diamond 
industry. I also thank the director of Indian Diamond Institute, Surat, Mr K K Sharma and the Chairman of Gems and Jewelery Export Promotion Council, Mumbai for their useful insights.

Partial findings of this research were presented at several international conferences. I thank each and every reviewer and participant who gave their feedback. Prior to joining academics, I had worked for seven years in the corporate India with companies like Crompton Greaves and G.E. in Mumbai and in Gujarat, that work experience also added to my understanding of the organized and un-organized.

I acknowledge support from the Indian Institute of Management, Ahmedabad (IIMA) in Gujarat, India for awarding me a Post Doctoral Fellowship from 20082010. I also thank my guide Prof P.K. Jain, Director, Faculty of Management Studies, MLSU, India, for guidance through my first $\mathrm{PhD}$ in Management completed in 2006. I have grown due to mentoring of my teachers and professors in school, and in engineering and management colleges, my sincere gratitude to Prof G. Raghuram, Prof D. M. Pestonjee and Prof Kalpana Mishra.

I also acknowledge funding support from Florida International University, USA from (2006-07 and 2011-13), and all faculty for helping me learn to conduct traditional research, FIU is where I completed coursework and passed the competency exam for a $\mathrm{PhD}$ candidacy. Then, unfortunately, a series of personal circumstances (including loss of my father and then of my beloved brother Tarun who passed away in the line of duty) didn't allow me to continue to live in the USA and I returned to India. Prof Kuldeep Kumar, holding professorship at FIU and at University of Twente, kindly suggested me to move to Twente. Prof Jos van Hillegersberg, from the University of Twente, generously accepted me as an external $\mathrm{PhD}$ candidate and offered all support. It is due to rigorous guidance and support from my promotores at Twente that I have been able to work on and complete this thesis.

Lastly, I thank almighty God for his blessings so as to finally end this long struggle towards an international $\mathrm{PhD}$ degree. I express my heartfelt gratitute to all friends and family who cared for and inspired me during this journey. My mother Dr Shail Gupta has given strength to me. My husband, Dr Kaveti Laxminarayana Rao and my sons, Aditya, Arjun and Aryan have patiently stood by my side with their unfailing love, encouragement and support. I dedicate this thesis to my kids, to my husband and to my mother.

Dr K. Indu Rao

email id:- igkln4@gmail.com 



\section{Contents}

Chapter 1. Introduction.......................................................................... 1

1.1 Background of the Study............................................................. 1

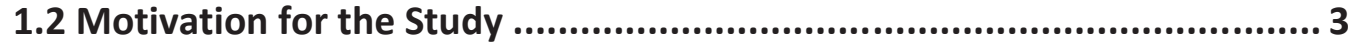

1.3 The Research Problem ........................................................................ 7

1.4 The Research Objectives ................................................................. 12

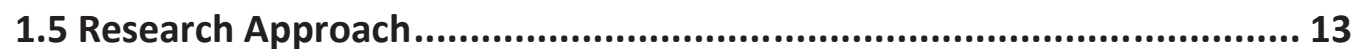

1.6 Layout of the Thesis................................................................... 16

Chapter 2. Literature Review ................................................................... 19

2.1 Why study Informal Economy and the Informal Firm ? ......................... 19

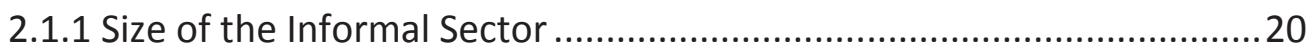

2.1.2 Meaning of the Informal Economy ..................................................20

2.1.3. Theories of the Informal Sector ........................................................24

2.2 Why study Organizational Culture ? ............................................... 26

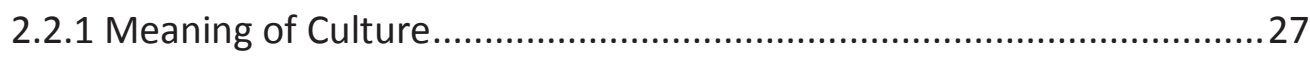

2.2.2 Concept of Organizational Culture ..................................................2 27

2.2.3 Ontological Status of Organizational Culture ......................................28

2.2.4 Relevance of Study of Culture in ISFs .................................................29

2.3 Measuring Organizational Culture...................................................... 29

2.3.1. The Competing Values Framework (CVF) ...........................................30

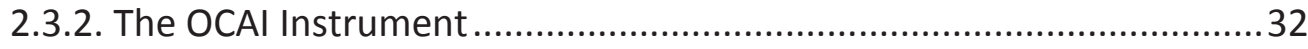

2.4 Constructivist Grounded Theory ...................................................... 34

2.4.1. Why Grounded Theory as a methodology? .......................................34

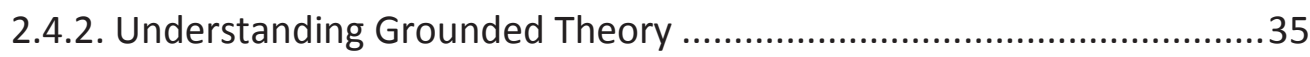


Chapter 3. The Emergence of the Informal Sector Firms in International Business: The Globally Distributed Indian Diamond Industry ........................ 39

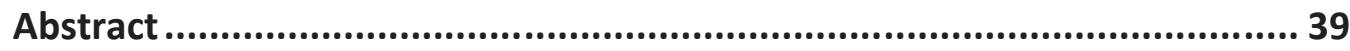

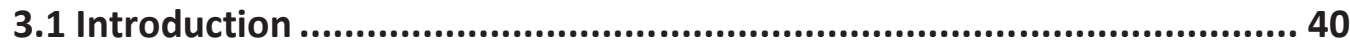

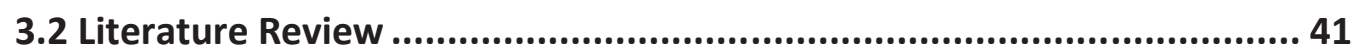

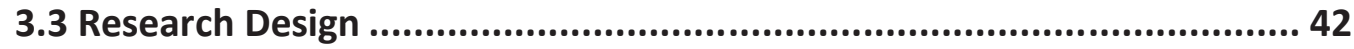

3.3.1 The Research Context.................................................................... 42

3.3.2 Sample and Data Collection .........................................................4 44

3.4 Summary of Findings: The Industry Overview .................................... 45

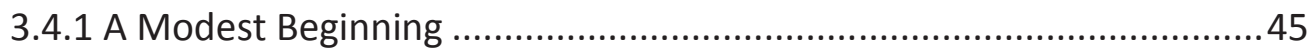

3.4.2 The Incredible Growth Years ..............................................................45

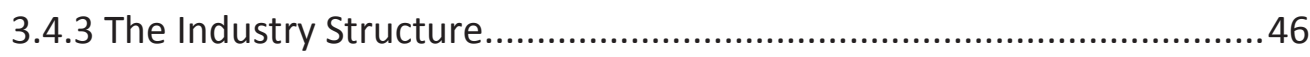

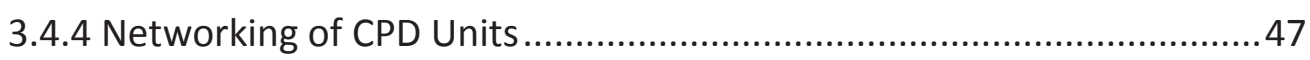

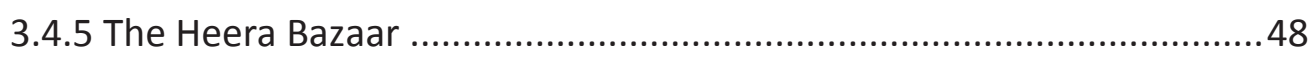

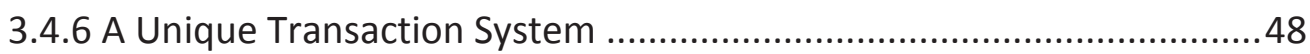

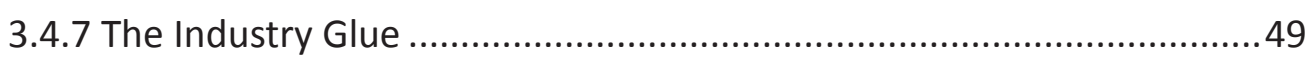

3.5 Summary of Findings: The Firm Overview ........................................ 49

3.5.1 The Initial Growth Phase .................................................................49

3.5.2 Defining the Concept of the Workplace...............................................50

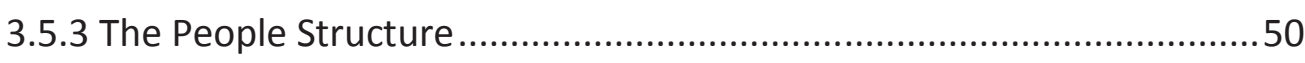

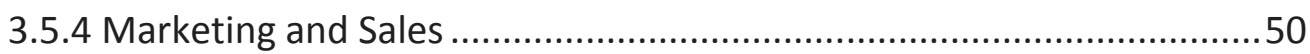

3.5.5 Achieving Quality in Production ........................................................51

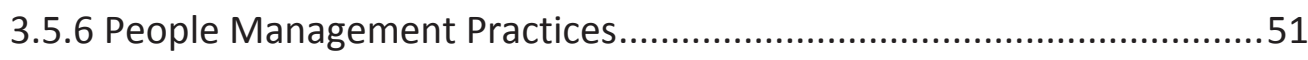

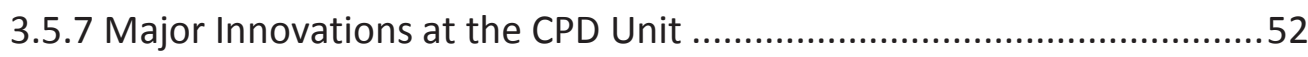

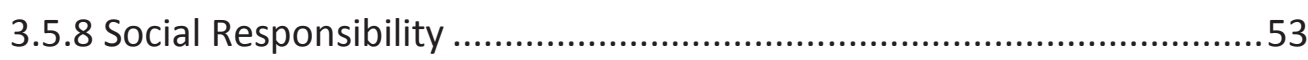

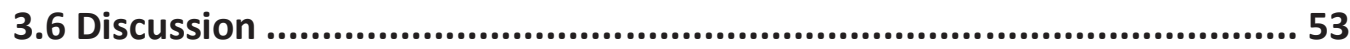

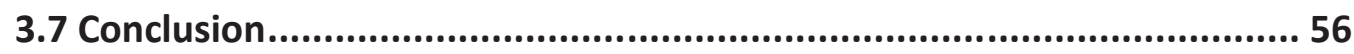

3.7.1 The Significance of ISFs to International Business ..............................56

3.8 Implications for Future Research ................................................. 57 
Chapter 4. Surviving the Recession: Venus Jewel -A Case Study from Indian Diamond Industry............................................................................... 59

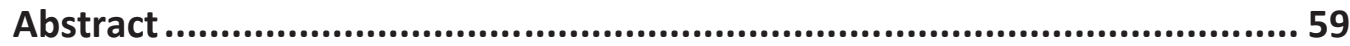

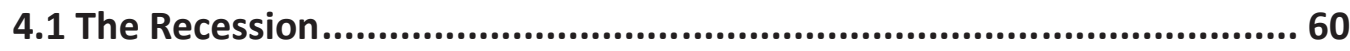

4.2 Global Positioning of the Indian Diamond Industry ............................. 61

4.3 How does the Indian Diamond Industry Operate? .............................6 62

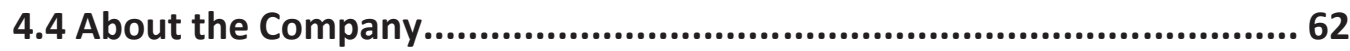

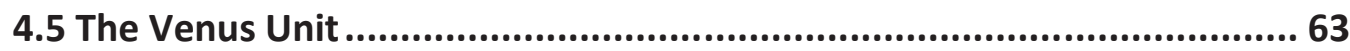

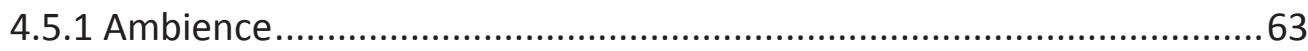

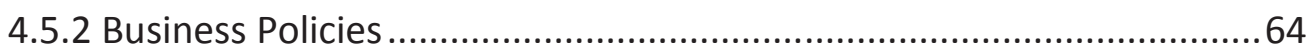

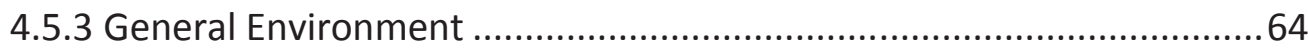

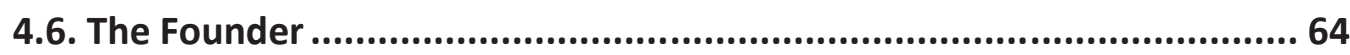

4.7 Major Innovations / Milestones ....................................................... 66

4.8 The Informal Organization Structure ................................................69 69

4.9 The Manufacturing Process Flow Chart ............................................ 70

4.10 The Unique Quality / Incentive Linked Wage System ........................ 70

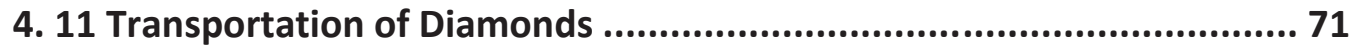

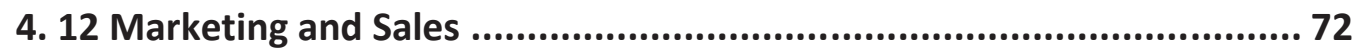

4. 13 IT Driven Business Model ............................................................... 72

4.14 People-Management Practices........................................................ 74

4.14.1 Training / Recruitment / Salary Structure ....................................... 74

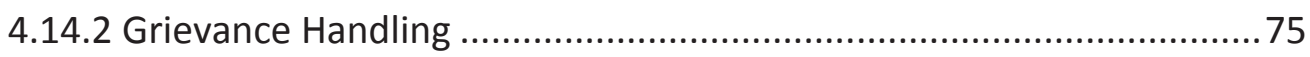

4.14.3 Welfare Measures ........................................................................ 75

4.14.4 Communication Channels .............................................................. 76

4.15. Adoption of Technology: Systems Oriented Management ................. 77

4.15.1 Online stock search system...........................................................77

4.15.2 Confirmed Order Requirement (COR) system.................................. 77 
4.16. Contribution to the Diamond Industry ......................................... 78

4.17 Contribution to Society.............................................................. 78

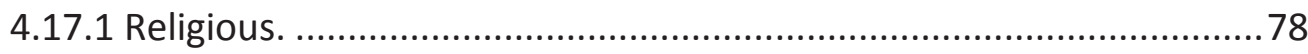

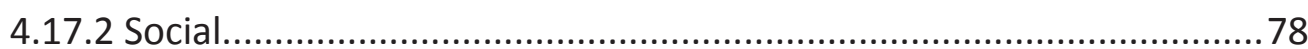

4.18. The Road to Future .................................................................... 80

Chapter 5. The Behavioral Equivalence of Organizational Culture:-A Conceptual Framework ................................................................................. 83

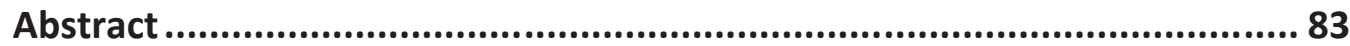

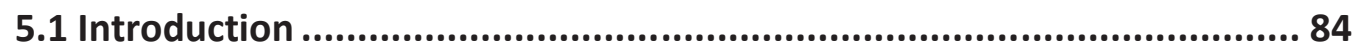

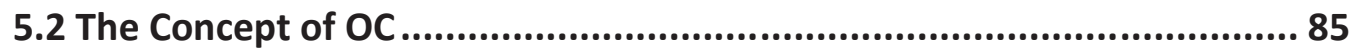

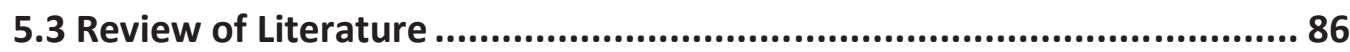

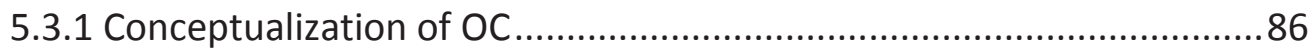

5.3.2 Interrelating $\mathrm{OC}$ with other variables.................................................90

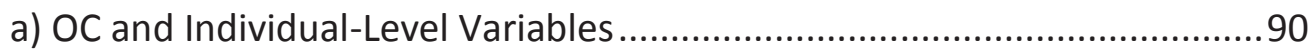

b) OC and Organizational -level Variables ..................................................91

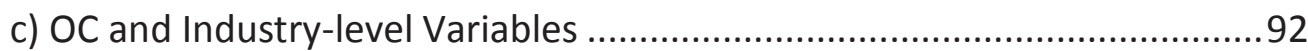

d) OC and Intra-organization level Variables ...............................................93

e)OC and Environment-Related variables ..................................................94

5.3.3 OC Studies in Different Contexts and Countries ..................................95

5.4 Proposing a Conceptual Framework .............................................. 97

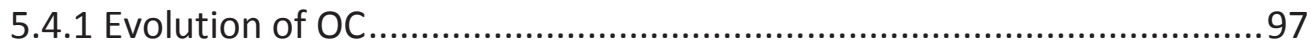

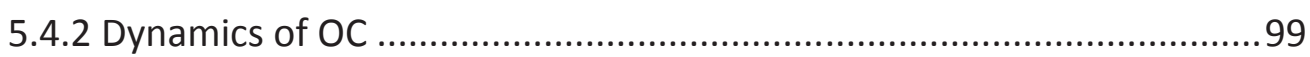

a) Sources of Behavior: Individual level .....................................................99

b) Sources of Behavior: Organizational level ............................................100

c) Sources of Behavior: Industry level .......................................................100

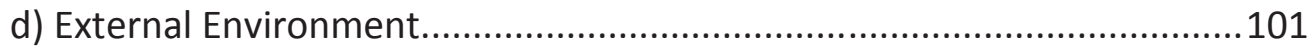

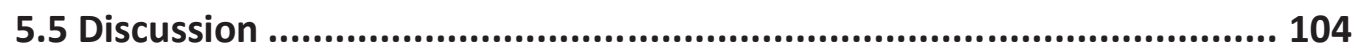


Chapter 6. Implications of Global Crisis: Integrate Sustainability with Organizational Culture ....................................................................... 107

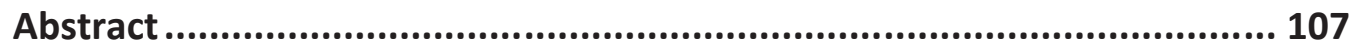

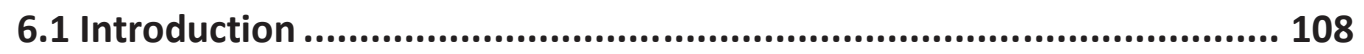

6.2 Literature Review ..................................................................... 108

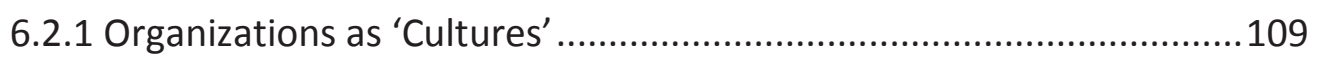

6.3 Sustainability of Organization ......................................................... 110

6.4 Organizational Culture and Sustainability ...................................... 111

6.5 Leadership, Organizational Culture and Sustainability ........................ 112

6.6 Trust, Organizational Culture, Sustainability .................................... 114

6.7 Leadership and Trust as Moderators ................................................. 115

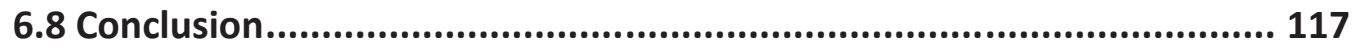

6.9 Implications for Future Research and Practice .................................. 117

Chapter 7. Results of Organizational Cultural Assessment using OCAI......... 119

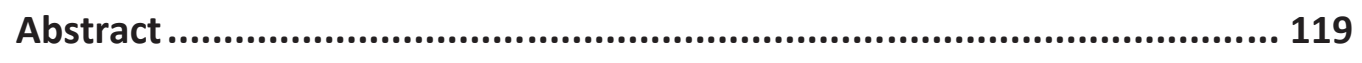

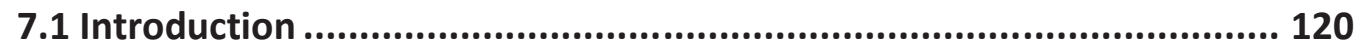

7.2 Literature Review ........................................................................ 121

7.3 Research Method ............................................................................. 123

7.3.1 Selection of the Firm. ..................................................................123

7.3.2 Selection of the Instrument ...........................................................123

7.3.3 Translation and Validation of the Instrument ...................................124

7.3.4 Sample and Data Collection ........................................................ 125

7.4 Demographic Profile of the Sample.................................................... 125

7.5 Results: Cultural Profiles ............................................................. 128 


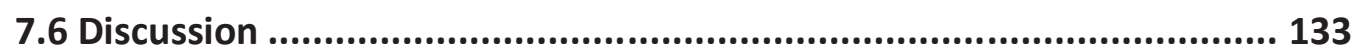

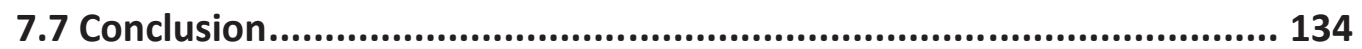

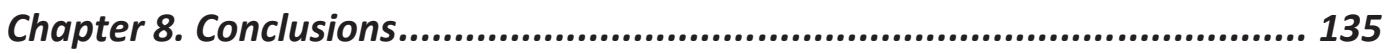

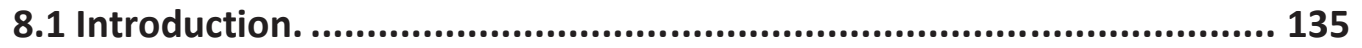

8.2 Insights from the Study of ISFs in Indian Diamond Industry (Objective 1)

8.3. Towards an Initial Theory of the Informal Firm ( Objective 2) ............. 141

8.3a Our View of the Informal Firm ...........................................................144

8.4 Contributions of the Study ....................................................... 149

8.4 a. Contribution to Practice ................................................................. 149

$8.4 \mathrm{~b}$ Contribution to Scholarship .......................................................... 150

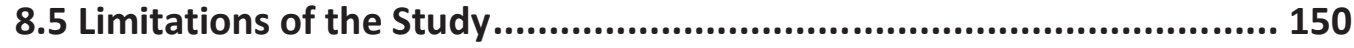

8.6 Implications of the Study and Directions for Future Research .............. 151

Appendix A. The Meaning of Informal Sector ........................................ 169

Appendix B. Theories of Informal Sector............................................ 172

Appendix C. The Meaning of Informal Economy ................................... 170

Appendix D. OCAl Instrument.................................................. 172

Appendix E. The List of Variables Used in Analysis .................................. 174 


\section{List of Figures}

Figure 1 Global Market Share of Sales of Polished Diamond by Countries.............8

Figure 2 Competing Values Framework (CVF) .................................................. 32

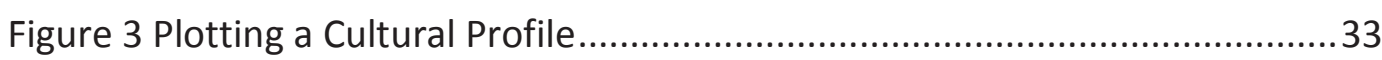

Figure 4 Growth of Exports of cut and polished diamonds from India .................43 43

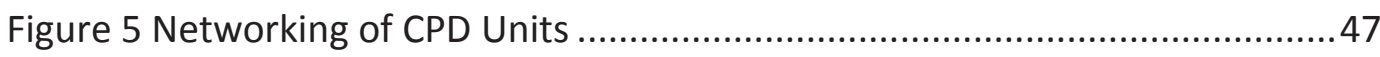

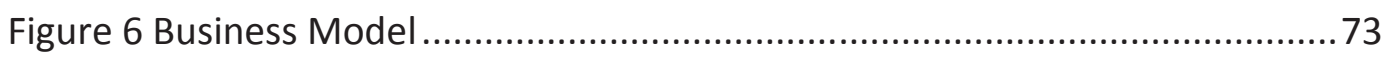

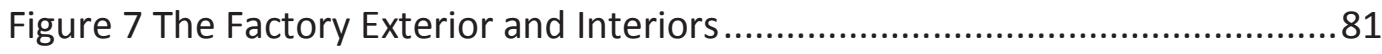

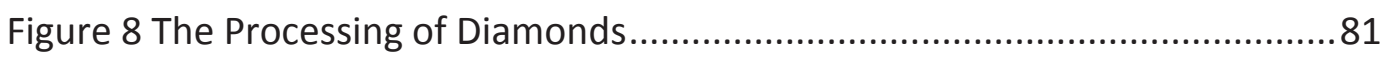

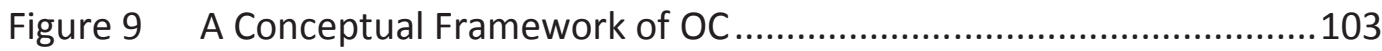

Figure 10 The Competing Values Framework...................................................124

Figure 11 Demographic Profiles of the CPD Unit...........................................126

Figure 12 Overall Cultural Profile ...................................................................129

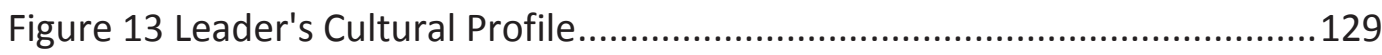

Figure 14 Dimension-wise Cultural profiles...................................................130

Figure 15 Comparative Cultural Profiles..........................................................132

Figure 16 A Model of Informal Economy, proposed by Godfrey, 2011 ..............142

Figure 17 Our View of the Informal Firm ........................................................ 147

\section{List of Tables}

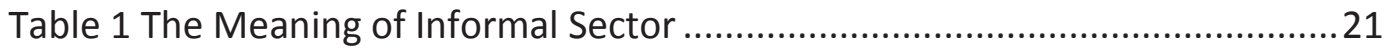

Table 2 The Meaning of Informal Economy .........................................................22

Table 3 Countries exporting Polished Diamond (by value) ...................................44

Table 4 Cultural Perceptions along six dimensions of OCAI .............................128

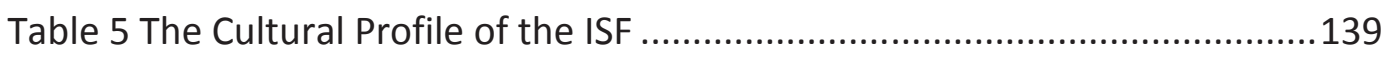

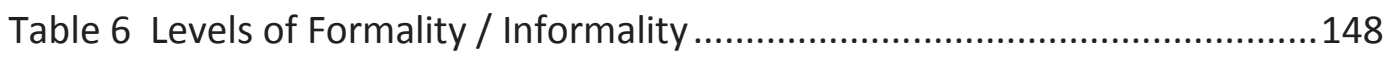




\section{Chapter 1. Introduction}

\subsection{Background of the Study}

Although traditional research in management has largely focused on the organized sector and formal organizations, recent literature suggests that the so-called unorganized or the "informal economic activity represents a significant new frontier for management scholarship and investigation" (Godfrey, 2011). In another view (Bruton et al, 2012) observed that, "the informal economy is the final frontier of the management domain", and that informal economic activities "may yield a quantum theory for management scholars, provide insights about economic and organizational activity at the very smallest and - paradoxicallythe very largest scale" (Turner, 2004). Scholarly attention to the informal economy and informal economy firms was further highlighted as the Academy of Management (the world's largest association of management scholars) adopted the theme "The Informal Economy" for its 2012 Annual Meeting in Boston.

Understanding the informal economy and informal sector has been problematic. While, currently, various definitions of the informal economy exist in the literature (Appendix A, B, C); very few articles in management literature deal with organization of informal firms (Bruton et al, 2012). Although there is some effort at theory construction (Khavul et al, 2009; Webb et al, 2009), we still need clarity on which firms can be classified as an informal firm, and still need to investigate and understand the organizational aspects of informal firms.

The earlier view in organizational theory was that "informal organization is the aggregate of personal contacts and interactions and associated groupings...informal organization is indefinite and rather structure-less" (Barnard, 1938, p115). However, the meanings of informal firms have changed over-time (Appendix A). There is an increased recognition of the fact that informal economy constitutes a major share of the world's business activity (Schneider et al, 2000). Therefore, we believe, and this research has discovered, that the informal firms do have some kind of organization which helps them continue to survive, thrive, and grow. This lack of knowledge about the organizational aspects of informal economy firms identifies a research gap that we have tried to address in this study.

The concept of the informal sector was originally identified in 1972 by the international labor organization (Bangasser, 2000). The International Labor 
Organization (ILO) defined ISFs (informal sector firms) as: firms that were small scale, had a low resource base, low entry barriers, family ownership, were laborintensive, used adapted technology and skills acquired outside the formal sector, and operated in unregulated and competitive markets (ILO, 1972). What followed was seminal and subsequent work on informal economy by Hart $(1973 ; 2005$; 2006; 2007). Researchers in this stream suggested that informal firms produce goods and services, with the primary objective of generating employment and income for its stakeholders but that they are also a key form of organization for production of goods and services in rural and urban areas (ICMISIE, 2009).

An informal firm is a complete business and includes all functions of a traditional formal business organization. Except, typically in an informal firm, these functions may not be formally assigned to specific persons. The same person often assumes many of these classical functional roles. Similarly, depending on the situation, at different times, different persons may perform a role. While this organization may detract from the recognized benefits of functional specialization; it also leads to synergies of thinking and acting in an integrated manner.

The conceptual terrain of the informal economy includes several functional/academic disciplines. The construct of an ISF can span several levels of analysis, from micro-level concerns with knowledge, skill, and management ability of individuals, through the macro level issues of organizational form, competitive advantage, and institutional setting, to the meta-level national and international issues of tax, education, and legal policy (Godfrey, 2011; LaPorta \& Schleifer, 2008).

In our research, we restrict ourselves to a firm level analysis of informal sector firms, specifically the "organizational culture" of the firm. See Appendix C for a review of how various management scholars (Zinnes, 2009; Poppo \& Zenger, 2004) have studied the informal economy. It should be recognized that an informal economy may consist of many informal firms. Thus informal firms operate within the informal economy and may inherit characteristics of the informal economy.

For this new stream of research, we take informal firms to be "unregistered businesses which derive income from the production of legal goods and services" (Nichter \& Goldmark, 2009). But informality may be better captured or described by a continuum (DeCastro \& Bruton, 2012). Recent related articles in established management journals that have centered on informal economy deal with literature 
reviews (Godfrey, 2011; Williams \& Nadin, 2010) from domains like economics and sociology. Nevertheless, investigating organizational behavior/humanresource-management perspectives could be useful when examining informality (Bruton et al, 2012). Thai and Turkina (2012) find that national culture affects the degree of informality within an economy while Williams \& Nadin (2010) find that "enterprise culture is an important facet of informal entrepreneurship and cannot be brushed aside as some minor issue of relatively little importance." We can thus draw from the recent developments in the research on informal economy and informal firms that there is a need for clarity on defining the informal firm, a firm level analysis of informal firms, as well as the culture of such firms. At present we have only minimal literature about the values and perceptions that guide organizational action in the ISFs.

This thesis is an attempt to address this gap in knowledge about informal firms. The remaining chapter describes the motivation for the study and development of the research question and research objectives, followed by the research method and layout of the thesis.

\subsection{Motivation for the Study}

There is recent call for indigenous research in this new stream of research about informal firms. ".......there is a need for an indigenous examination of the firms and managers in institutional settings where informal firms dominate.... Too often scholars from mature economies, who commonly have little to no grounding in the institutional setting they are examining, will find significance in their statistical analysis but may be revealing results with little materiality or face validity. Thus, there is a need for scholars with an intimate knowledge of the context to help define the questions to ask and also ensure that the evidence found provides material and important insights into the actual setting at hand." (Bruton et al, 2012)......

Rightly then, I have identified the informal firms engaged in cutting and polishing of diamonds of the Indian diamond industry in an institutional setting where informal firms dominate, and empirically investigated their organizational culture using mixed-methods.

While the 2012 Academy of Management conference has spurred an interest in the study of informal firms, my interest in the subject is much older. From 19962006, while studying for MBA and first $\mathrm{PhD}$ degree, I lived in the state of Gujarat, in West India. Gujarat predominantly has an entrepreneurial culture consisting of start-ups that have grown to become large within the time-space of a generation (Adiga, 2004; Banerjee, 2014). Many of these firms are engaged in 
exports and international business. These firms are run by local entrepreneurs, and have contributed to the economic prosperity of the state as a whole.

A large number of my friends and neighbors were connected to the diamond business flourishing in this city. Hearing their discussions and stories, about the diamond business, I was intrigued and made several informal visits to the firms engaged in cutting and polishing of diamonds. I found that there was very little connect in the way these firms were managed and organized, and what I studied in the journals and books on management literature and courses in Management Schools. The owners and employees of these firms had little formal education and barely had business school training. But they seemed to know well their business, and ways of organizing them.

Between, 2000 and 2006, I lived in the city of Surat in Gujarat. Surat is the not just the hub of the Indian diamond industry, but it also manufactures $95 \%$ of all diamonds processed in the world. With the help from local friends, I visited small and large firms engaged in manufacturing of diamonds and contacted their founders, owners, managers, and employees. I discovered that that many of these smaller firms were run from inside private homes. Some firms did not even have a registered postal address.

Nonetheless, tens of thousands of such firms (nobody seems to know the exact count of such firms) are well integrated in the overall supply chains of the Indian diamond manufacturing industry. While completing my first $\mathrm{PhD}$ degree in management during this period, surrounded by and observing these highly dynamic and successful firms on a day-to-day basis, I increasingly became uncomfortable with the situation that the current management literature provided no theories and insights explaining the existence of informal sector firms, and describing them.

The Indian diamond industry has been typically labeled as unorganized. Despite attempts by large companies to corporatize their businesses, these firms are still considered to be in the unorganized sector (Gaitonde, 2014). However, the large numbers of firms that constitute the thriving diamond business in India, surely have a way of organizing themselves. Perhaps, this way is quite different from the more "formal" ways of organizing traditional firms. Perhaps that is why they have not formally registered on the awareness of traditional management scholars. This perceived gap in knowledge about these "informal firms (IFs)" ignited my desire to better understand them 
From my own personal experience with these firms, and comparing them with the scholarly literature on traditional formal firms, I realized that compared to the formal structures, processes, and governance structures of formal firms, these firms were really "informal" and could truly be called IFs (Informal Firms). However, unlike traditional researchers, rather than ignore these firms, I considered them as an opportunity to study and report on these unorganized (in the traditional sense), but nonetheless a significant proportion of the business firms, in emerging countries.

As I investigated this different form of organizing, I made the first research presentation of my preliminary findings about the Indian diamond industry in 2007, at the International Conference on Management of Globally Distributed Work at the Indian Institute of Management, Bangalore. My second presentation on this topic was in 2008, at the International conference on Globalization and Emerging Economies held at Indian Institute of Management, Indore. The response to my presentations at both academic conferences was positive and encouraging.

Next, I got an opportunity to work as a Post-Doctoral Fellow at the Indian Institute of Management, Ahmedabad (India's premier Business School) from 2008-2010. At IIM-Ahmedabad, I continued to pursue my research in IFs. As the topic of informal firms was new to the field of management, it was difficult to choose a specific area or department at IIMA to work with. My selection committee and I mutually agreed on "organizational behavior" area as my home department. (IIMA is not organized along functional lines. Equivalent of Functional Departments are called "Areas" at IIMA).

By this time, I had the following preliminary research question in my mind:

\section{"Without formally defined processes and structure, how do Informal Firms in the Indian diamond industry organize themselves?"}

In the years that followed, findings of this research were disseminated in international conferences and publications. I continued to get positive responses during presentation of different stages of my research on diamond industry: at the Academy of International Business Conference at Rio de Janeiro, Brazil, in 2010; the Academy of International Business, South East Conference in Orlando, in 2011; and then at the Academy of Management Meeting in Boston in 2012. The submissions were also accepted for presentation at International HRM Conference in Aston, UK; Pretoria, in South Africa and the Academy of International Business Meeting in Australia. In all, I was motivated enough to continue to 
research and publish findings of this research on ISFs of the Indian diamond industry and they are included in the chapters of this thesis.

I was able to visit many small, medium and large, largely informal, firms, and had discussions with different stakeholders in these firms. While there were no specific answers to my question, one word, "culture," (...as in,"it is in our culture"; "business is in our culture") kept recurring in my conversations with various stakeholders. In the minds of these stakeholders, it was their "culture" that made them special, different from other formal organizations, and was the main reason that they were structured and managed to operate "informally" as they did.

I decided to investigate this "culture". These firms, unlike formal firms, both for their internal structure, processes, and governance, and for their business with others in the Gujarat CPD industry, seemed to work mainly on trust and relationships. They seemed to be organized as family-clans within local industryclans. Like their formal counterparts, their organizational culture encompassed several aspects of organizing like, leadership, employee management, and organizational glue. But these aspects were quite organized differently than those in formal organizations. There was clearly a need to understand various aspects of organizing in the informal firms. This investigation required a qualitative approach not just statistical analysis of existing concepts in literature. After a year of searching and reviewing literature, I inferred that in the absence of formal organizational business practices such as stated mission and vision statements, defined organizational structures, explicit strategies, and defined processes; it was the "organizational culture" that governed and guided business practices in these firms in the Indian diamond industry. To understand these firms, it was important to understand their culture.

This conjecture was also supported by the extant management literature on formal organizations. Organizational Culture has been referred to as a "powerful determinant of organizational life" (Brown, 1992; Smircich, 83). Some scholars go as far as to even suggest that an organization is nothing but its culture; or a coalition of cultures, and that everything in the organization is just a manifestation of its culture. Thus, the organization's culture plays an important role in understanding that organization.

Although informal economic arrangements have been mentioned in mainstream areas of management research such as relational governance ( J. H. Dyer \& Singh, 1998; Chakroborthy, 1997) and considered as key innovations in the businessmodels in entrepreneurial cultures (Saxenian, 2000), we did not find a specific 
study of organizational culture conducted in the informal firms. Literature suggests that the culture of an organization can also be a source of sustained competitive advantage (Barney 1986). Therefore, for this study, we decided to investigate the culture of the informal firms of the Indian diamond industry.

\subsection{The Research Problem}

The informal economy has been acknowledged as an important context for management research (Godfrey, 2011). Unfortunately, except for limited studies, such as in the Italian industrial districts Giacomo Becattini,(1991), Piore and Sobel (1984) and Kumar, van Dissel, and Bielli (1996), informal sector "firms" have not been of particular interest to scholars in the formal streams of management research.

We do not lay any claims to whether such "informal" arrangements are good or bad. They may or may not work in the long run. Due to non-compliance with regulations, or the lack of documentation in transactions, there could be threats and risks to both the firms, as well as the employees of such firms. Nevertheless, this unique, currently successful phenomenon calls for investigation into the organizational structures, processes, and cultures of these firms. Academics, managers and practitioners accustomed to formal organizational structures are typically mystified when dealing with these firms. For management scholars, it is important to understand what is keeping these firms not only functioning, but operating successfully, and even thriving, internationally (Bain \& Company Report, 2013), see Fig 1.

This paucity of research in this potentially rewarding area could be due to lack of availability and access to primary data about these firms. While, many of the people engaged in the industry have little formal education, they are still continuing their business successfully without it. They do not see much value in formal education and research. On the other hand, this lack of research could also be due to small economic significance attached to the informal sector firms by researchers, due to their informal nature. Finally the paucity of research on IFs could also be due to a lack of existing vocabulary and concepts that can be used to describe IFs. Due to this lack of vocabulary the researchers cannot simply recognize and identify these concepts in real life, much less observe or measure them. 
Global sales of polished diamonds by selling country, $\$$ billions

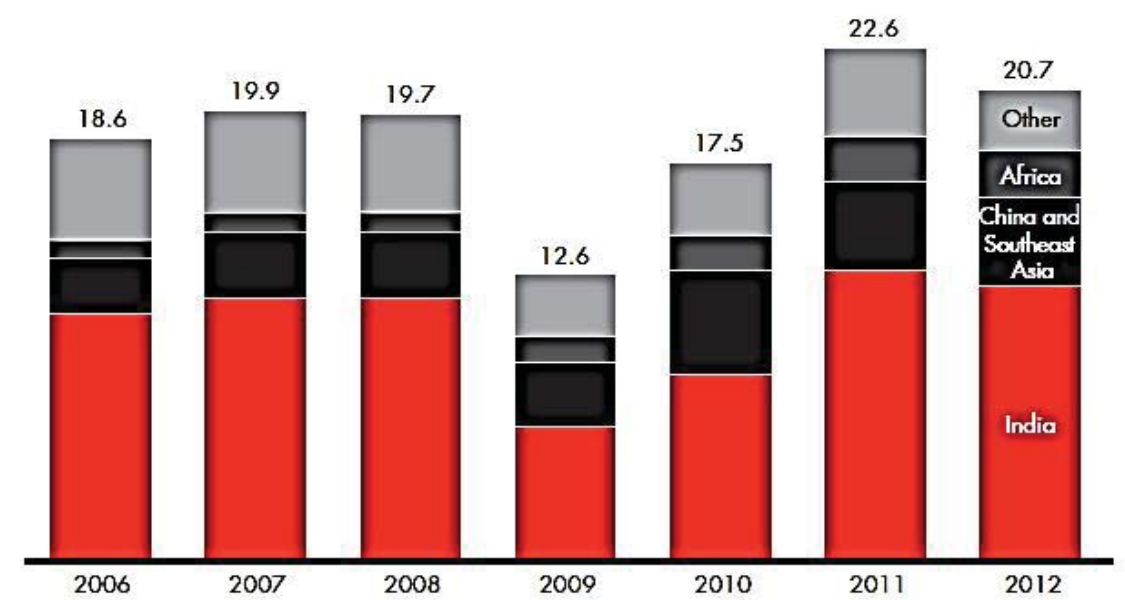

However, these so-called unorganized sector firms may be more organized than originally thought. Their organization may come, not from formal structures and procedures, but from trust-based relationships, and cultural traditions. Despite their lack of formal structures and processes, these firms continue to thrive, and demonstrate high levels of success in growth, productivity, and increased global market presence (Bruton et al, 2012). "Neither theorists nor empiricists have studied this phenomenon of the globally successful informal sector firms, especially in the diamond industry" (Rao \& Von Glinow, 2012).

The above discussion shows that, at present, not much is known about Informal Firms (IFs) in the diamond industry in India. For the customers and suppliers of these ISFs, who regularly trade with them, understanding what makes these firms tick, is a not just an academic exercise, it is a matter of considerable strategic concern. Moreover, with their lack of formally defined structures and procedures, classical organizational theorists presently do not understand how these informal sector firms continue to come into being, exist, operate, prosper, and grow.

These IFs are no longer just low-cost outsourcing destinations for diamond cutting and polishing. Traditional transaction costs theory or traditional hierarchy and arm's length arrangements generally used to explain international business of firms (Williamson, 1975; Coase, 1937) are insufficient to explain such 
organizations. We need to first acknowledge that informal firms, such as those of the Indian diamond industry, are successful global firms (Fig1 above). The people governing these firms, owners, managers and employees are conducting significant amounts of global business. These people have values and beliefs which guide their organization of business activity. As scholars, we need to know what values and beliefs are held by their members, values that drive their business practices. Such informal firms have their organizational culture, a shared pattern of values, beliefs and assumptions in a firm (Schein, 1983) and has apparently led to sustained competitive advantage (Barney, 1986).

Further, imprinting theory suggests that firms founded in a particular point of time in history carry forward with them the organizational forms, and the cognitive categories which reside in the perceptions of the members of their organizations (Stinchcombe, 1965; Johnson, 2007). These cognitive categories of the organization held my members is their perception of their organizational culture and described as cultural types in the competing values framework (Quinn and Rohrbaugh, 1983). The organizational culture is what it is as a result of external adaptation and integral integration as the firms evolved from the conditions of founding and grew over time. As imprinting theory suggests, the organizational culture however, once formed is stable over the period of time as the firms have grown from a small size to medium, to and large.

Moreover, we know that relatively recently, only three hundred years ago ${ }^{1}$, before the invention of the modern corporations by the Dutch business as a way of furthering their colonial adventures ${ }^{2}$, unorganized firms were the pre-dominant form of organizing in Europe (and the world). In History of Modern Corporations; Alfred P. Sloan from GM was the pioneer of the modern formal organization form (The Boston Globe, 2011). Now, we have got so used to studying the formal organization that the informal was forgotten in management studies.

\footnotetext{
${ }^{1}$ Three hundred years, while seeming a large time frame, is not a large duration when considered in relation to ancient civilizations such as China and India.

2 The Dutch East India Company (VOC) was the first company in the world to be financed by freely negotiable shares. This type of trade formed the beginnings of the Amsterdam Stock Exchange, the oldest stock exchange in the world. This information is evidenced by a share certificate which dates back to 27 September 1606 and originates from the Amsterdam City Archives. "What makes this newly found document so special is that it contains detailed descriptions of the dividend distributions up to 1650". http://www.worldsoldestshare.com/. Publicly listed companies are formalized to some extent by reporting requirements.
} 
But the informal firms continue to be the predominant form of business in emerging economies (ADB, 2007). "Mature economies such as those of the Unites States, Germany, and France, have relatively large formal economies and firms. However, an informal economy does exist in developed markets, and the firms in these markets are often larger than their counterparts in developing economies." (Bruton et al, 2012). Thus, from both the perspective of understanding the traditional roots of business organizing, as well as understanding the emerging modern organizational forms, it is useful to investigate and report upon the so-called "unorganized" sector of the economy.

However, at present there is only little management research, which studies and describes firms that operate in the informal economy. At this time, we still do not know what goes on inside these firms in the informal sector, nor do we understand their operations and value-creation practices. Most importantly we do not understand their organizational culture, which influences the ways firms organize their structures, operating processes, and governance.

Incidentally, the Indian diamond industry got started in about 1950, soon after the independence of India from the British rule in 1947. The informal firms of the diamond industry are thus likely to have an organizational culture which has roots in the history of their inception, aligned with local industry and influenced by external environment, national, social and political. According to imprinting theory, people in organization evaluate their experiences based on the schemas, mental models, and values that they carry in their minds. These schemas, mental models, and values are cognitive categories. These cognitive categories affect the decision-making and organizational actions of these firms (Rosch \& Lloyd, 1977; Schank and Abelson, 1977; Romanelli, 1991; Kapoor \& Lee, 2013). In turn, they affect the structures and processes in the organization. Thus, the organization of these firms is based on the organizational culture prevalent in the organization. To understand these firms, we also need an understanding of the economic and social contexts that gave rise to these firms, and sustain their growth. In this study, in addition to studying one of these firms in detail, we will also examine the industrial (economic and social) contexts that gave rise to and nurtured these firms.

Organizational culture is defined as a shared pattern of values, beliefs and assumptions that organizations develop as the firm deals with external adaptation and integration (Schein, 1983). Organizational culture is said to be stable over a period of time. How it is formed and evolves, depends on the circumstances surrounding its period of evolution, these circumstances are likely to be context- 
specific, and they continue to sustain and provide direction to the organizational evolution during its life-span (Stinchcombe, 1965).

This focus on culture leads to our primary research question:

\section{"What is the organizational culture of the informal firms of the Indian diamond industry?"}

In the diamond cutting and polishing (CPD) firms in Gujarat, India these informal sector firms have collectively organized themselves into informal economic arrangements and have made major inroads in the international diamond business.

Other industries like textiles, chemicals and automotive also flourish in the state of Gujarat. But the global market share of diamond industry makes the CPD industry unique. The Indian CPD firms annually process billions of dollars of unpolished stones into brilliant cut and polished diamonds. These diamonds are traded across global distances, making Gujarat, a western state of India, the world's largest diamond cutting, polishing, and trading center.

The diamond cutting and polishing hub that used to be centered in Antwerp and Amsterdam for about five centuries, has, over last three decades, shifted to Gujarat. Today, eleven out of every twelve diamonds set in jewelry worldwide are cut and polished by these ISFs in Gujarat. Gujarat, firms engaged in cutting and polishing of diamonds (CPD units), account for $60 \%$ by value and $95 \%$ by number of pieces, of the market share of total global exports of polished diamonds (GJEPC-Gems and Jewelry Export Promotion Council of India, 2014).

This processing of diamonds is carried out in thousands of medium- to small-size CPD units in Surat, Gujarat. Most of these units are unregistered. Collectively, they employ more than a million people. Together, these CPD units make up a close-knit network of diamond cutting, polishing, and trading firms. Moreover, many of these one million people have minimal formal education. Neither their owners nor managers learned business management at business schools. The interesting part is, as my personal interactions revealed, that they do not seem to be interested in scholarly lessons. On the other hand, as a researcher, I was interested in knowing what they knew about such informal forms of organizing.

This study attempts to address this gap in knowledge by using the competing values framework-CVF developed by Cameron \& Quinn, 1983 and the associated culture assessment instrument called OCAI (Organizational Culture Assessment 
Instrument) to understand and map their cultural profile. We discuss the choice of CVF and OCAI in Chapter 2.

We attempt to examine the culture of these firms and address this important gap in knowledge about IFs. We will explore this hitherto unexamined form of organizing, by mapping the intangible aspect of organizing, or the organizational culture of the IFs.

\section{The purpose of this dissertation is to identify and describe the organizational culture of the IFs in the Indian diamond industry.}

We believe that the findings of this study will provide valuable insights into the culture and the practices of these IFs.

This contribution will help both practitioners and scholars. Managers of the formal sector firms, who interact, negotiate, communicate and deal with the managers of the informal sector firms will begin to understand how these firms work, leverage their strengths, and adjust their strategies accordingly. Thus, they can begin to device their interaction tactics from an informed perspective. For scholars, it opens up a new set of new opportunities to investigate new micro and macro level organizational variables.

\subsection{The Research Objectives}

As we have mentioned above, on the one hand, literature on organizational studies suggests that organizational culture can be a source of sustained competitive advantage for organizations. On the other hand, informal sector firms in the Indian diamond industry seem to have unique cultural advantages that have made them globally competitive and successful. We are interested in further understanding their organizational life. Culture in organizations has been identified as the underlying basis for creating and defining the organizational life (Smircich, 1983). Organizational culture, if rare, valuable, and un-imitable, can be a source of sustained competitive advantage (Barney, 1986). We believe that the IFs possess a unique culture that helps them organize and sustain themselves in the absence of formal systems of governance. It then follows that organizational culture of the informal firms (IFs), is a useful concept to gain understanding about their organizational life. The objective of this dissertation is thus to describe the organizational cultures of the ISFs. In this study, we investigate, identify, and describe the organizational culture of these ISFs.

Our research objectives and their sub-objectives are: 
Objective \#1: To understand and describe the organizational culture of IFs in the Indian Diamond Industry. To describe this culture we will

a. First describe the industry context of the diamond industry

b. Describe various organizational aspects of a firm within the diamond industry and

c. Develop an organizational culture profile of the firm along cultural dimensions.

Objective \#2: To develop an initial theory of IFs to explain the organizational dynamics

\subsection{Research Approach}

At this time, Informal Firms (IFs) and their context (the Indian diamond cutting and polishing (CPD) industry) are under-researched. Only minimal theory and understanding about IFs and their context currently exists in management literature. I adopt a mixed methods approach to conduct the research.

As mentioned above, my research interest in this topic was stimulated in 2006 when I visited some small, medium and large CPD units in Gujarat, India, and after having completed my MBA and first $\mathrm{PhD}$ degree in India. At that time $\mathrm{I}$ began to wonder as to what is the organizational culture that makes these firms unique and successful. Subsequently, I began collecting and analyzing in-depth field data about these firms. My research and findings are grounded in these data.

As there is no government census or registry of these firms, aggregate firm level data in this industry is not available. The only official data we currently have is country level data, from the official website of Gems and Jewelry Export Promotion Council of India. The Gems and Jewelry Exports Promotion Council (GJEPC) operates under the aegis of Ministry of Commerce, Government of India.

My unit of analysis is a firm. However, in order to understand the informal firm, an understanding of the industrial context was necessary. To gather both firm and industry level data, I conducted informal discussions with various actors of the industry and the firms. These interviews were conducted at the Indian Diamond Institute in Surat, at the GJEPC offices in Mumbai, and at the home-sites of the small, medium and large firms engaged in CPD. 
While studying these firms, I discovered that many CPD units did not even have a postal address. We were able to reach them and their principals, only through confidential local contacts. Nobody seems to know the total number of such units that may be operating in Gujarat. But, informally they continue to operate and conduct business smoothly. After preliminary field visits and field research, we soon realized that due to their internally-focused clan culture, and resistance to confiding in others, precious little can be done about gathering hard quantitative data like financial or structural information from these IFs.

Therefore, for this research, we focused on the intangible aspects of organizing, their organizational culture (Schein, 1983), that is, on the fundamental values, beliefs and assumptions that are shared by the members of these IFs.

Our research approach consisted of seven steps:-

Step 1. Developing a preliminary understanding of the Indian Diamond Industry. This step included:

a. Field visits and informal discussions with the members (founders, owners, managers, employees, and sub-contractors) of firms in the Indian diamond industry

b. Search for secondary data on the Indian diamond industry and its global positioning.

Step 2. An Exploratory Study of the Indian Diamond Industry, including visits and discussions at:

a. GJEPC Offices in Mumbai

b. IDI (Indian Diamond Institute), Surat

c. Small, Medium and Large CPD Units

d. Brokers, Traders, Artisans of the CPD Units

e. Owners and Managers of the CPD Units

Step 3. An In-depth Case Study of a Large CPD Unit. This included

a. Identification of the Unit based on:

Triangulation with the stakeholders mentioned in part 3

Selection based on size, years in the industry

Reputation in the Industry

Willingness to help the Researcher for the Study 
b. Detailed visits / interviews with the specific case study unit:

The Founder of the Unit

Second generation leaders of the unit

The Surat manufacturing factory of the firm

The Mumbai Trading Offices of the firm

Employees (Artisans/ Supervisors/Managers/Others) of CPD units

Step 4. Identification of the domain of study (organizational culture of IFs), and reviewing broader literature on "Organizational Culture":

a. Reviewed peer-Reviewed Journals of over three decades

b. Identified an initial relevant Model of Organizational Culture

Step 5. An Empirical Investigation of the Organizational Culture in the CPD unit, using a Culture Assessment Instrument - Organizational Culture Assessment Instrument (OCAI). The step included:

a. Identification of a survey instrument

b. Obtaining permission from the CPD Unit

c. Scheduling appointments for data collection

d. Translation and Validation of the Instrument into Local Language (OCAI is not available in the local language, Gujarati; most respondents are semi-literate and have little knowledge of English)

e. Sampling

f. Administration of the Instrument

g. Results of the survey

\section{Step 6. Analyzing Data}

a. Data Analysis

b. Developing and Proposing an Initial Theory of an ISF.

Step 7. Developing Conclusions and Implications of the Study. This included synthesizing results of the above steps.

a. Contributions of the Study to 

i Scholars
ii Practitioners
b. Implications for Future Research

\subsection{Layout of the Thesis}

In this chapter, I have highlighted the importance of studying ISFs in the context of CPD units (ISFs engaged in cutting and polishing of diamonds) of the Indian diamond industry and that a firm's culture is influenced by its industry (Reynolds, 1991). In chapter 2, I present an initial literature review. Next, I report the findings of exploratory study of the Indian diamond industry (chapter 3) followed by a case study of a specific firm (chapter 4). In chapter 5, I describe with an extensive literature review of organizational culture why understanding the organizational culture can help us gain insights into organizational behavior and thus in the ways of organizing of the ISFs. The firm under study in chapter 4 was founded at the same time as did the Indian diamond industry and has survived for more than forty years, including the 2008 global recession. The economic recession of 2008 is well known for having impacted small and large firms, all over the world, it has also severely impacted the firms of the Indian diamond industry. Therefore, in chapter 6, I present a conceptual piece on how organizational culture can be useful for sustainability of organizations. An empirical investigation of organizational culture is done in chapter 7, using OCAI (Organizational Culture assessment instrument) which sheds useful insights on ISFs. Chapter 8 is a conclusion chapter. The chapters are organized as follows:-

Chapter 1 is about the importance of studying informal firms (IFs) and of the Indian diamond industry and identifying research objectives.

Chapter 2 is a literature review about existing literature on the informal economy and firms and importance of studying informal firms and of organizational culture of these firms.

Chapter 3 is an overview of the Indian diamond industry and cultural aspects with respect to its history, evolution, different stakeholders, networking and transacting.

Chapter 4 is an in-depth case study of a 40 year old firm engaged in cutting and polishing of diamonds in India and sheds light on the values and beliefs held by its members. The case was written in the context of 2008 economic crisis and how the organization had sustained itself by surviving the recession 
Chapter 5 is a review of literature of organizational culture. It draws a conceptual model to explain how organizational culture translates to organizational behavior and thus asserts as to why understanding of organizational culture of the ISFs helps us in understanding ISFs.

Chapter 6 is an article on sustainability of organizations and is a conceptual paper. The ideas were a result of having observed the unit under study in chapter 5, and an attempt to make a theoretical contribution about integrating sustainability with organizational culture, leadership and trust as moderators.

Chapter 7 is an empirical investigation of organizational culture of the CPD of the case study in Chapter 4. We use the OCAI (Organizational Culture Assessment Instrument) to measure the salience of four cultural arche-types, i.e. Clan, Hierarchy, Market and Adhocracy. We study these arche-types with regards six dimensions of organizational leadership, management of employees, strategic emphasis, criteria of success and organizational glue.

Chapter 8 is a summary of how we have met the objectives of the study with help from the findings of the above chapters. We propose our view of the informal firm from the insights gained from our study. In the end, we outline limitations of the study, contributions to literature and practice and directions for future research. 


\section{Chapter 2. Literature Review}

In this chapter, we review the existing literature in four key areas: Informal Firms, Organizational Culture, instruments for measuring organizational culture, and Grounded Theory methods. As mentioned in Chapter 1, attention towards research on informal firms is very recent. Currently, scholars have proposed a variety of definitions to explain the informal economy, informal sector and informal firms. There is little coherence and consistency in these definitions. However, each of these definitions gives us useful perspectives on both, understanding the phenomenon of the informal firms, and the growing influence of the informal economy in global business.

Section 2.1 deals with the existing literature on informal economy. Section 2.1.1 describes the size of the informal economy, its importance and how the meaning of informal sector has changed over time. Section 2.1.2 draws from the management, economics and sociology literature and describes various perspectives on the meaning of the informal economy and its firms. Section 2.1.3 draws from literature on economics and labor related areas to discuss existing theories of the informal sector.

Section 2.2 describes the concept of organizational culture, its relevance and its significance to understanding organizations. It specifically discusses the relevance of studying the culture of the IFs of Indian diamond industry. Section 2.3 is a review of different ways of measuring organizational culture. In this section we also include details of construction and validation of OCAI, the culture assessment instrument that we use for collecting empirical data. Section 2.4 discusses the proposed grounded research methodology used in our research.

\subsection{Why study Informal Economy and the Informal Firm?}

In our thesis, we will use the terms IFs (informal firms) and ISFs (informal sector firms) interchangeably, as we study them in the context of the informal Indian diamond industry. ISFs or IFs refer to companies that are engaged in legitimate business activities but may not fully comply with regulatory obligations. 


\subsubsection{Size of the Informal Sector}

The informal economy accounts for $40 \%$ of the Gross National product (GNP) of low-income countries, and 17\% of GDP of high income countries (Farrell, 2004; Charmaz, 2000). In India, an emerging economy country, the unorganized sector accounts for a significant $62 \%$ of GDP, $50 \%$ of gross national savings and $40 \%$ of national exports (ILO 2002 a). The 1999-2000 NSSO ${ }^{1}$ survey reported that approximately $92 \%$ of the Indian workforce (370 million workers) was employed in the unorganized sector. Any macro-analysis of business activity would find it hard to ignore these numbers. The meaning of the informal sector has evolved over time (Table 1 and Table 2).

\subsubsection{Meaning of the Informal Economy}

The article by Godfrey (2011), once again, draws the attention of scholars to the significance of the informal economy. Earlier works of Barnard (1938) have looked at both the dualistic nature of informal economic activities and their fundamental interconnectedness. Barney and Hansen (1994) and Hosmer (1994) write about the competitive value of trust - a key governance feature of informal economic activity - and how advanced firms can win in their markets by becoming distinctly less formal. Spicer, McDermott, and Kogut (2000) describe the powerful role played by informal economic arrangements in the transition from command to capitalist economies in Eastern Europe. Khanna and Rivkin (2001) outline the role of business groups, collections of firms combining formal and informal elements and commitments, in compensating for the lack of formal regulatory institutions in 14 (fourteen) emerging markets. Finally, Acquaah (2007) examine how managers in Ghana - an emerging or developing economyrely on informal social capital as a key method for gaining access to critical resources to grow their businesses. He notes the stickiness of informal arrangements and ways of doing business, even though the managers he studied all worked for firms competing in the formal economy.

1. The National Sample Survey Organization (NSSO), now known as National Sample Survey Office, is an organization under the Ministry of Statistics of the Government of India. The NSSO was established in 1950, it is the largest organization in India conducting regular socio-economic surveys. 


\section{Past}

The informal sector is the traditional economy that will wither away and die with modern, industrial growth.

It is only marginally productive.

It exists separately from the formal economy.

It represents a reserve pool of surplus labor.

It (the informal sector) is comprised mostly of street traders and very small-scale producers.

Most of those in the (informal) sector are entrepreneurs who run illegal and unregistered enterprises in order to avoid regulation and taxation.

Work in the informal economy is comprised mostly of survival activities and thus is not a subject for economic policy.

\section{Present}

The informal economy is 'here to stay' and expanding with modern, industrial growth.

It is a major provider of employment, goods and services for lower-income groups.

It contributes a significant share of GDP. It is linked to the formal economy - it produces for, trades with, distributes for and provides services to the formal economy.

Much of the recent rise in informal employment is due to the decline in formal employment or to the in-formalization of previously formal employment relationships and contracts.

It (the informal sector) is made up of a wide range of informal occupations - both 'resilient old forms' such as casual day labor in construction and agriculture as well as 'emerging new ones' such as temporary and part-time jobs plus homework for high tech industries.

It (the informal sector) is made up of non-standard wage workers as well as entrepreneurs and selfemployed persons producing legal goods and services, albeit through irregular or unregulated means. Most entrepreneurs and the self-employed are amenable to, and would welcome, efforts to reduce barriers to registration and related transaction costs and to increase benefits from regulation; and most non-standard wage workers would welcome more stable jobs and workers' rights.

Informal enterprises include not only survival activities but also stable enterprises and dynamic growing businesses, and informal employment includes not only self-employment but also wage employment. All forms of informal employment are affected by most (if not all) economic policies.

Source: Chen, Martha, Joann Vanek and Marilyn Carr. 2004. Mainstreaming Informal

Employment and Gender in Poverty Reduction: A Handbook for Policy-makers and Other

Stakeholders. London: Commonwealth Secretariat. 
Table 2 The Meaning of Informal Economy

\begin{tabular}{|c|c|c|c|}
\hline Author & Year & Discipline & Key Variable Definition \\
\hline Barnard & 1938 & Organization & $\begin{array}{l}\text { p. 115: "by informal organization I } \\
\text { mean the aggregate of personal } \\
\text { contacts and interactions and } \\
\text { associated groupings . . . informal } \\
\text { organization is indefinite and rather } \\
\text { structure less." }\end{array}$ \\
\hline $\begin{array}{l}\text { Boisot and } \\
\text { Child }\end{array}$ & 1996 & $\begin{array}{l}\text { Interpersonal } \\
\text { relationships }\end{array}$ & $\begin{array}{l}\text { p. 604: Chinese business exhibits "a } \\
\text { preference for interpersonal } \\
\text { accommodation . . . the process is } \\
\text { self-reinforcing in that the absence of } \\
\text { a rational-legal institutional } \\
\text { framework fails to engender } \\
\text { confidence in a wider system of } \\
\text { bureaucratic or market transacting } \\
\text { outside networks based on personal } \\
\text { power, commitment, and trust .. } \\
\text { [we] labeled this tendency the 'iron } \\
\text { law of fiefs."' }\end{array}$ \\
\hline Apressyan & 1997 & $\begin{array}{l}\text { Illegal products- } \\
\text { ethical implications }\end{array}$ & $\begin{array}{l}\text { p. 1563: "the shadow economy was } \\
\text { based on more entrepreneurial and } \\
\text { efficient business. However, since it } \\
\text { was dependent upon illegal usage of } \\
\text { state material and financial } \\
\text { resources, or thefts, it was essentially } \\
\text { parasitic by its character. }\end{array}$ \\
\hline Chakraborty & 1997 & $\begin{array}{l}\text { Clandestine sales, } \\
\text { inflated } \\
\text { prices-ethical } \\
\text { implications }\end{array}$ & $\begin{array}{l}\text { p. 1530: "The phrase 'black market' } \\
\text { rolled into circulation during the } \\
\text { Second World War and has remained } \\
\text { since that time. It denotes the process } \\
\text { of clandestine sale of scarce, rationed, } \\
\text { controlled commodities at inflated } \\
\text { prices." (India) }\end{array}$ \\
\hline $\begin{array}{l}\text { Spicer, } \\
\text { McDermott, } \\
\text { and Kogut }\end{array}$ & 2000 & $\begin{array}{l}\text { Socially embedded } \\
\text { ties }\end{array}$ & $\begin{array}{l}\text { p. 639: "Informal networks of local } \\
\text { firms . . . [characterized by] dense } \\
\text { horizontal socioeconomic ties } \\
\text { emerged to help managers and work } \\
\text { teams, suppliers and customers, } \\
\text { firms, and local party members } \\
\text { coordinate continual adaptations to } \\
\text { the shortage environment." }\end{array}$ \\
\hline
\end{tabular}




\begin{tabular}{|c|c|c|c|}
\hline $\begin{array}{l}\text { Hudson and } \\
\text { Wehrell }\end{array}$ & 2005 & $\begin{array}{l}\text { Regulatory } \\
\text { control-ethical } \\
\text { implications }\end{array}$ & $\begin{array}{l}\text { p. 288: those in the informal economy } \\
\text { avoid "various regulations to which } \\
\text { they might otherwise be subject. The } \\
\text { regulations they avoid may include } \\
\text { labor legislation concerning wages } \\
\text { and safe working conditions, business } \\
\text { registration, zoning restrictions with } \\
\text { regard to commercial locations, } \\
\text { licensing requirements of various } \\
\text { sorts and even business tax } \\
\text { obligations." }\end{array}$ \\
\hline Nwabuzor & 2005 & $\begin{array}{l}\text { Burdensome } \\
\text { governments- } \\
\text { ethical implications }\end{array}$ & $\begin{array}{l}\text { p. } 126 \text { "Informality is a response to } \\
\text { burdensome controls, and an attempt } \\
\text { to circumvent them." }\end{array}$ \\
\hline $\begin{array}{l}\text { London and } \\
\text { Hart }\end{array}$ & 2004 & $\begin{array}{l}\text { Social } \\
\text { embeddedness }\end{array}$ & $\begin{array}{l}\text { p. 352: "In the developing world, on } \\
\text { the other hand, it is simply too costly } \\
\text { or complicated for many } \\
\text { entrepreneurs to enter the formal } \\
\text { economy ... In the informal economy, } \\
\text { relationships are grounded primarily } \\
\text { on social, not legal, contracts." }\end{array}$ \\
\hline $\begin{array}{l}\text { Li, Zhou, and } \\
\text { Shao }\end{array}$ & 2009 & Interpersonal ties & $\begin{array}{l}\text { p. 342: "in emerging economies ... } \\
\text { firms must rely on informal } \\
\text { institutional constraints, such as } \\
\text { interpersonal ties, to facilitate their } \\
\text { economic exchanges." }\end{array}$ \\
\hline $\begin{array}{l}\text { Webb, } \\
\text { Tihanyi, } \\
\text { Ireland, and } \\
\text { Sirmon }\end{array}$ & 2009 & Legality & $\begin{array}{l}\text { p. 492: "We define the informal } \\
\text { economy as the set of illegal yet } \\
\text { legitimate (to some large groups) } \\
\text { activities through which actors } \\
\text { recognize and exploit opportunities." }\end{array}$ \\
\hline
\end{tabular}

Source: Adapted from Godfrey (2011): Towards a Theory of Informal Economy

However, as mentioned in Chapter 1, traditional organizational research is seldom carried out with informal sector firms, much less about the context in which they are formed and thrive. While the informal economy has traditionally been the subject of research in economics and labor-related areas (de Soto, 1989; 2000) firm level analysis has typically been scarce in the management literature and research. This lack of research in these organizations could be due to high mobility and turnover of staff, their seasonality, their lack of recognizable 
features, and due to reluctance of actors in these firms to share information (ADB, 2007).

Recently, there has been renewed interest in informal work arrangements or informal labor markets (ADB, 2007; Godfrey, 2011; Bruton, 2012). This interest could stem from the fact that informal work arrangements have not only persisted in emerging economies, but have also emerged in new guises and at unexpected places in developed economies (WIEGO, 2009). Governments and researchers have finally begun to accept that IFs and the informal economy have always been a major part of the economic landscape, and will continue to be so. Ignoring them, as many academics and researchers have done in the past, would be to ignore key concepts and actors in the economic and industrial landscape.

The Table 2 is a list of various definitions in different disciplines as attributed to the informal economy.

\subsubsection{Theories of the Informal Sector}

Scholars have long tried to explain the existence and nature of the informal sector. In the following discussion we identify four key theoretical approaches to ISFs: the Dualist Approach; The Structuralist School; The Legalist School; and the Neo-Classical View.

- The dualist approach (ILO, 1972) considers the informal sector as comprising marginal activities, distinct and unrelated to the formal sector. Sethuraman (1976) and Tokman (1978) observe that informal activities emerge due to limited opportunities in the formal sector. They suggest that surplus labor, low economic growth, and high population growth rates act as catalysts for the under-privileged segment of the population to operate in the informal sector. These firms provide income for the poor and a safety net in times of crisis.

- The structuralist school describes the informal sector as subordinated economic units (micro-firms). Workers in these subordinate units serve to reduce input and labor costs for large formal firms, thereby increasing their competitiveness (Moser, 1978). Unlike the dualist model, the 
structuralist model views the formal and informal sectors as co-existing and inextricably linked and interdependent (Castells \& Portes, 1989). The focus of the structuralist perspective is on the nature of capitalist development, rather than on a lack of economic growth.

- The legalist school posits that the informal sector is comprised of microentrepreneurs who choose to operate informally to avoid the costs, taxes, time and effort of formal registration (de Soto, 1989). This school believes that the IFs will continue to produce informally so long as government procedures are cumbersome and expensive. The difficulties in creating legal businesses compel these relatively resource-poor firms to skip the formal-legal aspects of the process. Maloney, 2004, a neo-liberal economist, suggests that informal entrepreneurs deliberately avoid regulations and taxation and may deal in grey-market goods or even illegal goods and services. Informal entrepreneurs choose to operate in the underground or black economy illegally, or even criminally, so as to avoid taxation, commercial regulations, electricity and rental fees, and other costs of operating formally.

- According to the neo-classical view (Schneider, 2000), the informal economy responds to the economic environment's demand for urban services and small-scale manufacturing. It adds a dynamic and entrepreneurial spirit to the industry and can lead to increased competition and higher efficiencies. The informal sector may also contribute to the creation of markets, increase financial resources, enhance entrepreneurship and transform the legal, social and economic institutions necessary for accumulation (Asea, 1996).

Our data, reported in the following chapters, suggest that these views are complementary - they are not substitutes. Rather than being a complete theory in itself, each of the following four perspectives describe different aspects of the same phenomenon, that is, informal economy and Informal Sector Firms. Our findings, presented in chapters 3 to 7 , and summarized in Chapter 8, is that these four views are complementary - they are not substitutes for each other. Each of these perspectives describes different aspects of the same phenomenon, ISFs. 
In order to understand these organizations (academic purpose) and interact with them (a pragmatic purpose) we need to learn about the culture, the shared patterns of values, beliefs and assumptions that exists in such informal sector firms.

I address this gap by studying the firms in the diamond cutting and polishing industry. This community currently exists in the "so-called" unorganized sector and is composed of numerous CPD units. The next section describes why the study of organizational culture will help in our research purpose.

\subsection{Why study Organizational Culture?}

Why is it important to study "organizational culture" in the context of the ISFs or IFs? Although traditional academic research pertains to studies of culture conducted in formal organizations, these studies can equally be applicable to informal sector firms. As we attempt to understand ISFs/IFs as organizations, we draw from the extant management literature on organizational culture, to clarify culture's role in organizational studies.

Few aspects of organizational studies have such diverse and fragmented literature as organizational culture (OC).

Dominated by psychologists in the mid-1950s, initially the field of organization studies had a micro-orientation. Early 1980s saw the introduction of the concept of Organizational Culture (Pettigrew, 1979). By the mid-1990s, scholars realized that with this "micro" psychological focus, they had been focusing more on "Behavior" than "Organization" of micro-organizational behavior. Occupational sociologists, organizational theorists and psychologists, needed to collaborate for developing a multi-disciplinary field of organization studies. This new field encompasses micro, meso and macro perspectives and paradigms (Schien, 1996). Perhaps, this could be the reason for the current attention to organizational culture studies, as these studies provides for a combined macro and micro analysis. Moreover, after 'strong' and 'excellent' cultures were "discovered" in the popular press to have significant positive associations with success of American and Japanese firms (Deal \& Kennedy, 1982; Peters and Waterman, 1982; Ouchi, 1981), there has been a proliferation of interest in studies of organizational culture. 


\subsubsection{Meaning of Culture}

The extant management literature provides multiple definitions for "culture". As early as 1952, Kroeber et al compiled a list of 164 definitions from literature. Since then the usage of the term "culture" and its definitions have only proliferated. While presence of the concept of "culture" in sociology and anthropology is almost as old as the disciplines themselves, the introduction of 'organizational culture' to the field of organizational studies is generally credited to Pettigrew in 1979 (Detert et al, 2000). Since Pettigrew, researchers have studied a variety of questions such as: what is culture?, who shares it?, how did it come to be (Pettigrew, A.M., 1979), what is it composed of (Schein, 1996) how are its components structured, how it works (Martin, 1992), the conditions for the existence of various cultures, and conditions for culture to affect organizational efficiency as well as other organizational variables (Denison, 1996). Researchers have also examined as to why and how do we change culture (change management), in what way can culture contribute to controlling an organization? How can we measure culture? What is the vocabulary we can use to describe culture? What are the cultural differences between various contexts such as national (Hofstede, 1983), occupation, position, industry (Reynolds, 1996), firm, and its subunits; cross-cultural management in multinationals, mergers and alliances, and cultural conflicts. (Arogyaswamy \& Byles, 1987; Geertz, 1973; Harris, 1994; Martin \& Siehl, 1983; Pettigrew, 1979; Schein, 1996; Wilkins and Ouchi, 1983)

\subsubsection{Concept of Organizational Culture}

A key problem in studying organizational culture stems from the ontological status of the concept itself (Jones, 1983). Although, organizational researchers have used a wide variety of definitions, most empirical work has centered on culture as an enduring, autonomous phenomenon that can be isolated for analysis and for inter-organization comparison (Alexander, 1990). The intricate and complex nature of organizational culture has led to differences and controversies about its definition, dimensions, and measurement (Cameron \& Quinn, 1999).

However, among scholars, a consensus exists that organizational culture is holistic, historically determined, and socially constructed (Smircich, 83) It 
involves beliefs and behavior, exists at a variety of levels (individual, team, and organization), and manifests itself in a wide range of behaviors and features of organizational life (Hofstede, Neuijen, Ohayv, \& Sanders, 1990; Pettigrew, 1990). Organizational Culture is expressed and transmitted through artifacts, stories, myths and symbols (Martin, 1982; Siehl \& Martin, 1981; Wilkins, 1980; Pettigrew, 1979). Underlying these symbolic manifestations are patterns of basic assumptions (Schein, 1983, 1985; Dyer, 1985); and a set of shared understandings, interpretations or perspectives (Van Maanen, 1988) and shared expectations.

\subsubsection{Ontological Status of Organizational Culture}

Broadly, two schools of thought about organizational culture exist: (a) whether organizational culture means something that an organization 'is' or (b) it is something that an organization 'has'. Accordingly, researchers have analyzed the concept of Organizational Culture, both as a root metaphor, i.e. organizations as expressive forms, and manifestations of human consciousness (Cameron, 1999; Smircich, 1983) and as an attribute of an organization, that is, possessed by the organization and observable. Some researchers would like to study what appears to them to be more fundamental issues of meaning, and the processes by which organizational life is possible (that is. an organization 'is' culture). Others give high priority to the principles of prediction, generalizability, causality, and control (that is, an organization 'has' culture).

Both approaches share the conception of organizations as organisms that exist within an environment. The environment presents the organizations with imperatives for behavior.

Culture has been defined as the system of publicly and collectively accepted meanings operating for a given group at a given time. It is an important practical consideration in an extended stream of time, events, people, and processes (Pettigrew, 1979). However, a firm's culture cannot be captured without knowledge of it's context (Reynolds, 1986). Within an industry, firms share industry driven cultural elements that are influenced by characteristics of its industry and are based on assumptions about the competitive environment, customer requirements and societal expectations Gordon (1991). Therefore, in this 
study, we study both the industry and firm level cultures in Chapters 3 and 4 respectively.

\subsubsection{Relevance of Study of Culture in ISFs}

If it is valuable, rare and only imperfectly imitable, organizational culture can be a source of sustained competitive advantage (Barney 1986). The three levels of manifestation of an organization's culture, i.e. its basic assumptions, its values and beliefs, and its visible artifacts (Schein, 1984) are extremely powerful determinants of organizational life. They are intuitively incorporated into the actions of skilled executives who use them to manage people, formulate strategy, and induce organizational change (Brown, 1992). Kotter and Heskitt (1992) report that firms with cultures suited to their market environment perform better.

Within an industry, firms share industry-driven cultural elements. These elements are influenced by industry characteristics and are based on assumptions about the firm's competitive environment, customer requirements and societal expectations (Gordon, 1991). Thus, although organizational culture is unique to a firm or its subunits, industries exert influences that cause the organization's cultures to develop within defined parameters.

We, therefore, first make an attempt to understand the overall CPD industry, before we study the culture of a representative firm nested within the industry. Within this firm we examine its organizational culture by an in-depth survey of various aspects and components of its culture. The following section has excerpts from the extant literature on the assessment of organizational culture.

\subsection{Measuring Organizational Culture}

Next, we reviewed the current management literature identifying organizational frameworks and their associated measuring instruments for defining and assessing organizational culture. The following is a list of the some key frameworks and culture assessment instruments found in our review. These are only illustrative studies. We realize that currently there exist many attempts at describing and measuring culture. We have only included some of the most popular studies: 
- Hofstede's Survey Instrument (1980) adapted from Hermes Values survey and Cooke and Lafferty's (1983), Organizational Culture Inventory and Paul Reynolds' (1986) culture-dimensions; is among the most popular instruments, developed during the 1980s, for measurement of Culture.

- Empirical work using conceptual frameworks and validated instruments dominate cultural studies of the 1990s. The Organizational Culture Assessment Questionnaire (Sashkin,1990), Organizational Cultural Profile by O'Reilly et al (1991), Cameron and Freeman's (1991) model of Competing Values Framework (CVF), Organizational Cultural profile (Chatman and Jehn 1994) and Denison's Organizational Culture Survey(1996) were developed during this decade.

- During the early twenty-first century, Detert et al (2003) reported the development and validation of a survey instrument for measuring the culture of Quality Management (QM).

Some researchers suggest that, due to the ambivalent nature of behavior, or the reluctance of people to commit their real feelings to paper, the instruments used to measure organizational culture may not fully take account of the pervasiveness of culture and the unconscious nature of basic assumptions (Lewis, 1994). However, as Hofstede (1986) observes, there is a strong need for speculating less and measuring more.

\subsubsection{The Competing Values Framework (CVF)}

After evaluation of different frameworks to study organizational culture, we found the CVF suitable for our purpose. The CVF classifies organizations into four quadrants based on organizational forms as discussed in organizational science. Since our purpose is to understand these new forms of organizing, using the CVF will guide us into understanding the informal firms along different organizational dimensions of the OCAI (organizational culture assessment instrument) using vocabulary that is well-established in existing literature of organizational studies. In this study, therefore, we use the theoretical model - of culture, the Competing Values Framework and its associated culture assessment instrument Organizational Culture Assessment Instrument (OCAI). The CVF framework is 
based on a statistical analysis of the key indicators of organizational effectiveness proposed by John Campbell et al (1974). It is formulated on the basis of fundamental assumptions about how organizations work and how they are managed. CVF and OCAI describe and assess organizational culture at micro (individual) and meta (organizational) levels. As our focus is on understanding the ISF firms, and their behavior, CVF and OCAI are appropriate framework and instrument for our research.

Competing Values Framework (CVF) is based upon the work by Quinn and Rohrbaugh (1983) on organizational effectiveness indicators. The authors analyzed these organizational effectiveness indicators and organized them into four main clusters along two major dimensions (Fig 2). One dimension differentiates an effectiveness criterion that emphasizes flexibility, discretion and dynamism from criteria that emphasize stability, order and control. Thus, the first continuum ranges from organizational versatility and pliability (Flexibility and Discretion) on one end to organizational steadiness and durability (Stability and Control) on the other. The second continuum ranges from organizational cohesion and consonance on the one end (Internal Focus and Integration) to organizational separation and independence on the other (External focus and Differentiation).

Cameron and Quinn (1999) name the four quadrants produced by the intersection of these two dimensions: clan, hierarchy, market and adhocracy (Fig 2). It should be recognized that Cameron \& Quinn state that all organizations may have some characteristics of each of these arch-types. However different organizations can be differentiated by dominance of one or more of these arch-types.

The CLAN arch-type is like an extended family based on internal focus, agility, and flexibility. A HIERARCHY is characterized by a formalized and structured place to work. The MARKET form is based on transaction costs as foundation of organizational effectiveness. ADHOCRACY refers to a temporary, specialized dynamic unit, is based on assumptions that innovation and creativity leads to success. 


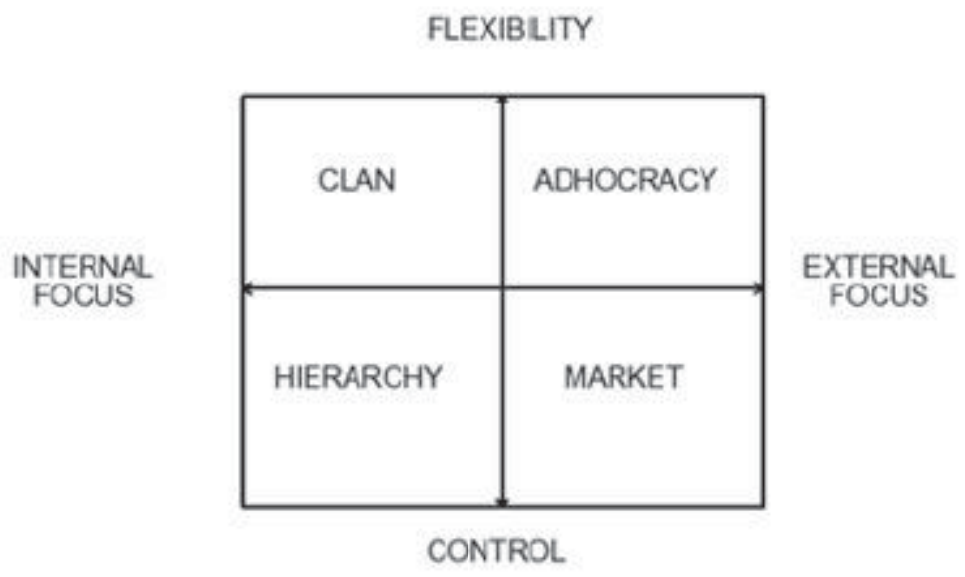

Figure 1: Competing Values Framework

\subsubsection{The OCAI Instrument}

The Organizational Culture Assessment Instrument (OCAI) designed and validated by Cameron \& Quinn is based upon the above Competing Values Framework. It measures the strength of above four organizational culture types along six content dimensions (see Appendix D). Altogether, OCAI includes 24 (4x6) items on which data from the respondents is collected. An organization may have scores on each of the four cultural types, just more or less of each.

The sum total of responses to all items marked Ä's is calculated as CLAN culture and plotted on the diagonals in the CLAN quadrant, as represented in Fig 3. Similarly, we plot scores for all other three quadrants. When we join the dots (representing total scores) on each diagonal, it results in the cultural profile of the organization. An example of an organization's cultural profile is shown in Fig 3. The more the area of the cultural profile in a particular quadrant, the more is the dominance of that culture arche-type. The cultural profiles can be plotted separately for all the six dimensions on the OCAI scale and can be analyzed for different demographic variables for further investigation and interpretation. After translating (into Gujarati) and validating the translated instrument, we used the 
translated OCAI instrument for the assessment of the quantitative Organizational Culture profiles for our case study (chapter 7).

Figure 3 Plotting a Cultural Profile
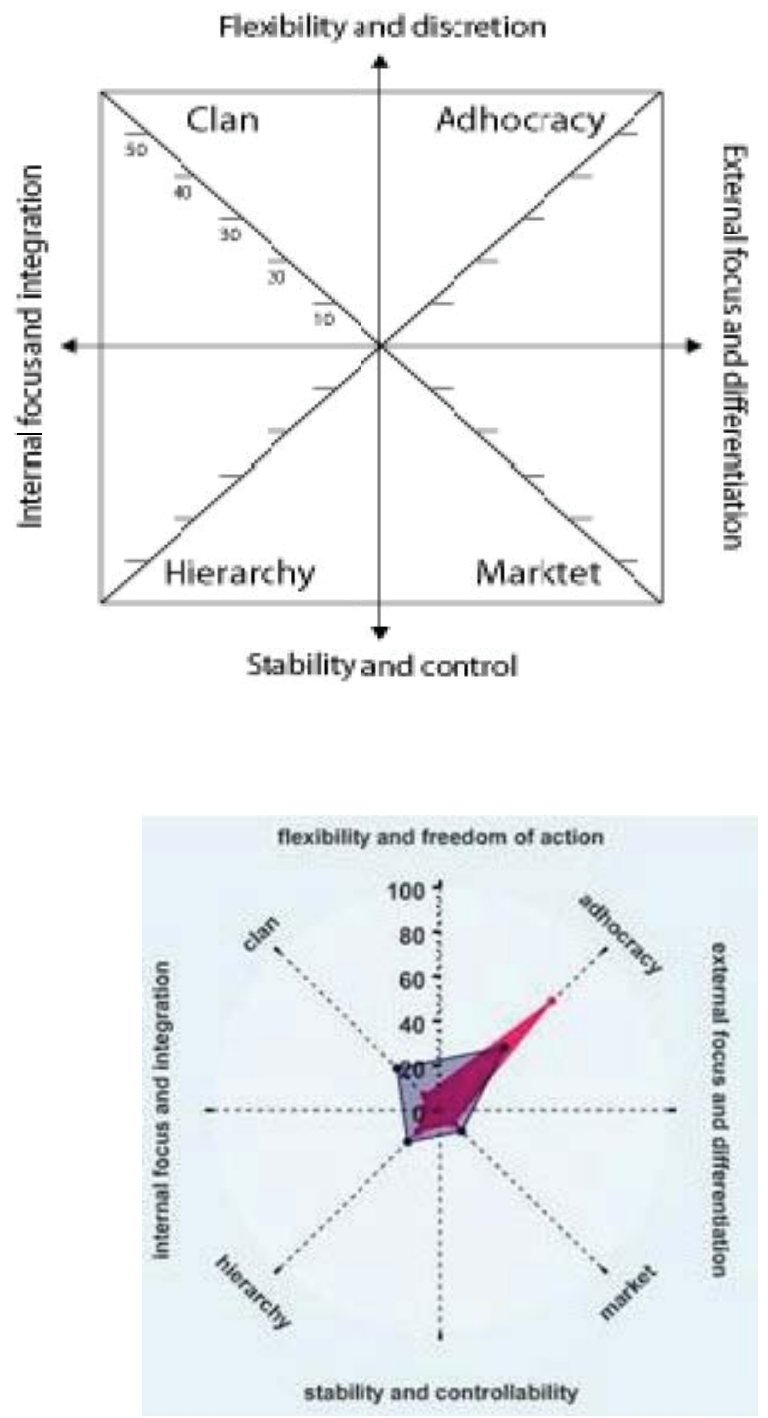

So far, we have established the significance of the informal sector firms, the need to understand how they are organized, and of the concept of organizational culture 
that can help us understand the organizing aspects of informal sector firms. In the next section, we describe a grounded theory approach to developing theories of phenomenon, and explain why the grounded theory methodology is best suited for this dissertation.

\subsection{Constructivist Grounded Theory}

We constructed our theory of ISFs through an empirical, mixed-methods, constructivist grounded theory methodology. We collected both qualitative and quantitative data for the purpose. In this section, we first justify the appropriateness of qualitative and mixed-methods research and constructivist grounded theory for our study. Next, we locate the origins of constructivist grounded theory and trace its development.

\subsubsection{Why Grounded Theory as a methodology?}

Grounded Theory is a formal and rigorous research methodology for discovering and constructing theory from Empirical Data. The objectives of this dissertation are to describe the organizational culture of ISFs of India's diamond cutting and polishing industry (objective \#1) and to develop a preliminary theory of IFs (objective \#2). The current management literature includes theories of the informal economy but not of the informal firms (IFs). Therefore, to meet our objectives of describing the organizational culture of IFs and to build an initial theory of the IF, we need to discover and construct a theory that can help us in answering our research questions questions...Therefore we take a "Theory Discovery and Construction" approach to the problem.

However, we need some initial guidelines for research design to begin to collect and analyze data. Just like there are many shells available on the seashore, there are a lot of data available in the diamond industry. Which data to pick up and which to discard - needs an initial objective for research. Given the abundance of data, it is difficult for the human mind to decide as to what data to collect and to let what data speak for themselves.

Consequently we turn to a proven framework, CVF, and a tested and validated measuring instrument, OCAI. We have justified the choice of CVF and OCAI 
earlier (section 2.3). As a starting point we use Cameron and Quinn's (1983) CVF and the Organizational Culture Assessment Instrument (OCAI) to guide our data collection. CVF and OCAI are used as our original scaffolding upon which we build our data collection and analysis efforts.

\subsubsection{Understanding Grounded Theory}

Before using Grounded Theory, to understand it, we examined key grounded theory (GT) texts. Grounded theory serves at the forefront of the qualitative studies (Denzin \& Lincoln, 1994).

The seminal book, "Discovery of Grounded Theory" by Barney G. Glaser and Anselm L. Strauss (1967) was a critical turning point for the history of social sciences. The authors defended qualitative research and countered the dominant view that only quantitative studies can be used for systematic social scientific inquiry.

The development of Grounded theory can be seen as an evolving methodological spiral that began with Glaser and Strauss' original text (Glaser \& Strauss, 1967) and still continues today. Glaser and Strauss's work came along at a time when the ethnographic tradition had been marginalized in social sciences by the ascendancy of quantitative methods. While researchers were increasingly using secondary and primary quantitative data to draw inferences, the use of in-depth qualitative field observations and research, and their associated analysis of interpretive qualitative data had waned.

Eisenhardt's seminal article (1989), published in the Academy of Management Review (AMR) suggested that the process of inducting theory using case studies, grounded in empirical evidence and tightly linked to data (both quantitative or qualitative), is especially important in development of new topic areas. Therefore, we have made use of the case study of the Indian diamond industry as well as of a firm operating in the Indian diamond industry. Eisenhardt stated that the resulting theory is often novel, testable and empirically valid. Also, it is grounded theory's intimate connection with empirical reality that permits the development of testable, relevant and valid theory (Glaser \& Strauss, 1967). 
Eisenhardt (1989) extended Glaser and Strauss's (1967) work with previous work on qualitative methods (Miles \& Huberman, 1984) and case study research design (Yin, 1981). Eisenhardt extended grounded theory in areas such as: a priori specification of constructs, triangulation of multiple investigators, within-case and cross-case analyses, and the role of existing literature. Glaser, and Strauss and Corbin later evolved grounded theory in divergent directions (Glaser, 1992; Strauss \& Corbin, 1990, 1994, 1998). However, "both these initial streams of grounded theory remained embued with positivism in their objectivist underpinnings" (Guba \& Lincoln, 1994).

We use Strauss and Corbin's (1998) texts (an off-shot of the original Glaser and Strauss text) on grounded theory to reflect constructivism in their approach to inquiry and that of Charmaz's landmark work (2000, 2001, 2003) on constructivist grounded theory regards her positioning of the researcher in relation to the participants, analysis of the data, and rendering of participants' experiences into grounded theory.

Constructivism is a view in philosophy according to which all "knowledge is a compilation of human-made constructions" (Raskin, J.D., 2002). The current generation of Grounded theory aims to an interpretive understanding of subjects' inter-subjective meanings, recognizes mutual creation of knowledge by the viewer and the viewed, and the construction of a joint view of reality (Guba \& Lincoln, 1994).

Grounded theory can be used with both qualitative and quantitative data (Eisenhardt, 1989). Descriptions of Grounded Theory Methods typically do not include data collection techniques. However, an initial definition of the research question, at least in broad terms, is important (Eisenhardt, 1989). The researcher needs to go into organizations for data collection with a well defined focus to systematically collect specific types of data (Mintzberg, 1979). Without this research focus, it is easy to get overwhelmed by the volume of data.

For this reason, we have narrowed our data collection around the concept of organizational culture. 
Grounded theory has evolved over time. Glaser's epistemological position (1978, 1992) was that of traditional positivism, assumptions of an objective, external reality, a neutral observer who observes or discovers data, reductionist inquiry of manageable research problems, and an objectivist rendering of data. Strauss and Corbin's $(1990,1998)$ stance was also that an objective external reality exists independent of the observer. The researcher, on the other hand, based upon her/his biases and mental mindset, observes and interprets this objective reality. Strauss and Corbin aim towards unbiased data collection and propose a set of technical procedures and espouse verification. Their position moves data collection into post positivism.

Relativists start with the assumption that we can never understand each other because we come from different experiences and cultures. As post-positivists, Strauss and Corbin reject the relativist idea of the incommensurability of different perspectives. Most post-positivists are constructivists, who believe that we each construct our view of the world based on our perceptions of it. Strauss and Corbin also propose giving voice to their respondents, representing them as accurately as possible, discovering and acknowledging how respondents' views of reality conflicts with their own views, and recognizing the art and science of the analytic product and process (c.f. Strauss \& Corbin, 1998)

Constructivism (Charmaz, 2003) assumes the relativism of multiple social realities, recognizes mutual creation of knowledge by the viewer and the viewed, and aims towards an interpretive understanding of subjects' meanings (Guba \& Lincoln, 1994). It celebrates the first hand knowledge of the empirical worlds, a middle ground between postmodernism (a philosophical direction which is critical of the foundational assumptions and universalizing tendency of Western philosophy) and positivism (a position that holds that the goal of knowledge is simply to describe the phenomena that we experience. The purpose of science is simply to stick with what we can observe and measure).

The power of the grounded theory lies in its tools for understanding empirical worlds. Unlike positivist research methods, grounded theory methods are flexible and heuristic strategies rather than formulaic procedures (Charmaz, 2000). Quantitative research uses data to test existing theory as developed by the logico- 
deductive model (an epistemology which relies upon established procedures for collecting observations that reflect reality, as much as possible, without bias or intervention by the person(s) making the observations, and using these observations to test or confirm hypothesis). On the other hand, constructivist grounded theory starts with data collection, and uses the collected data to infer theory.

At a starting point of this research, we start with the research design assumptions that (1) ISFs in India's CPD industry are unique and worth understanding; specifically it is important to understand the culture of ISFs and the dynamics of its cultural elements (2) instead of positivist hypothesis testing we plan to employ a constructivist grounded theory approach and a combination of quantitative and qualitative data to understand ISFs; (3) our starting point is a scaffolding (theoretical and methodological underpinnings) that begins with CVF \& OCAI to understand culture (4) the quantitative data from the OCAI survey will give us scores on cultural dimensions; these scores in turn can provide us directions for collecting further qualitative data and (5) we will use the approach of Constructivist Grounded Theory to develop a theory of ISFs.

In addition, once the initial grounded theory of ISFs is developed, we return to the extant literature and relate our empirical findings to other relevant theories. This analysis of data and a review of relevant theories can lead to further refinement of research questions and further data collection through an iterative process, until the returns for additional insights from collection of data are marginal. We propose to use a mixed methods approach (Creswell, 2011) to data collection using both qualitative and quantitative data. 


\title{
Chapter 3. The Emergence of the Informal Sector Firms in International Business: The Globally Distributed Indian Diamond Industry ${ }^{1}$
}

\begin{abstract}
This paper highlights and explores the emergence of informal sector firms (ISFs) in international business. Due to increasing size and significance of the informal economy in the global context (particularly emerging markets), we also attempt to understand the characteristics and relevance of these ISFs. The globally distributed diamond industry is one such instance, composed of thousands of informal sector entrepreneurial firms (ISFs) which export cut and polished diamonds (CPD) worth USD 20 billion annually. However, these firms thrive in the atmosphere of secrecy and informality that envelops the diamond trade and has for long been labeled as an unorganized sector of the world economy. Interestingly, the collective output of the ISFs in an emerging economy (India) enjoys a 95 percent market share of net global exports of cut and polished diamonds. This study reveals that networking of the Indian ISFs of the CPD industry resembles a close knit community which works on mutual trust, verbal commitments and familial and personal relationships mostly with informal systems in place. The so called unorganized CPD firms are possibly a different form of organizing which we call the "informal sector firm" and are clearly wellorganized and enormously successful in international business despite lack of formal systems and formal education of their people.
\end{abstract}

1.This paper has been published in 2012. Rao, Indu \& Von Glinow, Mary Ann. The Emergence of Informal Sector Firms in International Business: The Globally Distributed Indian Diamond Industry. Indore Management Journal. Vol 2 Issue 1 published by Indian Institute of Management (IIM), Indore 


\subsection{Introduction}

The informal sector offers a wide spectrum for study of firms as it has a wide diversity, constantly evolving structure and represents a fundamental component of the structure of economies (ICMIIE, 2009); the informal sector firms are a key form of organization of production of goods and services both in rural and urban areas. The pursuit of global business has traditionally evolved from the perspective of the MNE which is assumed to develop rather predictably from small domestic companies into large, mature, transnational firms (Bartlett \& Ghoshal, 1990) over time assuming a likewise organized sector behind the firm's global success. However, literature is less sanguine about such informal organizational forms that do not conform to the theory of the MNC.

There is a renewed interest in informal work arrangements or informal labor markets which stems from the fact that informal work arrangements have not only persisted and expanded but have also emerged in new guises and at unexpected places (WIEGO, 2009). International markets are now being viewed as networks of relationships in which firms are linked to each other in complex, invisible patterns which offer potential for building trust and commitment which are essential for internationalization (Vahlne, 2009). The informal economy has traditionally been the subject of economics and labor-related areas but is generally neglected in the management literature and subsequent research for small economic significance and impact and also for the lack of availability of data. There is high mobility and turnover, seasonality, lack of recognizable features for and reluctance to share information (Asian Development Bank, 2007).

The informal sector contributes significantly to production, consumption, employment and income generation, thus supporting livelihoods as well as output of developing countries and emerging markets; however our knowledge of the sector, its impact and inter-linkages with various economic and social spheres is still rudimentary (CITEE, 2009). According to World Bank estimates, informal economy accounts for $40 \%$ of the Gross National product (GNP) of low-income countries (Farrell, 2004). In India, the unorganized sector accounts for $62 \%$ of GDP, $50 \%$ of gross national savings and $40 \%$ of national exports (ILO Report, 2002 a). The 1999-2000 National Sample Survey organization (NSSO) survey reported that $92 \%$ of the Indian workforce (370 million workers) was employed in the unorganized sector; more than the total population of United States. Now that India is an emerging economy, any macro-analysis would find it hard to ignore these figures. 
Due to the increasing size and significance of the informal economy in international business (ILO Report, 2011), we conduct a qualitative research case study of the CPD (cutting and polishing of diamonds) firms of the Indian diamond industry to indicate that ISFs have moved up the value chain particularly in emerging markets and created success stories in the global business arena and therefore deserve management research focus. Such informal sector firms are likely to make use of informal relationships which thrive on trust and commitment created through their business networks over several years. The invisible part (Johanson \& Vahlne, 2009) may be explained by the influence of societal cultures (Parker, 2011) which support enterprise and networking amongst their entrepreneurs and in turn helps ISFs in some locales to become internationally successful.

Specifically, we have two purposes. First, we attempt to highlight and explore the emergence of the informal sector firms in international business and secondly, we attempt to understand the nature and characteristics of these ISFs. Our interest, indeed what intrigues us, is in these new organizational forms embodied by these globally-distributed ISFs as represented by the CPD (cutting and polishing of diamonds) firms of the Indian diamond industry, largely resident in the unorganized sector and composed of numerous informal sector firms (ISFs). An in-depth study of small and large ISFs in India is conducted to shed light on their role in IB today.

\subsection{Literature Review}

Organizational forms and types are determined by history and the purposes for which organizations were formed with the socially possible tools at the time of founding and if they work efficiently, such forms remain stable over a period of time (Stinchcombe, 1965) or perhaps until challenged. Thus, if an ISF grows with time in size and global reach, it is likely to retain its character of informality if it were found to work well over time and serve the purpose for which it was established. The organizational imprinting hypothesis suggests that organizations differ from one another because "they are of necessity created out of the specific technological, economic, political, and cultural resources available in the founding context" (Johnson, 2007). In this specific case of informal sector firms we explore how scholars have tried to explain the existence and nature of the informal sector. The dualist approach (ILO Report, 1972) considered the informal sector as comprising marginal activities, distinct and unrelated to the formal sector. Sethuraman (1976) and Tokman (1978) believed that informal activities emerge due to limited opportunities in the formal sector. 
The structuralist school describes the informal sector as subordinated economic units (micro-firms) and workers that serve to reduce input and labor costs thereby increasing the competitiveness of large capitalist firms (Moser, 1978). Unlike the dualist model, the structuralist model views the formal and informal sectors as coexisting and inextricably connected and interdependent (Castells \&Portes, 1989) and the focus is on the nature of capitalist development rather than a lack of economic growth. The legalist school posits that the informal sector is comprised of micro-entrepreneurs who choose to operate informally to avoid the costs, time and effort of formal registration (de Soto, 1989), and that they will continue to produce informally so long as government procedures are cumbersome and expensive. According to the neo-classical view (Schneider, 2000), the informal economy responds to the economic environment's demand for urban services and small scale manufacturing. It adds a dynamic and entrepreneurial spirit and can lead to more competition and higher efficiencies. The informal sector may also contribute to the creation of markets, increase financial resources, enhance entrepreneurship and transform the legal, social and economic institutions necessary for accumulation (Asea, 1996).

While existing theories throw light on why informal sector may exist in the first place, literature is scarce about how the successful firms of the informal sector organize themselves and traverse their way up the international arena. Our purpose here is to bring to light that the ISF is a different form of organizing even though it has for long been labeled as an unorganized sector and has lacked attention for study. We explore the globally successful ISFs of the Indian diamond industry dominating a lion's share in the $\$ 20$ billion global exports of cut and polished diamonds.

\subsection{Research Design}

3.3.1 The Research Context. Nearly 11 out of every 12 diamonds sold worldwide are cut and polished in India (Source: GJEPC). By way of context, for our study, raw material is called 'diamond rough', which is mined and procured from different countries around the world: Africa, Russia, Australia and Canada. This rough is imported by different countries where it is cut and polished. Table 1 shows the percentage share of polished diamonds by value for different countries. The finished product is traded mostly in Antwerp, Belgium, and exported to different parts of the world, the major consumer being the USA. Figure 4 shows the rise of the Indian diamond industry over the past two decades. The global diamond industry has had a presence in India for almost half a century and is understood to be part of the unorganized sector. 
Figure 4 Growth of Exports of cut and polished diamonds from India

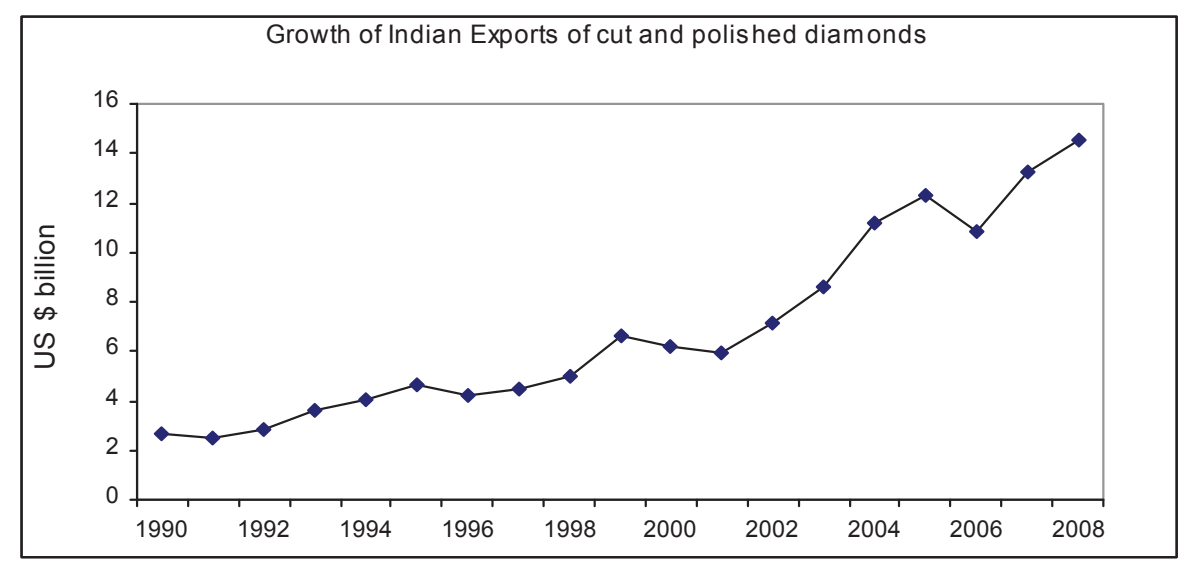

Source: gjepcindia.org

Table 3 Countries exporting Polished Diamond (by value)

\begin{tabular}{|ll|}
\hline \multicolumn{1}{|c|}{ Exporter } & Percent \\
India & 60 \\
Israel & 12 \\
Belgium & 2 \\
Russia/ CIS & 6 \\
South Africa & 5 \\
U.S. & 4 \\
Others & 11 \\
\hline \multicolumn{2}{l}{ Source: ICRA (www.icra.in) }
\end{tabular}

While Antwerp, Belgium was the manufacturing hub of cut and polished diamonds in the 1970s, it has shifted to India which is now the world's largest center for cutting and polishing of diamonds, earns significant foreign exchange and has contributed to the country's export-led growth. It is useful to note that the Indian diamond industry is composed of a network of thousands of ISFs of different sizes employing over a million people most with little formal education. 
Further, most of these informal sector firms are concentrated in Gujarat, a western state of India predominantly in the city of Surat, although industry associates are also in Mumbai. The data for net Indian exports is available from the GJEPC website which functions under the Ministry of Commerce, Government of India. Despite the global nature of the trade (India's primary consumers are global, not domestic) and the background of the workforce, networking of the ISFs has developed into an industry which enjoys a $95 \%$ global market share of exports by number of pieces, $82 \%$ share by carats and $60 \%$ share by value.

\subsubsection{Sample and Data Collection}

Since precious little can be done about collecting financial and other data sets from informal sector firms, we therefore attempt to explore the intangible aspects of organizing. Culture can be a source of competitive advantage if it is rare, valuable and non-substitutable (Barney, 1986). Although various firm practices in the informal sector may be influenced by culture unique to a firm or its subunits, industries exert influences that cause cultures to develop within defined parameters (Gordon, 1991). Therefore, we collected industry and firm level data using both primary and secondary sources for understanding the ISF of this industry. The industry export-import data were collected from Gems and Jewelry Export Promotion Council (GJEPC), India to assess the size and growth of the industry. This information gave insights about overview of the trade at the global interface, that is, about transactions at the point of exchange between India and other countries, it did not reveal how the industry operates within India nor shed light on the ISFs per say. The two authors travelled extensively over the time period of 2006-2010 across the state of Gujarat to the small, medium and large sized cutting and polishing of diamonds, otherwise referred to as CPD units, mostly ISFs involved in manufacturing of diamonds and in Mumbai offices used for trading of these diamonds.

Some smaller ISFs were so tiny and existed in locations which did not even have an official address, nobody seemed to know the exact count of all ISFs and estimated the number to be anywhere between tens of thousands to a million, access to these small ISFs was purely via word of mouth. In-depth interviews were conducted with diamond manufacturers, traders, exporters, workers, artisans, representatives from the related government agencies and at the Indian Diamond Institute (IDI) as well as with others who were knowledgeable of the diamond industry for triangulation. As there were limited records for the distribution of the various CPD units and their location, judgment and convenience sampling technique was adopted for the respondents interviewed. We interviewed 
respondents from 11 companies, 2 large sized, 3 medium sized and 6 tiny CPD units, and from the office of the GJEPC and the IDI to draw insights about the overall industry.

In order to understand how an ISF traverses its journey from a small local firm which served the purpose of an outsourcing destination to changing the rules of the game and becoming a large global player, we conducted an in-depth analysis of a large-sized successful CPD firm which has existed and grown in this informal sector for the last 40 years. Again, as there is a lack of comparative data to list the more successful firms in this industry, this firm was identified after analysis of inputs obtained from the exploratory study and of those received from responsible actors in the industry for triangulation.

\subsection{Summary of Findings: The Industry Overview}

We present our summary of findings in two parts. First we describe our understanding of how the industry evolved and then we narrate how a successful ISF traversed its way within this industry to emerge successful in international business.

3.4.1 A Modest Beginning. In the 1950s, the processing of diamonds was done mainly in Antwerp in Europe. As more diamond mines were discovered, there was increase in the availability of diamond rough. Also, there were enormous price differentials in the processing of large and small sized diamonds. The diamond manufacturers of Europe were faced with the problems of handling a large chunk of rough diamonds and were willing to share the production of small sized diamonds which gave lower returns on investment (personal discussion, 2008). At the same time, a newly born Indian democracy (India received independence from the British rule in 1947) was crippled with problems of unemployment and poverty and weak institutions. Our study revealed that a few enterprising Indians who went to Antwerp agreed to bring to India the left-overs of diamond rough for polishing. These were very small pieces of diamonds or 'grains of sand' in diamond terminology. The entrepreneurs from Gujarat in India utilized this opportunity to develop indigenous methods of cutting and polishing of diamonds in small factories (CPD units). The finished product, the processed diamond was then exported to the globally centralized trading market which existed in Antwerp. This was outsourcing of low-valued diamond rough to an under developed country in those times.

3.4.2 The Incredible Growth Years. Between 1970-80, there was an increase in the size of the industry, and in the number of CPD units (ISFs) in India (personal 
discussion, 2008). The secrets of this business were shared with and restricted to the members of a local community in Gujarat. The community members were largely simple, religious and possessed very little formal education. Personal discussion also revealed that those who were interested in going to school were attracted to the diamond business and dropped out of their studies. Despite the lack of management education, management styles and organizational skills were developed. They tirelessly worked on upgrading the skills of artisans as well as on the techniques of diamond processing. As these informal sector firms (CPD units) increased in size, they moved up the value chain and some even set up their own trading offices in Antwerp in Europe. After creating a niche in the diamond arena with small diamonds, some of these ISFs developed skills and technology for cutting and polishing larger stones and fancy cuts. Improved technology and product quality helped 'in-sourcing' of higher valued raw material, the larger sized diamond rough to India. The larger ISFs eventually developed a worldwide marketing network of global suppliers and clients on their own. The entire process, by the dawn of the $21^{\text {st }}$ century, led to a shift in the global production base of diamonds to a country which by now had transformed into an emerging economy. The ISFs were successful in leading the remarkable growth of the CPD industry from 0.12 billion US\$ in 1975-76 to 14 billion US\$ in 2008-09(Source: GJEPC)

3.4.3 The Industry Structure. Our visits suggest that even today, there exists a huge network of traders, manufacturers, artisans and brokers engaging perhaps more than a million people. Also, it appears to be difficult for anyone to predict the actual number of diamond manufacturing units or the actual number of people employed, as processing is done in large, medium and small units spread across the state and reaches many villages and even homes for which there are no records. We visited many of these small ISFs, many of whom were family based, with fewer than 10 family members, or extended family members engaged in CPD. The workers worked in humble conditions, some in sweat-shop conditions; nevertheless the families graciously welcomed us into their homes, many of which had no concrete flooring. In some shops, technology required heat fire and temperatures soared to high levels inside the shops as well as outside, while in others, they made use of laser technology and the CPD units were centrally airconditioned.

As in any other industry, some ISFs performed better and have grown faster. As a result different sizes of units exist, which can be categorized as small, medium and large depending on the number of diamond pieces, the size of individual diamond pieces, the quality or grade of diamonds being polished and the number 
of people employed. The large-sized diamond units are few in number but have risen to be centers of excellence in various aspects of management of resources, human and material, and of doing business, both within and outside the country. Some of these Indian diamond polishing factories are today, on par with the world's best and make use of laser machines, computerized yield planning machines, advanced bruiting lathes, diamond impregnated scaives, etc. They also sell up to $50 \%$ of their polished diamonds through internet.

\subsubsection{Networking of CPD Units.}

Figure 5 Networking of CPD Units

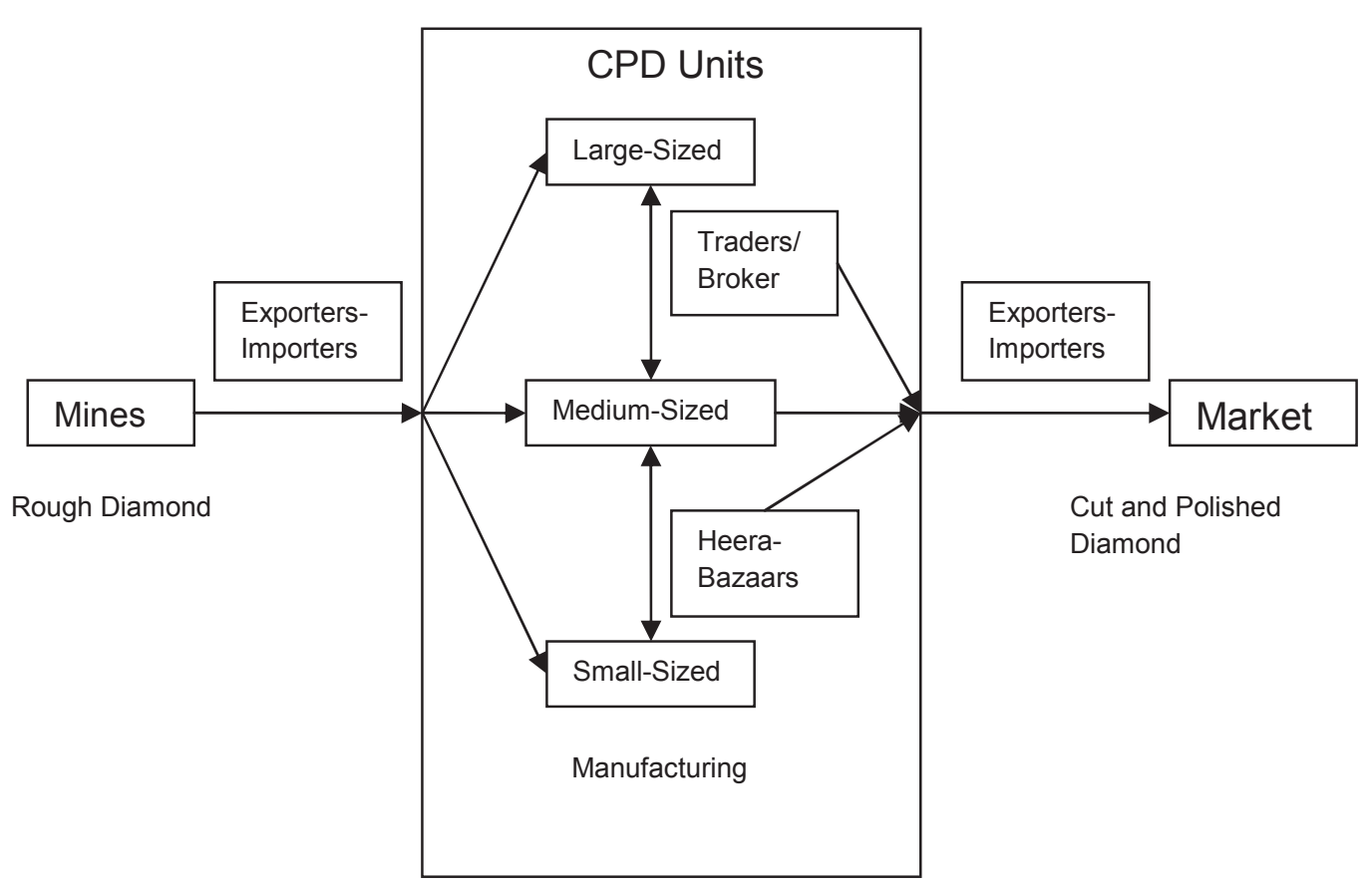

Different categories of CPD units are equipped to cater to cutting and polishing of different categories of diamond rough. The large CPD units have subsidiaries and outsource the smaller and lower quality rough to the smaller CPD units. 
Discussions revealed that the imported diamond could pass through different channels before being exported (Fig 5).

It is now possible for a large manufacturer to directly import, process and export diamonds. The medium sized CPD units may depend on the traders and brokers who are involved in the intermediate buying and selling. Smaller units at the lower end of the chain participate in the Heera Bazaars to collect their share of the diamond rough for polishing. These bazaars are (men only) trading markets which buy and sell all forms of small diamonds for subsequent processing. Since we were two female researchers, we had to receive permission to enter the Heera Bazaar, and needless to say, we caused quite a spectacle.

3.4.5 The Heera Bazaar. Trading across various levels between importers, exporters and manufacturers is carried out through thousands of brokers operating at the same time on open streets in markets called 'Heera Bazaars'. Diamond packets worth millions of dollars continue to exchange hands without formal receipts. There are Heera Bazaars located in different parts of the state of Gujarat which cater to the nearby ISFs. The rough diamonds as well as the polished ones are traded here. It appears impossible to track and account for the exact number of such transactions or the number of people involved in them, however, they seem to be well-connected to the industry network and are engaged optimally to produce the overall output of the industry. We could discern no real pattern of organization amidst the yelling and shouting (imagine the trading floor of the US Stock Exchange to the uninitiated). How and why two traders came together, agreed on a fair price and exchanged money had no 'handbook of instructions or directions' that we could tell, and no one would address the issue with us.

3.4.6 A Unique Transaction System. The transaction of diamonds is carried out through special mechanisms. The transportation of diamond packets, both rough and polished, is largely done through angadias. Angadias are people (couriers), members of a local community of Unja Patels, who have specialized in carrying diamonds safely within the industry for a period of over four decades and have achieved trustworthiness of the highest order. There are often no written contracts, many transactions occur in cash, and stones worth millions of dollars are transported with virtually no security. The angadias could also be carrying these diamond packets in their pockets and traveling in the economy class of a train. The whole industry they say, works on trust. One trader showed us what the packets looked like, and they were packets of paper folded around perhaps hundreds of small-sized diamonds, all of which fits into a shirt pocket of the angadia. 
3.4.7 The Industry Glue. Thus, the Indian diamond industry mainly consists of members of a particular community who are often socially/familialy-related to each other. They seem to share an industry culture with few formal systems unlike what we see in the so called organized sector. Most functioning of the industry seems to be nested in psychological contracts and trust which is reinforced through social bonding. It resembles a close-knit community that thrives in the atmosphere of secrecy and informality that envelops the diamond trade. Selfimposed rules, discipline and order is observed and the business dealings carry out smoothly with few formal policies and procedures or documentation. Whereas in the US, when people transport gems and other precious jewelry they must be bonded, and do so with heavy security, in India, there are none of the controls we observe in more advanced economies. Equally stunning, is that despite opportunity, there appears to be little to no theft or heists.

\subsection{Summary of Findings: The Firm Overview}

We now turn to our study of a large-sized CPD unit and include a description of its culture, innovations and practices. We believe that this selected firm has all characteristics of the informal sector firms and the industry it is a part of as its rise is synonymous with the rise of the industry. Established in 1969 by two brothers with a handful of employees, the second generation of the family joining later, the annual revenues of this unit grew from approximately one million USD in 1988 to 350 million USD in 2008, the employee headcount now stands at 1500 . The owners did not seem to remember any financial revenue figures for the time period before and said that it was a very humble beginning with some 20 people in their workshop forty years ago. Today, the firm enjoys the reputation of having revolutionized the domestic and international diamond cutting and polishing industry, and of redefining the concept of a modern diamond processing unit and its innovative human resource practices.

3.5.1 The Initial Growth Phase. Initially, the office and the factory of the CPD unit were separated by a distance of $3-4 \mathrm{~km}$, (the separation of white and blue collars) which resulted in a few misunderstandings and led to worker protests. The founders realized the importance of a regular interaction and communication between the workers and the managing staff so in 1982, they conceptualized a CPD unit with an office and a production facility in the same premise; the concept was later accepted by the management and other CPD units of the Indian diamond industry. Coping with an industry that was booming and manufacturers were roping in workers from other companies, they used their business acumen. Compromising on quality was not acceptable, neither were the employees 
penalized for doing so, instead, salaries were doubled and a unique quality/incentive-based wage system was established. They resolved to provide good working conditions and better salaries to their employees. Further, methodologies were invented to achieve quality and they were quick to adopt new technology. In less than 10 years after inception, along with routine business activities, the firm also began allocating funds to social and religious welfare activities.

3.5.2 Defining the Concept of the Workplace. Far from the sweat shop images that we portrayed earlier (and are still common to some extent in the small and medium-sized CPD units), in June 2002, the company's new US \$ 12 million state-of-the-art manufacturing facility was made operational. It is a centrally airconditioned 8 floor factory premise of 260,000 sq. ft. area on a 6.5 -acre plot in Surat, providing an excellent working environment. There are landscaped gardens, spotless buildings, product line arrangements neatly divided into separate rooms, smartly dressed security guards who welcome visitors with warmth and hospitality and hi-tech automated security systems to guard the place. We were hosted in their ultra modern guest house, where we interviewed the founders and the top three in his management team. More than a thousand workers and skilled artisans work diligently and with discipline on their respective machines using computerized tracking systems, cutting edge laser technology and the most modern and sophisticated diamond processing equipment.

3.5.3 The People Structure. No formal organization structure exists, people are grouped into different work areas; a manufacturing unit exists at Surat and a sales and marketing office in Mumbai. About $86 \%$ of employees work in manufacturing, $7 \%$ as support staff including canteen attendants and security watchmen, about 5\% are employed at the Mumbai sales and marketing office, and the remaining for administration, data processing and audit. It appears that overhead is minimized.

3.5.4 Marketing and Sales. Expenses on conventional marketing are kept to a minimum. The logic here is that if you offer transparency in the attributes of the product, it translates into customer confidence which goes on to build more customers through word of mouth. And yet, talk of buying -selling norms, there exists a law of non-negotiable price. Take it or leave it, the first offer is the final offer and is determined by a computerized system, based upon a long list of parameters which 'do not' emphasize the fluctuating prices and the profitability of the company. No lengthy credits of up to 9 months to customers at this CPD unit, the average receivables in 2008 were just 10 days. Initially, customers were angry 
and the sales went down, but the company adhered to its policies, refined the grading systems and ensured that the stones were exceptionally well cut. Over time, they developed a strong client base that was ready to buy their diamonds online without physical inspection of the diamond. This has cascaded into a strong global customer base that has spread across USA, Europe, Japan, Asia, the Middle East, Australia, Canada, New Zealand and South Africa to an extent that they are willing to pay a premium.

3.5.5 Achieving Quality in Production. No two diamonds are alike just as no two humans are, and achieving quality in polishing diamonds is not an easy task. The rough diamonds are sorted and valued depending on shape, quality, color and size. In this unit, some 1270 skilled artisans, assorters, graders make use of their traditional knowledge as well as the high tech laser technology and machines to convert the rough stone into polished diamonds through a well designed manufacturing scheme. There is no QC department in the set-up, but a unique system of individual accountability and responsibility has been designed for every action/decision, which inherently ensures the best possible quality control. We were allowed to watch this process of quality control, and unlike other ISO standards, their grading system is transparent and comprehensive.

3.5.6 People Management Practices. It doesn't end with the diamonds and their manufacturing and selling, at lunch time all employees including the owner eat together in their company canteen facility with the unit's own kitchen staff serving vegetarian food free of cost. The CEO notes, "It is not free lunch, because it is only for those who work here. If the workers are happy, they perform better, if they perform better, our clients are happy, if my clients are happy, so am I." Annually, every employee has two vacations (Diwali and summer) which are three weeks long. Everyone works eight hours per day; they have pension plans, and workers self-supervise. Closed circuit cameras monitor many parts of the factory, particularly the assembly line.

Negative thinking or "acting out" has no place, according to the founder. People are encouraged to think and act positively, as well as to not shout or even raise their voice during discussions. Before vacation begins, the founder addresses all employees through the public address system, or in a town meeting, and advises them on various issues related to their personal safety and family welfare, advising them to drive carefully, and to not indulge in bad habits like tobacco. He explains to his workers that their life also belongs to their family members and therefore they should take care of it. It was common for employees to confess that their behavior at home had improved since they started working at this CPD 
company. In turn, the families of these workers have also developed deep regards for the founder.

Generally, the company prefers to promote from within. It recruits experienced workers who have a proven track record of honesty, diligence and dedication in their area of work. The founders believe that people need to be made aware of the immense unused potential lying within them. In addition, they never ask a person to perform a task below the level of his/her potential. This is perhaps how they make optimal use of their human resources. Safety of the valuable diamond pieces in CPD units is important, hence fingerprints as well as palm-prints of new recruits are taken. Nevertheless, they still utilize the angadia system of transporting gems and cut diamonds.

In order to keep people motivated, an innovative quality/incentive-linked wage system and unique methods of resolving disputes have been devised. State of the art safety standards and welfare measures take care of the employees. Since inception, the founders have stressed effective communication and any lapse is not accepted on any employee's part irrespective of rank, job or position in the company. "People have a tendency to send selective messages; we have meticulously tried to nullify them. If any worker or artisan tries to approach me, I listen to him with utmost priority" claimed the founder.

3.5.7 Major Innovations at the CPD Unit. Surprisingly, unlike the reputation of the industry, a unique IT-driven business model is in place which seamlessly merges manufacturing, grading, pricing, sales and marketing aspects of the business. The CPD unit started computerizing in 1987. A Grading system was invented in 1996 at this CPD unit for a diamond piece which became the standard for the global diamond industry. Beyond what we normally think of as the 4 "C's" - color, cut, clarity and carat, they have evolved a criteria of 17 grading attributes, 17 C's sets standard in the industry, and this means world-wide. 'Online Sales' was launched in1997, a first for any manufacturer in the global diamond industry. For a product such as a diamond, it calls for a great deal of credibility of a company to give the confidence to its buyers to purchase online without physical inspection. In 2005, the company hosted an in-house web server, providing the entire inventory on real time basis for their online buyers. Later, besides the grading details, digital images of diamonds were also made available. Sales through the website totaled about $37 \%$ of total sales in 2006 which, is an amazing reflection of customer trust and confidence given the nature of the product. 
In 2003, the company introduced Confirmed Order Requirement (COR), a revolutionary system of buying diamonds on specification without personal inspection. Apart from boosting consumer confidence in the business integrity of the company, the system alone contributed to $12.31 \%$ of sales in less than six months. Sales crossed the US $\$ 150$ million mark in the year 2003. Exports crossed US \$100 million in 2002 on year-to-date basis. Sales grew from US\$ 67.09 million to US\$ 174.80 million in a period of 3 years between 2001 and 2004.

3.5.8 Social Responsibility. The importance of CSR as we know today was practiced by these Indian entrepreneurs for the last three decades. Besides developing industry best practices as mentioned above, they contributed to other aspects of diamond trade and industry like suggesting government policy decisions. This CPD unit has made numerous and significant contributions towards religious, social, educational and disaster management needs of society.

\subsection{Discussion}

"Firms did not exist at the dawn of economic history" (Weber, 1929) and all economic action then, were apparently informal in nature. As industry and capitalist structures got more organized, formalization came into effect with smaller firms first, which later grew into larger domestic firms and thereafter into multinational companies. The growth of the firms and their trajectory of transition from domestic to international are well documented and explained by scholars (Penrose, 1957; Hymer, 1960; Dunning, 1982; Rugman, 1973; Ghoshal, 1983; Mcdougall, 1990). However, most frameworks assume formal sector firms and formal transactions, and more often than not, begin by dissecting the large multinational firm from the perspective of the developed countries. We now present our understanding drawn from the industry and firm level exploratory field study conducted in the informal sector firms.

There is evidence from this study that informal sector firms are not just local firms but can also have global reach. The analysis of the findings from the exploratory study of the Indian diamond industry and that of the case study of a large CPD unit leads to useful insights. The Informal Sector Firms which have made it big on the global front have flourished like a close-knit community with entrepreneurs like the one we have described above leading at the forefront. As the volume of business increased, they passed on the business to others connected to the same community. Despite little formal education, professionalism exists where verbal commitments are honored and met, and a high order of integrity is exhibited, and 
it is all a part of their societal culture. Culture is a shared pattern of values, beliefs and assumptions (Schien, 1996).The networking of ISFs as observed in the diamond industry ISFs, works on a culture of trust and mutual respect. The people involved take pride in their work and in what they have achieved. A sense of belonging to the community is a big motivating factor and people try their best to be known and respected by adhering to the norms as established by their culture. A display of simplicity, sincerity to work, diligence and discipline was observed down the line from the large to medium and small sized CPD units.

It appeared that the smaller units were not underpinned by the larger ones, and were happy to be operating from their native places, the location of their respective villages where they shared their life with the members of the family and kith and kin. However, the mention of the big company names did evoke a sense of respect and motivation to grow. It was observed that in the broader context of the Indian diamond industry, there is lack of formal systems like documentation of the diamond packets exchanged and of the financial transactions or that of the recording of employee details or number of units etc. However, it appears this made them feel proud of their ability to conduct a business of a huge global dimension based on mutual trust within their community. Not delivering on the verbal commitments or any symptoms of dishonesty and they would be dispelled from the community. The community or clan feeling appeared so strong that the mere thought of being ousted from the group and from the diamond business engaging the community motivated them to behave as per norms.

Also, it was uniform across the sizes of the CPD units that the unit owners were sensitive to the family concerns of their employees which in turn helped employees to be loyal and devoted to their work. Another interesting observation at least in the smaller units, was that after the workers and the artisans learned the art of cutting and polishing a diamond, they were likely to start their own CPD unit and employ others known to them through personal references. A culture of individual responsibility which goes in line with entrepreneurial spirit as is demonstrated by these ISFs drives them to start their own units. The ISFs would like to have their cultures more attuned to their societal cultures which they are passionate about. If the ISF is non-compliant it also means it cannot expect any help from the institutions and the informal sector by default makes the entrepreneur responsible.

It is not that some societies are completely impervious to commercial incentives or international influences such as trade, investment, technology. It is just that some cultures accept these ideas more readily than others, and that different 
cultures often promote commerce and enterprise differently (Samuelson, 2001).Close personal relations and family ties there helped foster economic development created the very same security and trust needed for trade relationships that laws and an independent judiciary had fostered in the West. In the postwar era, the reliance on family-dominated firms meant that many Asian nations did not have to wait until they had a well-developed commercial legal system before growth could accelerate (Samuelson, 2001).

An enterprising spirit was omnipresent and everyone understood the importance of what they were doing irrespective of the place they were operating in on the value chain. The huge network of these thousands of ISFs was held together by a common goal of doing and improving the business of diamond cutting and polishing and they understood exactly the informal systems in place. Most large sized unit owners mentioned that they had a dream of making Surat the world's largest diamond cutting and polishing center, which they achieved and it gives them a sense of fulfillment. And they contributed to the society by getting involved in social, religious and other pro-social human endeavors.

Due to lack of formal systems, we suggest that an ISF's behavior is largely influenced by the dominant values and beliefs which result as an interaction of societal culture, industry culture as well as values and beliefs held by the founders of the firms and of those with influence within the ISF. The firm's behavior is guided by the complex interactions of these three different cultures and is therefore more flexible and adaptive to dynamic external circumstances. The culturally-sensitive and culturally-strengthened ISF is perhaps what explains the resilience of such firms during the recent global crisis. Economies which are dominated by the informal sectors as in emerging economies have also exhibited the first signs of revival as demonstrated in the case of the diamond industry.

Earlier, ISFs served as outsourcing and off-shoring units of production of goods and services, but have gradually moved up the value chain and networked with both formal and informal sector firms in different countries thus giving rise to an informal industry culture as evidenced in the global diamond industry. This industry culture is influenced by societal cultures in places where ISFs are geographically concentrated. In globally distributed industries and supply chains, different cultures merge to give rise to specific industry cultures which then influence cross-border behavior of firms.

Most existing approaches to ISFs make an implicit economic assumption that human nature is universal: confronted with the same incentives, people 
everywhere will respond similarly. However, human behavior is shaped by history, geography, religion, climate and tradition related influences that create culture and hence is not uniform (Samuelson, 2001). People across the globe have different values, beliefs and customs; they behave differently and create societies with different legal and political systems (de soto, 1989). Some societies may be more culturally-friendly to economic growth than others and these forces may also affect enterprise, invention and material accumulation (de Soto, 2001). This may explain why ISFs in some regions perform better globally than others. Even within countries, different regions and different groups have different experiences.

\subsection{Conclusion}

Although we have chosen one large CPD as our focal case, the authors visited dozens of small and medium sized ISFs and interviewed hundreds of respondents associated with the diamond cutting and polishing industry during the data collection phase. We think it fair to say that the informal economy thrives on an enterprise culture which cultivates entrepreneurship and facilitates its growth while contributing significantly to the economy. Informal sector firms are growing large and that more such firms can emerge from anywhere across the world in any industry because they have certain advantages of both local and global knowledge. As the world' borders become more porous and open to international trade and development, there is space for both the formal and informal sector firms to become global players. However, the societal cultures like the one we see in the Indian diamond industry are likely to play a significant role in internationalization of the ISFs. The countries with more of such ISFs will draw higher FDI as they provide for the structural support to the firms which have moved up from the lower band to the upper band as well as a cost structure to the industries of which they are a part. While many in the corporate business and the world economy in general continue to struggle with the aftermath of the recession, the ISFs we studied have shown sufficient resilience to bounce back. A possible outcome of this study is that industries and firms of the informal sector possess close knit community culture which helps them to survive the difficult times.

\subsubsection{The Significance of ISFs to International Business}

The study of the informal sector firms in the diamond industry provides useful insights. First, the ISFs organize as networks in specific industries and the firms benefit from competition, complementarities and common resources of the 
clusters, providing efficient production systems and processes. Second, these ISFs are embedded in networked communities with shared cultures which provide for solidarity and mutual trust, providing employment and entrepreneurship opportunities and livelihood to community members. Third, the ISFs provide for parts of the global value chains in sourcing of raw materials, processing, and in distribution networks. Fourth, the ISFs which traditionally catered to the industry and to larger firms to provide for outsourcing of certain parts and processes but with advent of ICT, have moved up the global value chains and established contacts with end consumers and suppliers alike. Fifth, the ISFs work with minimum overheads and transactional costs which are characteristic of their organizational form, possess flexible specialization skills and agglomerate to export products and services.

Thus, governments are incentivized to support the networks of ISFs and even create special export zones and benefits for them. The trade is documented at the country borders but not so much monitored at the firm level in the case of ISFs; the collective benefits for society, government and global value chains make way for institutions to allow the ISF clusters to organize and monitor themselves. However, given the growing significance of ISFs, it is important for both managers of formal sector firms as well as policy makers to gain further insights into the organizational forms of firms of the informal sector.

\subsection{Implications for Future Research}

This preliminary study on the multifaceted diamond industry opens significant new directions for future research. The ISFs, so called due to the absence of traditional corporate structures, strategies and statistics, remain under-researched and empirically undocumented. That these unorganized, globally-dispersed companies appear to gel or 'fit' into a more 'organized' framework later in the value creation chain challenges our current thinking on organizing and managing for competitive advantage. Neither theorists nor empiricists have studied these unorganized organizational forms, nor charted any so-called best practices despite this dominant global market share. Hence, this is a first such attempt to study these new organizational forms, as represented by the ISFs of the Indian diamond industry in India. We believe this study will have significant implications for theory as it explores new forms of organizing as displayed by the ISFs of the Indian diamond industry. There exists a large scope to learn from their innovative operations and value systems. 
It is evident that some unique leadership styles, management skills and culture exist within the ISFs as in the Indian diamond industry and its contribution to the growth of economy as well as to the study of organizations cannot be ignored. Study of the unique people management practices is likely to add to the body of literature on human resource management. It is therefore suggested that more empirical research be conducted to unearth the unexplored dimensions. Clearly there are implications for practice for SMEs in all developing countries. Given the cultural and social diversity, the informal sector is also differentiated and heterogeneous; nevertheless, a first step in analyzing globally distributed work here is to recognize it as an existing and potentially powerful driver of the economy. 


\title{
Chapter 4. Surviving the Recession: Venus Jewel -A Case Study from Indian Diamond Industry ${ }^{1}$
}

\begin{abstract}
The Indian diamond industry witnessed a severe recession in the year 2008. The industry is already showing signs of recovery in 2009 led by its large-sized firms. This case presents facts from a study conducted in a large-sized Indian diamond processing firm which has existed for the last 40 years and led the revival of the industry. It includes description of the company policies, management practices, innovations, the organization structure, and other unique systems. It also describes the exemplary business acumen and leadership qualities of the founder of the unit of our case. Besides, this is the first such study conducted in the Indian diamond industry which has otherwise remained undocumented in spite of an extraordinary global performance.
\end{abstract}

1. This paper has been published in 2010. Rao, Indu \& Bhatnagar, Deepti. Surviving the Recession: Venus Jewel. A Case Study from the Indian diamond industry. Vikalpa, Vol 34 Issue 3 published by Indian Institute of Management (IIM) Ahmedabad 


\subsection{The Recession}

In November 2008, the workers of Indian diamond industry had a tryst with destiny. An estimated one million workers returned after a customary 5 week Diwali vacation, usually availed by these diamond industry workers, just to find that owners of the diamond processing units wouldn't open gates for them. Thousands of such units in Gujarat, India, which cut and polished diamonds mainly for export, had been shut down. The decades old, and now US \$ 14.2 billion Indian diamond industry witnessed the severest recession in its history (Source: GJEPC). However, one unit allowed all of it's over 1500 employees to resume work as usual.

The 61 years old Sevantibhai Shah, the founder of 'Venus Jewel' fondly addressed by his employees as 'Kaka' (a respectful Gujarati word for uncle), was engrossed in his usual work in his office in Surat, in the afternoon of Nov 18, 08, when a group of employees approached him .... "Kaka, we have read in the newspapers this morning that all the other diamond units have decided not to reopen after Diwali due to severe recession. Will it not affect our company, if we, probably the only ones in the entire industry work? If required, please close the factory. We will understand". "It is not required." was Kaka's brief reply. The next day, the $19^{\text {th }}$ of Nov, the emotional employees came back to Kaka in big numbers, "We want to tell you something, but give us a promise that you will agree with it". "I can't give you any promise without knowing your demand", said Kaka. After they failed to get the promise in advance, they said, "Kindly reduce our salaries, except for those whose salaries are in four digits". "It is not required", Kaka said. Several employees had tears in their eyes. "I appreciate your feelings for the company and our family-like relations with each other. There is no need for the company to shut down or to reduce salaries, but if you want to do something for the company, I have an alternative". The employees were intrigued, "What is it, please tell us". Kaka replied ... "Ensure that no damage is done to any stone (the diamond rough), and cooperate with the management by giving your best".

.....this is a story which will keep doing rounds in this city of diamonds, perhaps for decades.

"Around 6 lakh people lost their jobs from October 2008 following the impact of recession and most of them are from Surat's diamond and jewelry industry. About 500,000 people lost their jobs in the October-December 2008 period, while over 
100,000 were shed in January this year" (Economic Survey presented in the Indian Parliament on July 3, 2009)

Reports suggest that many diamond workers who were immigrants from Saurashtra, Bihar and Uttar Pradesh, and whose families were totally dependent on their jobs in Surat, were left stranded during the crisis, some tried to commit suicide, others who struggled for a few months, either switched to other business or withdrew their children from local schools and packed their bags for their native places. "Diamond had become as good as stone" remembers a middle-aged artisan. Six months later, the industry has somewhat recovered from its lows with around a quarter million jobs added after January and signs of global recovery. But it is now difficult for several units whose workers wouldn't return. Venus Jewel not only retained its staff, but also invested more in rough diamonds.

"Our turnover has come down from \$335 million in 2007-08 to \$217 million in 2008-09, but we have survived. We suffered heavy losses but the efficiency has increased, and we are happy to have earned the enhanced loyalty and trust of our people”, said Kaka.

\subsection{Global Positioning of the Indian Diamond Industry}

Of the world's total export of cut and polished diamonds, the Indian diamond cutting and polishing industry accounts for 95\% share in terms of pieces, $80 \%$ share in terms of caratage, and $57 \%$ in terms of value. 11 out of every 12 diamonds set in jewelry worldwide are cut and polished (CPD) in India, 90 percent in Surat. India's gem and jewelry industry is one of the most dynamic and fast growing sectors of the Indian economy and a major contributor to the country's export-led growth. The Gems and Jewelry Export Promotion Council (GJEPC) is the apex governing body of this dynamic industry, and was set up by the Ministry of Commerce and Industry, Government of India, in 1966.

The industry has registered a remarkable growth over the last four decades, with exports having grown from US \$29.35 million in 1966-67 to US \$ 21.11 billion in 2008-09 accounting for 19.1 percent of total Indian exports. Export of Cut and polished diamonds (CPD) accounts for $67 \%$ of the export basket of Indian Gems and Jewelry and is therefore a leading foreign exchange earner for India. No diamond mines exist in India today, and hence the rough stone (raw material) has to be entirely procured as imports. The rough diamonds are mined in South Africa, Botswana and Canada, Russia and Australia, traded mainly in Antwerp, Belgium and processed (cut and polished) in India, Israel and now also in China, thereafter, polished diamond is exported across the world, USA being the major consumer. 


\subsection{How does the Indian Diamond Industry Operate?}

The industry resembles a close-knit community that thrives in the atmosphere of secrecy and informality that envelops the diamond trade. A majority of India's skilled diamond workforce is employed by small family-owned firms or units that process diamonds on a job-lot basis. In the $80 \mathrm{~s}$ and $90 \mathrm{~s}$, the diamond industry was in the eye of the storm for the poor working conditions of the hundreds of one and two room units mushrooming in Surat and nearby places. Even today, there exists a huge network of traders, manufacturers, artisans and brokers engaging more than five million people who have little or no education. It is difficult to predict the actual number of diamond manufacturing units or the number of people employed, as the processing is done in large, medium and small units which spread across the state and reaches many villages and even homes for which there are no records.

The trading across various levels between importers, exporters, manufacturers is carried out through thousands of brokers on open streets in markets called 'Heera Bazaars' for which there is no way of tracking. The transportation of diamond packets, both rough and polished, is done through angadias, members of Unja Patels, a local community who have specialized in carrying diamonds safely within the industry and achieved trustworthiness of the highest order. There are often no written contracts, many transactions occur in cash, and stones worth millions of dollars are transported with virtually no security. The whole industry they say, works on trust. No small feat, then, that the local entrepreneurs captured a lion's share of the global diamond exports.

However, the global recession of 2008, meltdown of the US economy and devaluation of US dollar did not spare these diamond cutters whose lives were dependent on exports. But, Venus was different.... it grew at an astonishing $47 \%$ in fiscal 2007-08 which was witnessed the world over as a year of economic slowdown...

\subsection{About the Company}

Venus Jewel was established in 1969 by Mr. Sevantibhai P. Shah, and his brother Mr. Ramnikbhai P. Shah. Venus employs more than 1500 persons. The turnover of Venus grew from about Rs 5 crore in 1988 to around Rs 1400 crores in 2008. The company has earned reputation of having revolutionized the domestic as well as international diamond cutting and polishing industry, and of redefining the concept of a modern diamond processing unit. 
Venus specializes in manufacturing of premium solitaires in sizes 0.50 to 5.00 carats \& above, D to J colors and IF to I2 clarities and a variety of shapes. The management remains under the control of the five family members, i.e. Kaka, his elder brother, and nephews Mr. Anil Shah, Mr. Rajesh Shah and Mr. Hitesh Shah, who represent the second generation in the family business.

"Venus is a trusted supplier of solitaires, recognized for its commitment to excellence, transparent business practices, ethical values and is also considered a benchmark for providing one of the best working environments in the world" said the Chairman, GJEPC, Mumbai during a meeting in his office in Mumbai in July 2007. "We are proud of the way this company has grown setting standards and without compromising on their principles" said the Director, IDI (Indian Diamond Institute), Surat, personal discussion in December 2006.

\subsection{The Venus Unit}

We visited several factories of the Indian diamond industry, from the largest manufacturers to the small four room operations and to single machine being worked upon in a small house in a village. But once inside the Venus gate, after a five minute ride from the Surat railway station, it was as if one entered a different world. An 8 storied 260,000 sq. ft. centrally air-conditioned, state-of-the-art manufacturing facility built on a 6.5 acre plot (Exhibit 1) in Surat that can easily be compared to the best in the world. Landscaped gardens, spotless buildings, smartly dressed security guards welcomed with warmth and hospitality which was later found to be omnipresent in this Venus campus. One of the security guards escorted us, passing through the high tech security systems, to the escalator, pressed the lift button, smiled and left. On reaching the eighth floor, there was another security guard waiting to take the case writer to Mr. Rahul, the general manager, who was prepared to facilitate the case study.

\subsubsection{Ambience}

It was amazing, the well designed, sparkling structure, product line arrangements neatly divided into separate rooms, which were spacious, aesthetically lit and providing an ambience which is rare to be found in the best of corporate houses. More than a thousand workers and skilled artisans worked diligently and with discipline on their respective machines using computerized tracking systems, cutting edge laser technology and the most modern and sophisticated diamond processing equipments. Far from the norms when one earlier imagined an India based manufacturer/exporter of the diamond industry, there was no child labor, no 
abuse, no small goods, no polishing of grains of sand (small sizes of diamonds) here. Everything was bigger, brighter and better than the world outside their enclave; many diamonds were 2 carats upwards on the wheel.

\subsubsection{Business Policies}

Talk about selling, there is a law of non-negotiable price. Take it or leave it. It is perplexing to note that amidst thousands of units, this one works like a monopoly. Their first offer is their final offer and is determined by a computerized system, based upon a long list of parameters which do not emphasize the fluctuating prices and the profitability of the company. Every parcel contains a single diamond piece and carries detailed description of the diamond, a practice they were first to start in the industry. No lengthy credits, up to 9 months to customers which had become a hallmark of the industry; at Venus, the average receivables in 2008 were just 10 days. Initially, customers were angry and the sales went down, but the company stuck to its policies, refined the grading systems and ensured that the stones were well cut. Over time, they developed a solid client base that was willing to buy their stones through website without physical inspection of the diamond.

\subsubsection{General Environment}

It doesn't end with the diamonds and their manufacturing and selling; come lunch time and all employees including the owner ate together in the excellently maintained canteen facility with the company's own kitchen staff serving hygienic vegetarian food. An aura of peace and satisfaction resided on any employee's face, pick anyone, and he is willing to share openly about the environment and work and about the fondly respected 'Kaka'. Two vacations for Diwali and summer, each of three weeks, eight working hours per day, pension schemes, and workers encouraged to self-supervise. Of course, closed circuit cameras monitor many parts of the factory.

An unmatched quality of polished diamonds is achieved and the mystery surrounds in other units about how they do it? Here was a company which not only defied all trends but also succeeded in setting many new ones. Discussions with family members, employees and even competitors invited a common response. "Kaka's name is synonymous with credibility. The diamond sells by his name."

\subsection{The Founder}

Kaka is credited to be the man who has transformed diamond processing in India. Born in 1948, in a family of moneylenders in a remote village, Vadgam near 
Palanpur, he lost his father at an early age. Values in life were imbibed from parents and eldest brother, who were very caring and affectionate. All his life he treated his employees with the same empathy. Kaka had been a brilliant student of the first batch of a school in his native place up to class 11, beyond which he did not receive any formal education. Out of the four brothers he was the most daring and had strong beliefs. A perfectionist who was uncompromising and determined to pursue his beliefs, he always led a simple and disciplined lifestyle. Simple food habits, gentle and caring attitude, clear thought process, strong will power, dedication towards his duties to all and high moral values are some of the attributes which distinguish him from contemporary industrialists.

Technology, scientific management and human resource management were never learnt by this humble and simple man in any management school, yet he has set an example of an exemplary businessman who was the first to adopt and develop unmatched world class technology and systems, and also took people along with him as he struggled to reach the top. A firm believer in punctuality, discipline and commitment, Kaka believes that 'life without struggle is no life at all'. Some stories of his childhood he narrates,

"I did not believe in superstitions and when in class eight, a discussion took place with my friends that there is a ghost in the lake in our village, which naturally I did not believe. I took this as a challenge and went to the lake alone at night to fetch water, of course, with a torch to avoid any risk of snakes or scorpions.

He was very good in Math and some politics in the school led to the resignation of a Math teacher loved by the students; all the students went on strike which was broken by calling parents, and students were forced to apologize. Kaka refused to do so, as he said that they had not done anything wrong, and instead stopped attending school in protest. Few months later, the chairman of the school lovingly took him back to school to rejoin.

Kaka came to Surat in 1965, and was in a dilemma whether to study further or not, and ultimately decided to take admission in an engineering college. But everyone was talking about the opportunities in the diamond industry in those times. Even an artisan could earn 3-4 times more than what a teacher earned. He decided not to study further and switched to diamonds.

"There were uneducated people in the business and those who were studying stopped doing so because of this, but all were intelligent and hard working... and there was scope for a large number of people to get employed in diamond business. I learned about diamonds while moving in different units and was one of the few 
persons trading actively on streets. In 1969, we started our own company, Venus, named after the planet which shines brightest in the sky." Kaka said.

"In 1978, the founder returned from a pilgrimage after 50 days, organized by his family for 700 persons, and was completely dissatisfied with the quality of work done in their absence, industry was booming, manufacturers were roping in workers from other companies. Inferior quality was not acceptable, he almost doubled the salaries so as not to compromise on quality, and established a unique incentive based wage system.

"Working in a manufacturing unit was considered below status in the business community, trading was dignified. People didn't want to have offices attached to the manufacturing unit. In 1982, I was the first person to conceptualize a unit with office and production in the same premise; the concept was later accepted by the industry", Kaka clarified.

The owners operated from an office and the factory was at a distance of 3-4 km. In the late 70's, the workers went on strike and the manager informed them about the seriousness of the matter. Kaka instructed him to lock the stones in a safe, and do nothing. After a few days, some workers walked to the office.

Kaka asked them to sit but did not utter a word. Ultimately, one worker then hesitantly said, "What should we do"? The founder replied, "Did you consult me before going on strike, why consult now". They decided to resume work. "A change may not be understood at first by them, but later on when it proved beneficial to all, they understood." Kaka asserted.

All these years, while growing in an industry which largely belonged to the unorganized sector, the founder adhered to his principles, observing the law of the land, providing good working conditions and also by being the best pay provider. He was among the first to adopt technology and invent methodologies to achieve quality which was unheard of in the Indian diamond industry. So, what has Kaka's Venus Jewel done over the years to be as successful as it is today.....

\subsection{Major Innovations / Milestones}

The company is credited with several firsts in the industry since its inception in 1969. A brief overview is given in this section and some of them are described in detail later. 
"Like others, I too got opportunities to make a fast buck, but never compromised on my principles till date. If you read history, it is the burden of bank interest along with buying on long credit terms which ultimately leads many to bankruptcy." said Kaka.

As early as 1971, in Venus it was decided not to borrow finance from anyone other than a bank. In 1994, they decided not to buy any rough on credit, only through cash. Both practices were otherwise very common in the industry.

"I was terribly hurt by some comments made on the poor quality of gems made in India and also of the poor working conditions that existed." Kaka resolved to correct that impression, an old employee said.

"I thought long and hard about how to make my employees happy, which automatically resulted in making them loyal and dynamic", remembers the leader.

In 1978, Venus established a unique incentive based wage system wherein the efficiency of each worker is calculated daily, aimed at maximizing value addition and this proved to be highly motivational.

In 1986, a new diamond manufacturing unit was established, with observance of all statutory regulations, deploying various staff welfare measures, good working conditions, and an efficient, motivating and ethical work culture, which became a benchmark for the otherwise unorganized diamond industry.

In 1987, the company started computerizing, which led to their achieving information technology governance, integrating all business functions from manufacturing to sales.

"It was difficult to find people trained in computer technology, then. The computer person, who was with us from 1987-1996, knew everything about our systems, but left suddenly for USA without informing us in advance. It was a severe problem. At that time we tried to take work from the trainees, sitting with them, making them understand the various logics of programs required for our systems" says Kaka.

"In February 1988, during a visit to Antwerp, I found that the price of polish for a large sized diamond was too good compared to the rough prices. After verifying this, I purchased the rough and started manufacturing diamonds 2 carats and above, on a large scale, thereby pioneering the concept of high value diamond processing in India. Prior to this, the world had doubts about India's ability to process such large sized diamonds. 
"I spent extra working hours to make this large sized diamond business successful. The key to success in this endeavor was strong focus on quality, attention to the minutest detail and utilization of latest technology as much as possible. Equally important was to offer to our people a healthy environment with social security, welfare benefits and the best wages in the diamond industry."

In 1996, the company developed its own Venus Grading System (VGS), which is in all likelihood, the most detailed grading system in existence in the industry. It specified 16 grading attributes for each diamond with multiple checking levels and more than 400 criteria specific master stones. The general trend of rating a diamond was on the basis of only 4 grading attributes, carat, cut, color and clarity, or the $4 \mathrm{C}$ 's as they are popularly known. (Exhibit 4)

"Our primary objective in launching this exclusive grading system was to reinforce our customers' confidence in their purchase decisions by bringing in greater transparency. The detailed and comprehensive description not only offers enhanced confidence and trust, but also peace of mind while purchasing diamonds." said Mr. Anil Shah, eldest of Kaka's three nephews in the business, and a partner of the company, who looks after the sales office in Mumbai.

In 1996 again, along with VGS, Venus introduced the concept of single piecesingle parcel; providing detailed information of diamonds on individual packets for each of them with the intention of helping buyers make a comfortable, well informed, and confident purchase decision. Buyers were not happy because earlier they were able to see many diamonds by just opening one packet, but here for each diamond, they had to open a packet. Naturally, they did not realize the benefit of it initially, which resulted in sales dropping drastically.

The company launched in 1997, the concept of selling high value diamonds through their website www.venusjewel.com - a first for any manufacturer in the global diamond industry.

"If you have a will, determination to do something and if you are convinced, be ready to sacrifice. Don't get satisfied with what is not OK, at that moment, you want to give up, but review it with faith, determination and belief".

In 2001, the Superannuation Scheme (pension scheme) was started for the benefit of employees; this was a voluntary and unparalleled move in the industry, in which Venus operated. Still, it is the only company in the diamond industry providing it. 
"If we believe in our responsibility to our people, take care of them, do not leave them in tough times, respect them, my experience is that they will put in their best."

In June 2002, the US \$ 12 million state-of-the-art manufacturing unit started functioning. It was a centrally air-conditioned 8 storey factory premise of 260,000 sq. ft. area on a 6.5-acre plot, providing an excellent working environment. Kaka recalls,

"I hired a fresh architect and was personally involved in the design of this new factory, it was my dream to provide a spacious and luxurious working place for my employees, and change the notion that diamonds in India were manufactured in sweat shops. Some, jokingly even commented whether I wanted to play football or manufacture diamonds when we bought this property".

Exports crossed US $\$ \mathbf{1 0 0}$ million in 2002 on year-to-date basis. In 2003, the company introduced Confirmed Order Requirement (COR), a revolutionary system of buying diamonds on specification without personal inspection. Apart from boosting consumer confidence in the business integrity of the company, the system alone contributed to $12.31 \%$ of sales in less than six months. Sales crossed the US \$150 million mark in the year 2003. Sales grew from US\$ 67.09 million to US\$ 174.80 million in a period of just 3 years between 2001 and 2004 .

"Trust comes through experience over a period of time. I did not succumb to pressure initially; people believe that if I say something, there must be some reasons well thought of in the interests of all. That people have been laid-off overnight in our industry, trust is lost, and will probably not come back easily."

In 2005, the company hosted an in-house web server, providing the entire inventory on real time basis for their online buyers. Later, besides the grading details, digital images of diamonds were also made available.

Sales through the website totaled about $37 \%$ of total sales in 2006 which, is an amazing reflection of customer trust and confidence given the nature of the product. During the recent terrorist attacks in Mumbai, buyers were scared to come to Mumbai to purchase diamonds. In such a situation, their grading standards as well as their online sales system became a boon for Venus.

\subsection{The Informal Organization Structure}

Venus operates through its manufacturing unit at Surat and a sales and marketing office in Mumbai. It is a partnership firm, with 5 members, Mr. S. P Shah, his elder 
brother, and three nephews. The company does not have a formal hierarchical organization structure. However, people are grouped into different work areas (Exhibit 2). A majority of around $86 \%$ of the employees are employed in manufacturing, around $7 \%$ as support staff including the canteen attendants and security watchmen, about 5\% are employed at the Mumbai sales and marketing office, and the remaining for data processing, audit, etc. It is easy to notice through the organization structure that the overheads are minimum.

"We aim to maximize on efficiency. What can be done through systems should not be ignored. Further when we ensure quality in our products, we need less marketing efforts. We have such systems in place that each person monitors himself, so there is little need for hierarchy."

\subsection{The Manufacturing Process Flow Chart}

"No two diamonds are alike just as no two humans are", says one of the senior rough diamond planners. The diamond cutting and polishing process includes assorting, planning, marking, shaping, cutting, polishing, grading, checking and measuring and is a labor intensive, highly skilled job. The rough diamonds are sorted and valued depending on shape, quality, color and size. High-tech laser machines are made use of in addition to the unique skills of the artisans. Each of the diamond processing sections employs artisans who have expertise in respective operations. The underlying assumption is to allow an artisan to excel in his area of specialization instead of providing discomfort in some other area; however they can develop a new skill by choice. Some 1270 skilled artisans, assorters, graders make use of their traditional knowledge as well as the high tech laser technology and machines to convert the rough stone into polished diamond through a well designed manufacturing scheme. (Exhibit 3)

In an attempt to discover the secret of the impeccable Venus quality, Mr. Hitesh Shah's response was, "Every stone is graded, re-graded and then again re-graded. Consistency is the key....." and this is supported by the wage system designed, or more correctly, invented by Venus.

\subsection{The Unique Quality / Incentive Linked Wage System}

"The focus here has always been on doing things differently and emphasis is laid on continuously outperforming our own selves"- a master cutter says. "Quality control is not the responsibility of a department or group. With us it is the individual responsibility of the artisan and employee working on the diamond, irrespective of the department or the part of the diamond he is forming". 
A unique wage system is in place: If any artisan from any department is able to identify an improvement opportunity in the stone, such that the result would come out better than what the planners / markers have estimated, the concerned planner / marker would earn negative credits for under-estimating the stone whereas the artisan who has noticed this would earn positive credits, i.e. an incentive over and above his basic salary. Conversely, if an artisan notices that a given stone has been over-estimated by a planner / marker, once proved so, it would again invite negative credits for the planner / marker and an incentive for the artisan. Also, if an artisan is knowingly or unknowingly not able to achieve the results on a stone as estimated by a planner / marker, the same rule applies. Additionally, within each department, the total employee strength is sub-grouped according to their performance levels which are dynamically monitored on a day-to-day basis.

Taking the planning / marking department as an example, a stone estimated by a planner / marker in the best performing sub-group could be randomly re-examined by another planner / marker, who may not necessarily be in the top sub-group. This method of intra as well as inter department checking is applicable up to the final grading stage in Mumbai, before a stone is put up for sale. A simple rule is that if one makes more mistakes, not only is he losing money, but stands to be downgraded to a lower sub-group. Again, being downgraded to a lower sub-group implies that better quality or big size stones will not be given to him for processing, as the stakes therein are higher, and mistakes will result in a big loss.

On the other hand, if one has been downgraded to the lowest performing subgroup, and through pure determination, he minimizes or eliminates his mistakes, he is sure to rise up in the sub-group rankings. The better you perform, the higher you rank, the more expensive are the goods given to you, and the more you can earn. In effect therefore, before a polished diamond finally reaches the sales department, it has been examined and re-examined by a number of different people assessing it from a number of different angles.

"Top class and unsurpassed product quality is the natural outcome of the process. There is no QC department in our set-up, but individual accountability and responsibility for all, and every action / decision taken, inherently ensures the best possible quality control." Mr. Rahul says with pride.

\section{11 Transportation of Diamonds}

Transporting diamonds from the manufacturing facility to sales office in Mumbai relies to some extent on the trusted angadias as described before. With the emergence of professionally managed domestic high value / precious courier cargo 
services like Brinks, Ferrari, Malca-Amit, Securicor, etc., the company also makes use of their services. As the goods are highly valued, insurance is done under the "Jewelers Block Insurance Policy". The local angadias also cover themselves under the same policy. However, the international couriers named above have their own insurance policies availed from global insurance companies.

\section{12 Marketing and Sales}

Humility and Simplicity are the key values of the company's principals, and they have percolated this belief into their business. Although pioneers of many pathbreaking trends in the Indian and the Global Diamond Industry, the company has been shy to talk about their own achievements. Conventional marketing practices have never been put to use at Venus Jewel, word-of-mouth is relied upon.

"Our aim has been to give the confidence to the end consumer that they are truly getting actual value for the money they are investing."

"If I can give to the market a product with transparency customers although slow to approach, are ultimately going to prefer it. We have got customers the world over, who have confidence in buying diamonds from us, and are even willing to pay premiums on it. Not only that, they in turn have introduced us to other customers also, and so on". Naturally, because of this, we do not need to spend much for various marketing measures.

Such experiences have purely through word-of-mouth, cascaded into a very strong customer base for us, across the world, in the USA, Japan, many countries in Europe, the Asia Pacific and Asia Arabia, in addition to Australia, Canada, New Zealand, South Africa etc .

\section{13 IT Driven Business Model}

A unique IT driven business model is in place which seamlessly merges the manufacturing, grading, pricing, sales and marketing aspects of the business. The sales and marketing personnel in the Mumbai office are in direct contact with customers across the world as well as the overall market scenario, receiving information on preferred choices and consumer trends. Analyzing the data received from the market and customers, concerned personnel make suitable adjustments to prices of goods that are in demand. Since the pricing database in Mumbai and the manufacturing database in Surat are directly linked, the price changes made in Mumbai instantaneously reflect in the said database in Surat. Manufacturing decisions are based on optimum yield attainment, which is decided 
/ indicated by the estimated price being displayed to the employees at the planning and marking stage.

Figure 6 Business Model
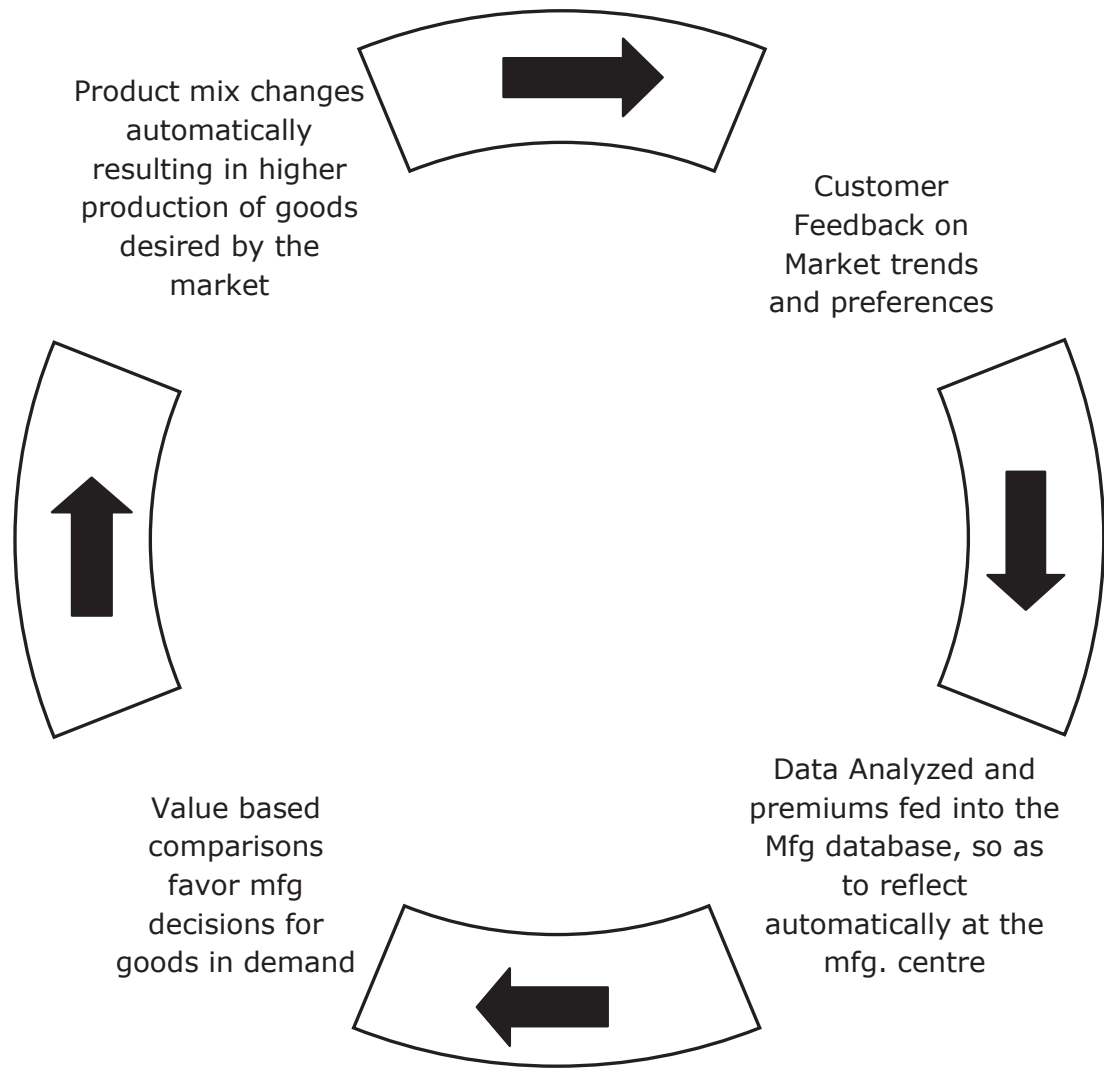

The planners / markers take manufacturing decisions in line with the option showing the highest value gain. As a result, the product mix changes automatically catering to the new market trend. Besides, if a customer has a unique demand for stones, the request is analyzed and a premium is proposed for manufacturing to be economical. It also allows for streamlining inventory, without any over production / over stocking. It is this very demand led flexible 
manufacturing system that has allowed Venus to also assist their customers in minimizing inventories. As product mix changes, customers will find on the inventory list only those goods those are selling fast in the market.

\subsection{People-Management Practices}

"We make our people aware of the dormant capabilities, the immense unused potential lying within each individual of our organization. In addition, we never ask a person to perform a task which is below the level of his / her potential."

To keep the employees motivated, the unique 'Incentive linked wage system' works effectively to deliver optimum performance, enabling them to earn higher wages as well as giving them job satisfaction. Complementing this are HR policies focusing and emphasizing on equal opportunity environment, encouragement to team efforts, human rights considerations, judicious grievance redressal systems, strictly regulated working hours as per prescribed norms, hygienic lunch for all employees at no cost to them, and provision of a medical center. Inside the company premises is a canteen where workers receive free lunch daily from a supervised hygienic kitchen, every member from the owner to the artisan or peon eats here.

"It is not free lunch, because it is only for those who work here. If the workers are happy, they perform better, if they perform better, our clients are happy, if my clients are happy, so am I."

\subsubsection{Training / Recruitment / Salary Structure}

The company prefers to recruit experienced workers who have a proven track record of honesty, diligence and dedication in their area of work. Generally, good references of workers already employed are preferred. Initially when a new employee is recruited, apart from the documentary requirements, as an added precaution, fingerprints of all ten fingers as well as both palm-prints are taken. About the salary structure, the employees we questioned were not clear; however there was a consensus that in general salaries at any level were at least two times those of their next best competitor.

"Learning comes from commitment, I feel he is my nephew or niece and teach him with feelings, it is the same way everyone learn", the leader tries to explain how people get trained here. 


\subsubsection{Grievance Handling}

A grievance handling system is in place to provide justice to any employee, irrespective of rank / designation, caste, creed or sex is ensured. For resolving production related disputes specially to account for the execution of the incentive based wage system, a hierarchical dispute handling system is in force. The first level involves the concerned employees discussing the issue amongst them and arriving at a suitable solution. In doing so, if they so wish they are free to avail the views of their colleagues.

If the dispute is not resolved at the employees' level, they can approach a 'disputer' who is an employee himself, but has considerable experience in the diamond cutting. The disputer reviews such cases and explains his judgment to both employees, without any compulsion being there to accept the disputer's verdict. In cases where either of the disputing workers is not satisfied with the disputer's judgment, they can approach the senior most disputer who for now, is one of the directors and has considerable knowledge of both diamond cutting and polishing technology as well as of the entire production set-up. This third level disputer first assesses the concerned stone himself and forms his own judgment. Following this, he calls both the disputing employees, listens to their explanations of the logic applied, tries to convince the employee who appears to have made the error, and then finally gives his judgment. If required, the $2^{\text {nd }}$ level disputer can also be called in to explain his viewpoint.

For other general grievances, if required employees are encouraged to meet even the directors. Once the grievance is heard, a solution is suggested by the director, and if the need be some administrative staff is appointed. For employees wishing to maintain anonymity, and to enable hesitation-free reporting, a complaint box has been placed. The key to this box is possessed by the directors, none else can open it.

\subsubsection{Welfare Measures}

Health and Welfare Benefits include a centrally air conditioned factory building, well lighted and ventilated work areas, company's own Medical Centre ,adequate sanitary facilities, RO processed potable drinking water, in-house canteen providing hygienic lunch in a spacious dining area, full-time Welfare Officer appointed, Works Committee constituted, HR policy and practices in place to implement these activities. 
"We not only provide these benefits to the employees but also explain to them the importance of these benefits."

Safety and Hazard prevention features include automated fire detection and prevention system, comprehensive surveillance system with over 350 CCTV cameras, smoke, gas and heat detectors placed strategically, Designated emergency exits, Stringent controls on use of flammable and / or hazardous materials, Statutory building and employee safety norms are fully complied with, Adequate safety gear is provided to designated personnel, a full time Safety Officer is appointed, and a Safety Committee has also been constituted.

\subsubsection{Communication Channels}

Since inception, founders have stressed on effective communication. Any lapse in communication is not accepted on any employee's part irrespective of rank, job or position in the company.

"People have a tendency to send selective messages; we have meticulously tried to nullify them. If any worker or artisan tries to approach me, I listen to him with utmost priority. ".

Both written and direct verbal communication is encouraged in inter-office and intra-office communications, the smallest issues are recorded / communicated in writing, to the best extent possible. External agencies like suppliers, buyers, tool manufacturers and any other allied associations are prompted to communicate through e-mails. Telephone conversations whether internal or external, are kept at minimum. An issue might be discussed and even resolved over phone, but it is still emphasized that the same be communicated to all the directors via e-mail. Employees in the lower ranks, who may or may not be very conversant with computers, are free to approach the principals either directly or through any of the administrative staff who can assist them in communicating their issue in writing.

Negative discussions and negative attitude have no place; people are encouraged to think and act positively, as well as not to even raise their voice during discussions. Before the vacation begins, Kaka addresses all employees through the Public Address system, or in a meeting, and advises them on various issues related to their personal life such as to drive carefully, not indulge in bad habits like tobacco and other such vices, and many other things. 


\subsection{Adoption of Technology: Systems Oriented Management}

\subsubsection{Online stock search system.}

Buyers can log in to the online stock section of the Venus website using the password and username issued to them. The online system allows a buyer to search inventory, feed their preferences for the parameters / characteristics of diamonds they want to buy, review the proforma and confirm order. If there are any particular queries regarding a stone which they want to buy, they can request a hold on that stone and post their queries from the website itself. As soon as a 'hold request' with a query or an order confirmation is received, the sales staff in Mumbai gets a notification and suitable procedures are initiated to respond to the request, or execute the order.

\subsubsection{Confirmed Order Requirement (COR) system.}

This is another indigenously developed extension of the online stock selection feature. This system basically assists buyers in two ways, one, for initiating an auto search for desired goods which are not currently on stock and second, for requesting specialized manufacturing requirements (also known as Premium COR system)

\subsubsection{Online goods tracking feature.}

This system has been devised to ease the hassles of manually keeping track of parcels that have been dispatched to customers across the globe. Apart from making management of extensive data easier, this system has almost eliminated the chances of errors occurring at the various manual data entry points. When export parcels are dispatched from office, the concerned courier / agent sends us copies of the Airway Bill, Invoice No. as well as other relevant data. Usually these documents are received in the evening. Upon receipt of these documents, the accounts department in Mumbai feeds in the relevant information for their record keeping.

When these entries are committed to the database system, an email is triggered to the concerned buyers informing them of the Airway Bill, Shipment Bill no., 
Invoice no. etc. Simultaneously the data also gets uploaded onto the website. Buyers wishing to know the status of their parcels, simply have to log on to website and access their Airway Bill nos. or Reference no. that has been sent to them through e-mail. Any special comments that need to be included can be added here.

\subsection{Contribution to the Diamond Industry}

Besides leading the path to the best practices in the diamond industry as mentioned above, Venus has contributed to other aspects of diamond trade and industry. Kaka has served in important positions as the first Convener, Gem \& Jewelry Export Promotion Council (GJEPC), Gujarat Region in 1987-88; the Vice President, Gujarat Heera Bourse; a Governing Body Member, the Indian Diamond Institute (IDI), and a Consultative Committee Member, the Surat Electricity Company (SEC), Surat. At present, he is a Managing Committee Member of the Gujarat Heera Bourse, and of the Southern Gujarat Chamber of Commerce and Industry (SGCCI). His contribution to planning of a prestigious SEZ project called the Gem \& Jewelery Park coming up in Surat is noteworthy.

Kaka has never received any awards for export performance from the GJEPC. "An award is an honor. If one has to 'apply' to avail an honor, I don't think it is right. If they want to honor someone, they have all the data, and can invite one, instead of asking for an application".

\subsection{Contribution to Society.}

Responsibility towards society has been a philosophy of life here. This successful businessman seems to have been blessed by his religious and social contributions as well.

4.17.1 Religious. Possessing strong religious values, in 1977, Kaka organized a 'pad-yatra' in which he walked from Surat to Palitana, a place of pilgrimage, along with 700 pilgrims; this walk lasted for 47 days. In 1991, one of his nephews became a monk. Kaka organized served lunch for about 1.5 lakh people who attended this ceremony, a fact which found a mention in the Guinness Book of World Records. Over time, he has bequeathed generously to the development of facilities for devotees at various places of Jain pilgrimage.

4.17.2 Social. Venus became a trendsetter by equally supporting other humanitarian activities beyond the barriers of caste, creed and religion. 
Contribution of Rs 5 million to the Computer Engineering Faculty of a College of Engineering and Technology at Surat, which was baptized in memory of kaka's father Late Shri Premchand bhai Ishwarlal Shah, and also generous contributions to the State Chief Minister's Fund for educating the Girl Child (Kanya Kelavni Nidhi) are just to name a few. In order to promote education, donations were made to various schools and educational institutions in the owners' native place, Vadgam in North Gujarat, in the tribal belts of Dangs district in South Gujarat, and elsewhere.

Other philanthropic activities range from the development of water resources in Saurashtra, a western dry region of Gujarat state, to the earthquake affected regions of Kutch, to the rescue and relief operations during the severe famines in Gujarat and in Rajasthan. Kaka is known to stand by the people in need during natural calamities or during communal tensions, and has contributed both in terms of donations and personal service towards the development of medical facilities at various hospitals.

During the major epidemic of the alleged plague in Surat in 1994, there was a mass exodus of the city's population. The leader of Venus decided to stay back and assist in restructuring of the city. There was tremendous pressure from the family as well as his acquaintances to leave the city. Kaka not only stayed back himself, but also utilized his virtues instrumentally in curbing the panic amongst his employees who also stayed back in the city. Venus was then the first factory to resume operations immediately on the appeal of the then Collector of Surat.The plague having received attention in global media at that time, Kaka was the first person from the city to be interviewed by the $\mathrm{BBC}$ radio for a global telecast about the city's condition and he urged people not to panic and that things would get back to normal soon. History of the city tells that after the plague in 1994, the city saw a turnaround from a dirty and filthy place to one of the cleanest and prospering cities of the country, and this was supported by contributions of such people.

A similar display of charity and wisdom was exhibited during the more recent 2006 flood situation in Surat. He had planned in advance, when the city was flooded, for providing drinking water, milk and vegetables as soon as the flood waters receded in specific areas. 


\subsection{The Road to Future}

Having achieved the dream of making Surat the world's largest diamond cutting and polishing centre, most diamond cutters now want to make this city the global trading capital for rough and polished diamonds.

On the recent recession in diamond industry, Kaka opines,

"What happened in 2008 was not a recession, but a correction, for people to undo their mistakes, and realize that it is of utmost importance to practice business ethics and to take care of employees during such times and not to leave them stranded."

Reports are that diamond industry is set to bounce back soon; the worst seems to have been over. Indeed there are so many uncontrollable factors like competition, availability of raw material, government policies at home and in the other competitor and/ or buyer countries, market fluctuations, changes in the trends, tastes and purchasing power of the people across the world which will have a bearing in the industry's position in future. However, industry is reviving and will establish new avenues and scale new highs, and so will Venus. This is the general sentiment of optimism and hope at the CPD unit of our case. 
Figure 7 The Factory Exterior and Interiors

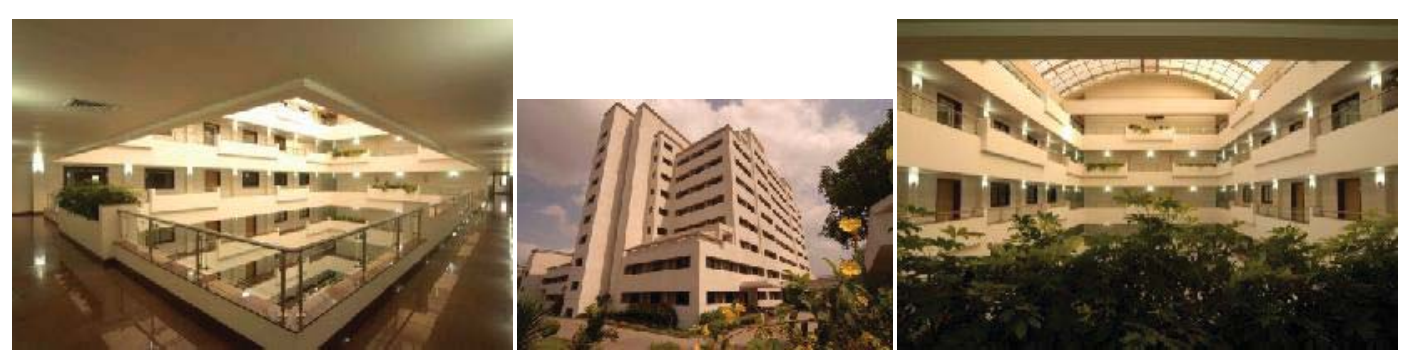

The Rough Stone

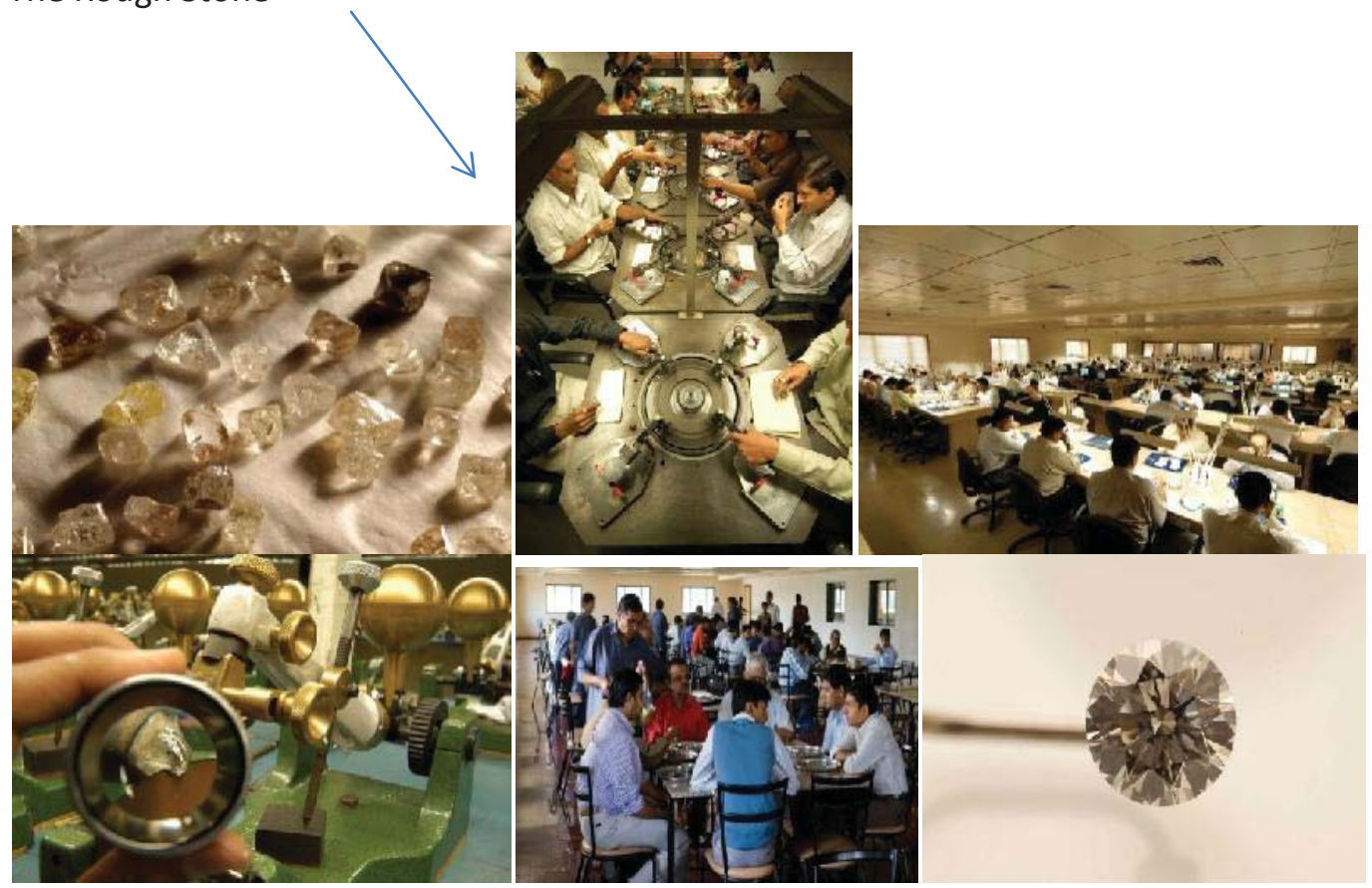

The Polished Diamond

Figure 8 The Processing of Diamonds 


\title{
Chapter 5. The Behavioral Equivalence of Organizational Culture:-A Conceptual Framework ${ }^{1}$
}

\begin{abstract}
This paper highlights the relevance of organizational culture (OC) with respect to individual, organizational, intra-organizational, industry and external environment related variables which is supplemented by an extensive review of literature on OC over the last three decades. A behavioral perspective on OC is then suggested and propositions are drawn to explain the dynamics involved thus contributing to the emerging process views on organizational culture. A conceptual Behavioral Model of OC has been derived.
\end{abstract}




\subsection{Introduction}

Few aspects of organizational studies have such diverse and fragmented literature as organizational culture (OC). Dominated by psychologists in mid 50s, the field of organization studies had a micro-orientation; early 80s saw advancement of the theoretical concept of OC. By mid 90s, scholars realized they were focusing more on "B" than "O" of micro-OB, more collaboration was required of occupational sociologists, organizational theorists and psychologists, developing a multidisciplinary field that encompasses micro, meso and macro perspectives and paradigms (Porter, 1996; Schien, 1996). This is perhaps the reason for the outburst of attention to organizational culture studies as it provides for a combined macro and micro analysis. It is also believed that after 'strong' and 'excellent' cultures were found to have significant positive associations with success of American and Japanese firms (Deal \& Kennedy, 1982; Peters and Waterman, 1982; Ouchi, 1981), there was proliferation of interest in OC.

The term 'culture' has different meanings. For example, Kroeber et al (1952) compiled a list of 164 definitions of "culture" from literature. While its presence in sociology and anthropology is ubiquitous and almost as old as the disciplines themselves, the introduction of 'organizational culture' to the field of organizational studies is generally credited to Pettigrew in 1979 (Detert et al, 2000). Since then, researchers have dealt with a range of questions from what is culture, who shares it, how did it come to be, what is it composed of, how are its parts structured, how it works, conditions for cultures to exist, conditions for culture to affect organizational efficiency as well as other organizational variables; to why and how do we change culture, in what way can culture contribute to controlling an organization, how can we measure culture, in what terms can we describe culture, the cultural change and the cultural difference in various contexts like national, occupational, positional, industry, firm, and its subunits, crosscultural management in multinationals, mergers and alliances and cultural conflicts.

As the concept of OC enters its fourth decade of existence, we conduct a review and content analysis of the extant literature. Based on our understanding of the concept we subscribe to the dynamic aspect of OC and define it is a continuous 
process of negotiation between the sources of behavior and the manifestation of behavior of an organization within internal and external environmental context. A behavioral model of $\mathrm{OC}$ is then presented followed by propositions about the different sources of behavior and organizational culture in our attempt to explain the dynamics of OC.

\subsection{The Concept of OC}

One of the principle problems in studying organizational culture stems from the ontological status of the concept itself (Jones, 1983). Organizational researchers have utilized a wide variety of culture definitions, but most empirical work has centered on the view of culture as an enduring, autonomous phenomenon that can be isolated for analysis and inter-organization comparison (Alexander, 1990). The intricate and complex nature of OC has led to differences and controversies about the definition, dimensions, measurement (Cameron and Quinn, 1999) and the context of organizational culture. However, there is some consensus that organizational culture is holistic, historically determined, and socially constructed, and involves beliefs and behavior, exists at a variety of levels, and manifests itself in a wide range of features of organizational life (Hofstede, Neuijen, Ohayv, \& Sanders, 1990; Pettigrew, 1990). Culture is expressed and transmitted through artifacts, stories, myths and symbols (Martin, 1982; Siehl and Martin, 1981; Wilkins, 1980; Pettigrew, 1979). Underlying these symbolic vehicles are patterns of basic assumptions (Schien, 1981, 1983; Dyer, 1982); a set of shared understandings, interpretations or perspectives (Van Maanen, 1983; Louis, 1983) and expectations (Schwartz, Davis, 1981).

Broadly, two schools of thought exist about organizational culture whether it represents something an organization 'is' or 'has'. Accordingly, researchers have analyzed the concept of $\mathrm{OC}$, both as a root metaphor, i.e. organizations as expressive forms, and manifestations of human consciousness (Cameron 1999; Smircich, 1983); and as an attribute, i.e. possessed by an organization and observable; and even as property (Linstead, 2001). This is because some researchers are concerned by what appears to them to be more fundamental issues of meaning and the processes by which organizational life is possible which is in line with the view that an organization 'is' culture; while others give high priority 
to the principles of prediction, generalizability, causality, and control drawing from the view that an organization 'has' culture (Smircich, 1983). Both approaches share the conception of organizations as organisms; existing within an environment that presents imperatives for behavior. However, literature is less sanguine about the reciprocal evolution of culture through behavior. Further, culture has been generally accepted to be a phenomenon which is enduring and relatively stable, which is why organizations across the world need external change agents to affect the cultural change intervention.

We support the recent emerging views on culture describing it as a process and as a dynamic phenomenon of an organization. Therefore, in this paper, 1) we examine how organizational behavior is manifested in organizational culture and how does behavior shape organizational culture, 2) we suggest that organizational culture is a process of continuous negotiation between sources of behavior and manifestation of behavior and 3) organizational culture is dynamic as it is nested within a dynamic environmental context, internal and external to the organization. The paper is divided into two sections. First, we present findings from research published during the period 1979-2009 asserting the continued interest and applicability of the OC concept in organizations. Second, we propose a new behavioral model for understanding organizational culture and contribute to the growing interest in studying the dynamic aspect of OC.

\subsection{Review of Literature}

Three decades of organizational cultural studies and we have seen change in both content and emphasis. Summarized below are insights gained from OC literature developed during the last three decades. Both conceptual and empirical studies have been reviewed and are spread across various contexts, countries and businesses.

\subsubsection{Conceptualization of $\mathrm{OC}$}

Culture in the early 1980s was about explaining the concept, and often prescribed methods for studying and diagnosing culture; while later research was concerned with a more utilitarian approach and asked questions such as "what use may be made of the gained information?" (Hofstede, 1986). A new line of enquiry began 
around 1987 about the effects of culture on an organization's performance (Arogyaswamy and Byles, Brown, 1992; 1987; Croft, 1990; Lewis, 1994; Nicholson et al., 1990; Petrock, 1990; Saffold, 1988; Sherwood, 1988; Van Donk and Sanders, 1993; Whipp et al., 1989); and whether and how culture can be changed to increase organizational effectiveness (Bettinger, 1989; Critchley, 1993; Fitzgerald, 1988; Hayes and Lemon, 1990; Poupart and Hobbs, 1989; Saraph and Sebastian, 1993; Smith et al., 1994). Since the first study of OC is accredited to Pettigrew in 1979, we begin by reviewing his paper.

Pettigrew, in 1979 defined 'culture' as the system of publicly and collectively accepted meanings operating for a given group at a given time, an important practical consideration in an extended stream of time, events, people, and processes with an example of sequence of social dramas where in each drama provided a clear point of data collection. Williams' (1980) theoretical model is based on an assumption of society being in a state of constant cultural change and negotiation. In any particular period there is a central, effective, and dominant system of meanings and values which are not merely abstract but which are "organized and lived". The residual culture is the still practiced residue of previous social formations (e.g. certain religious values, notions from a rural past, and notions from a colonial past) that are often retained in order to make sense of the dominant culture. The emergent culture, he explains are the new meanings, values, practices, and experiences which are continually being created, some of which are incorporated into the dominant culture and some of which are not. This theory supports our proposition of a dynamic culture, and environment, influencing the interaction of both behaviors and values and thereby affecting a cultural change. Hofstede (1980) published a cross-cultural report exploring the differences in thinking and social action that exist between members of 40 countries between 1968 and 1972 and called it 'national culture'. He argued that people carry mental programs developed early in the family during early childhood and reinforced in schools and organizations, and they contain a component of national culture. Though providing a starting point for understanding national cultures, the study has come under criticism for using a comparative logic in a heterogeneous setting at a time when quantitative comparisons of organizational cultures within a single cultural context were seen as unfounded (Denison, 1996). 
When Schien(1983) emphasized the role of the founder and stated that organizational culture will always reflect the complex interaction between the assumptions and theories that founders bring to the group initially and what the group learns subsequently from its own experiences, it also explained the importance of time and dynamics of change, of how the values came initially from the founder and, as the group learned while experimenting with behaviors over a period of time, culture was developed. It is thus implied that culture will change as environment goes through unpredictable times. The model that emerges is one of shared solutions to problems which work well enough to begin to be taken for granted-to the point they drop out of awareness. Martin, Siehl (1983) suggested that while organizational culture is used to transmit top management's interpretations of the meaning of events throughout the organization, generate commitment to their practices and control behavior, three subcultures may exist, 'enhancing', 'orthogonal' and 'counterculture'. Cultural mechanisms can also be used to undermine top-management objectives, which she called 'counter-culture'. In addition to serving integrative functions, cultures can express conflicts addressing need for differentiation among organizational elements, the conflicting subcultures. Thus, Martin extended the OC concept by explaining how parallel cultures could exist within an organization and their understanding could help in conflict-management. Further implications are that as new generations and new entrants become a part of the organization, they will not only influence the dominant, but also the parallel forms of existing cultures.

Barley (1983) offered semiotics as one avenue for conceptualizing and analyzing occupational and organizational cultures to address issues of what the culture is composed of, how are its parts structured and how it works. Trice and Beyer (1984) described specific rites and ceremonials as manifestations of culture; rites of passage, of degradation, of enhancement, of renewal, of conflict reduction and of integration and that it may help to focus researchers' attention on behaviors and occurrences that they otherwise might have overlooked. If semiotics represents culture, or at least is the visible part of culture, numerous examples from the corporate world about change of symbols e.g., company logos, statements of vision and mission, etc. in such case would only reflect a change in values and beliefs, 
which need not be the result of a conscious change intervention but a natural growth phenomenon.

Wilkins and Ouchi, 1983 called culture as 'clan' and that goal congruence and presence of a general paradigm in the interest of the collective helps clan control to govern organizations efficiently under conditions of ambiguity, complexity, and interdependence of transactions; market and bureaucracy form of governance would be more efficient where the level of complexity or uncertainty is relatively low or moderate. Organizational culture can be a source of sustained competitive advantage if it is valuable, rare and imperfectly imitable (Barney 1986). These themes can more explicitly be explained with the environmental context. Paul Reynolds (1986) adopted a more utilitarian perspective and argued that statements about organizational culture should reflect differences related to industries, technical or task requirements and that to expect the same cultural systems to foster success in all industries seems inaccurate. Given the multidirectional nature of the concept, Meyerson (1987) identified three perspectives of OC research: 'integration', 'differentiation' and 'fragmentation'. The integrationist perspective positions culture as an integrating mechanism, the normative glue; differentiation emphasizes that different groups in organization embrace different and even incompatible beliefs, values and assumptions; fragmentation perspective acknowledges that ambiguity is an inevitable aspect of organizational life and organizational situations exist in which it is not appropriate to identify consistency of values and basic assumptions.

Marcoulides (1993) proposed a new model wherein organizational culture is hypothesized to consist of three interrelated dimensions: a socio-cultural system of the perceived functioning of the organization's strategies and practices, an organizational value system, and the collective beliefs of the individuals working within the organization, possibly explaining why some organizations are not performing at desired levels of productivity. Detert et al (2000) presented another synthesis on $\mathrm{OC}$ in terms of eight dimensions of organizational culture, on the basis of truth and rationality in the organization, the nature of time and time horizon, motivation, stability change/ innovation, personal growth, orientation to work, task, and co-workers, isolation vs. collaboration, and responsibility and orientation and focus-internal and/or external and how these dimensions 
corresponded to the values and beliefs of TQM.. Daymon (2000) applied a multiperspective analytical framework to explore organization members' experiences as they adjusted to, and strove to shape, working life in a new television station. The paper suggests that culture formation is a fluid, ongoing process whereby cohesion, division and ambiguity continuously intertwine. Zheng et al (2009) in a recent framework propose that as the organization goes through its life stages of start-up, growth, maturity, and revival, organizational culture evolves through corresponding mechanisms of inspiration, implantation, negotiation, and transformation. This framework also contributes to the literature on the dynamic view of culture and suggests that human resource development professionals need to be perceptive of the life stages of their organizations and intentionally leverage different cultural mechanisms to respond to critical organizational needs.

\subsubsection{Interrelating $\mathrm{OC}$ with other variables}

Empirical work using conceptual frameworks and validated instruments dominate the cultural studies since $90 \mathrm{~s}$. Researchers have tried to relate OC, empirically and conceptually, with other organizational variables.

a) OC and Individual-Level Variables. Organizational culture has been found to be useful in understanding organizational variables like job satisfaction, work related attitudes like organizational commitment; individual's sense-making, selfefficacy and collective efficacy (Harris, 1994; Bloor et al, 1994; Maignan et al, 2001; Lund, 2003; Walumbwa et al, 2005). Harris (1994) proposed a schema based perspective that in the social setting of organizations, individuals make sense out of their experiences, based in large part on the outcomes of contrived mental dialogues between themselves and other contextually-relevant individuals or groups, again supporting the cultural negotiation process. Bloor et al (1994) attempt to identify the complex interplay between individual sense-making, group beliefs and culture in an Australian home-care service. The stability of an organization's operating environment is identified as a major factor which facilitates and constrains the propensity for professional subcultures to radically transform or incrementally refine dominant organizational cultures. Lund (2003) empirically investigated the relationship between OC types on job satisfaction in a survey of marketing professionals in USA. Job satisfaction was positively related 
to clan and adhocracy types of culture type and negatively to market and adhocracy.

b) OC and Organizational -level Variables. Hansen \& Wernerfelt (1989) empirically evaluated the relative importance of economic and organizational factors as determinants of firm performance and found that organizational factors were twice as effective in explaining the variance in profit rates. Scholars have also related leadership (Weese, 1995; Wallace, 1994; Jung and Avolio, 1999), quality practices like TQM (Bright, 1993; Zeitz, 1997; Detert et al, 2000; Lewis, 2002) and Ethics (Sinclair, 1993) extensively with OC. A descriptive research study was conducted to investigate the concepts of transformational leadership and organizational culture within the administrative levels of campus recreation programs of Big Ten and Mid-American Conference universities. (Weese, 1995). The researcher concluded that high transformational leaders direct programs that (a) possess stronger organizational cultures and (b) carry out culture-building activities, specifically the "customer orientation" function, to a greater extent than other leaders do. Another empirical study conducted in 69 Canadian YMCA organizations revealed that significant differences in organizational culture existed between the organizations led by transformational leaders who were rated high and between those who were rated low on transformational leadership (Wallace 1994). Collectivists (as in Hofstede's (1980) dimensions) with a transformational leader generated more ideas, but individualists generated more ideas with a transactional leader while performing a brainstorming task. Group performance was generally higher than that of individuals working alone. However, collectivists generated more ideas that required fundamental organizational changes when working alone (Jung and Avolio, 1999). OC affects how the topic of quality and its management is understood and implemented in organizations. It is found that total quality management (TQM) makes a number of assumptions about organizational culture, more so that it will support the change intervention. Without the knowledge of culture, companies' attempts for quality interventions are a failure (Bright, 1993).

Zeitz (1997) presented a relatively compact instrument that allows researchers and practitioners to measure perceived culture and TQM implementation among all types of employees, work contexts, and TQM program levels. Detert et al (2000) concluded that each of the normative TQM values addressed some aspect of the 
general OC dimension, and implies that that different OC dimensions could be used to explain several other change interventions. Lewis(2002) described how organizational culture was first linked with TQM and has since been associated with business process reengineering(BPR), organizational learning, and knowledge management, all are said to involve either changing a culture or working with an existing culture. Sinclair (1993) assessed the potential of organizational culture as a means for improving ethics in organizations. The feasibility and desirability of the prevailing approach that creating a unitary cohesive culture around core moral values is the solution to enhancing ethical behavior in terms of ethical outcomes is questioned. The model queries the existence of organizational culture at all, arguing that organizations are nothing more than shifting coalitions of subcultures. The arguments made suggest that a strong culture could be fostering dissent and under pressure forcing people to enact unethical behaviors. Thus it supports the need for our perspective on OC such that the organization is able to scan its environment, to anticipate and respond to the rapidly changing needs of all stakeholders.

c) $\mathrm{OC}$ and Industry-level Variables. Industry macro-cultures have also been found to influence organizational culture, and cultural studies have been conducted across service and manufacturing businesses revealing linkages of culture with performance and productivity (Gordon, 1991; Kotter \& Heskett, 1992; Gotwan et al, 1992; Brown, 1992; Zammuto et al, 1992). Levels of culture, industry effects, competitive environment and customer requirements have also been analyzed. Gordon (1991) developed the argument that organizational or corporate culture is strongly influenced by the characteristics of the industry in which the company operates. Within an industry, firms share the industry driven cultural elements which are influenced by industry characteristics and are based on assumptions about the competitive environment, customer requirements and societal expectations. Kotter \& Heskett (1992) conducted a number of related studies using 207 firms, over a five year period to examine the relationship of strong culture and performance and found only a modest correlation. However, firms with cultures suited to their market environment performed better. Gotwan et al(1992) demonstrated using data, from management surveys of 11 US insurance companies in 1981 that both a strong culture regardless of content and a substantive value 
placed on adaptability are associated with better performance for two to three subsequent years on two criterion measures of asset and premium growth rates from 1982 to 1987. The results support the findings of Denison (1990) that strength of culture is predictive of short-term performance.

Brown (1992) suggested that all three levels of organization's culture (basic assumptions, values and beliefs and visible artifacts; as by Schien, 1984) are extremely powerful determinants of organizational life, and are intuitively incorporated into the actions of skilled executives who use them to manage people, formulate strategy and induce organizational change. Zammuto et al (1992) examined roles that organization design and culture play in the varying levels of success experienced by advanced manufacturing technology adopting organizations. Kale et al (1992) provide a conceptual framework within which cross-national personal selling interactions can be studied, evaluated and integrated suggesting that the degree of congruence in organizational cultures will affect the level of buyer-seller compatibility and outcome of sale interaction. Gordon (1999) builds on the proposition that industry demands induce certain cultural characteristics, observed as consistent and widespread practices which are necessary for survival, but that these are not sufficient for superior performance. Empirical evidence was provided that industry membership, even at a crude level, is associated with certain aspects of a suitable culture as seen in practices, and that these practices are related to a firm's revenue growth within this broadly defined industry. Thus, OC has been found to explain a wide range of organizational phenomenon, addressing the limitations of other organizational variables, more tangible in nature.

d) OC and Intra-organization level Variables. With time, interest in culture of an organization as a whole shifted to sub-cultures 'in' and cultural gap 'between' different parts of an organization. Further, terminologies and forms like official and unofficial culture, political culture, conformance and resistance culture, espoused and true culture, security culture, practice culture and dysfunctional culture drew attention of the researchers (Bourantas et al, 1990; Buch, 2001; Fleet et al, 2006; Jermier et al, 1991). Evidence of presence of sub-cultures and culture gap in private and public Greek enterprises was reported; and that reduction of cultural gap was possible by the age and tenure of the manager (Bourantas et al, 
1990). 'Conformance' and 'resistance' subcultures in opposition to 'official culture' were discussed while comparing and contrasting an organization's official culture and its subcultures in a police organization (Jermier et al, 1991). Buch (2001) made a statement that organizations say one thing and do another. One is the 'espoused culture' and the other is 'true culture'. When there is a gap between the two, it needs to be realigned. Murphy (2002) explored the use of official company values as a device for the achievement of cultural control. The study reveals a perceived discrepancy between the official espousal of the values by the company and their actual enactment, especially in the attitudes and behavior of senior management. It is also argued that political considerations, including powerful, unofficial cultural and sub cultural norms, will override the impact of officially espoused, but un-embedded values.

e)OC and Environment-Related variables. The role of culture has been discussed by researchers in corporate citizenship, business process reengineering, organizational learning, organizational change, knowledge management, international alliances as well as in the emerging perspectives of strategic alliances, sustainability and future organizations (Harris, 2002; Lewis, 2002; Maignan et al, 2001; Rashid, 2003). Authors have also pointed out how culture can have negative consequences if not managed with care and have cautioned against corporate culturism (Harris, 2002; Murphy, 2002; Tourish, 2002) and that almost everyone has been in an organization that says one thing but does another (Buch, 2001). The article by Tourish (2002) examines transformational leadership (TL), a theory that has been closely linked to corporate culturism--a means of gaining competitive advantage through coherent cultures with a particularly focus on the downside of TL and its ability to lead an organization in a destructive manner. 'Unintended consequences of Culture interventions' by Harris (2002) elucidate eight forms of management action during culture change programs which had serious consequences for the organizations concerned. 'Dysfunctional Culture' styles were found to link with deficits in operating efficiency and effectiveness in a large study with data compiled from 60,900 respondents of four state government departments (Pierre, et al, 2006). Walumbwa et al (2005) conducted a cross-cultural study examining how collective and self-efficacy moderated the influence of transformational leadership on followers' work related attitudes of organizational 
commitment and job satisfaction across different bank branches in India, U.S. and China ; results revealed that US ranked higher on self and collective efficacy while India scored higher mean for organizational commitment and there was no significant difference in the job satisfaction suggesting the influence of individualistic and collectivistic national cultures on organizational variables.

\subsubsection{OC Studies in Different Contexts and Countries}

New directions emerged in the field of organizational culture studies during the last two decades. Cross cultural studies were reported in the last decade which also witnessed research in cultural studies being reported from different countries like Bangladesh, Canada, China, Hong Kong, India, Malaysia, New Zealand, U.K., U.S.A., Singapore, South Africa ( Bebbington et al ,2007; Bryson ,2008; Daymon ,2000; Jackson, 2005; Lee, Yu 2004; Ogbonna et al ,2002; Rashid ,2003; Taormina, 2008; Lucas, Kline, 2008 ) subscribing to the widespread interest in the field of organizational culture. OC studies have also taken place in areas of worklife programs (Chalofsky, 2008), organizational socialization (Taornima, 2008) and culture of family firms. Mintu et al (1996) conducted a study to examine sellers' co-operative behaviors, exploring the behavioral characteristics and environmental cues prior to and during the actual negotiation encounter. The study investigates individual, organizational, and demographic-related antecedent variables and the co-operative negotiation process of industrial exporters representing two different cultures. Williams (1998) developed a conceptual model of cross-cultural business relationships. An exploratory study was conducted to examine the impact of social and structural bonding as determinants of business relationship performance. The study found that knowledge of cultural orientation and its relationship to the social and structural bond that exists between partners is a key predictor of long-term commitment in cross-national business relationships.

Ogbonna et al (2002) performed a ten year, two phase study of UK Food retailing sector and suggested that industry macro-cultures may have impact on both the performance of individual firms and the management of organizational culture. Rashid (2003) studied the influence of organizational culture on affective, cognitive and behavioral attitudes towards organizational change in Malaysian manufacturing industries. Findings show that different types of organizational 
culture have different levels of acceptance of attitudes toward organizational change. A survey using Competing Values framework in Hong Kong confirmed the validity of the model as a tool in differentiating organizations (Kwan et al, 2004). Denison (2004) examined organizational culture in family and non-family firms and how it related to performance. It became increasingly clear that family business sustainability and accomplishment were rooted in something deeper, something beyond superficial explanation and it was their 'positive' culture.

Sirmon (2004) proposed a model of cultural differences and international alliance performance to explain the ambiguous findings regarding the influence of national cultural differences on alliance performance. Lee, Yu (2004) investigated relationship between corporate culture and performance in Singaporean firms and also demonstrated empirically that a set of replicable cultural dimensions exist across organizations, implies that culture can be measured with repeatable, easily administered instruments that permit systematic comparisons. Cultural Strength and innovation were found to be significantly correlated with sum insured in insurance industry, supportiveness was found to be related to growth in net profits in manufacturing industry and team orientation and task orientation were significantly correlated with staff turnover rates in hospitals. Some cultural dimensions were affected by industry membership while others were not.

Another study was conducted in South African military context as the wider society underwent transition from apartheid to democracy necessitating the integration of a multicultural force. Empirical study found significant differences in attitudes among cultural groups (Jackson, 2005). Barger (2007) suggested that in an international joint venture two cultures collide, a new culture is created and the culture of parent firm plays an important role in influencing the successful blending of cultures. This highlights the need for cross cultural management. Bebbington et al (2007) presented a World Bank funded case study in Bangladesh to illustrate the ways in which cultural interactions between varieties of organizations mediate the ways in which textual commitments are translated into a range of diverse practices. 'Security Culture' with eight dimensions was investigated by Ruighaver (2007) focusing on end-users and on the technical aspects of security in IT industry calling for a management focus on security culture. Bryson (2008) addressed the issues of time and perspectives which 
underlie the contested nature of culture by explaining the dynamics of organizational change through dominant, residual and emergent culture with a case study in New Zealand setting. Taormina (2008) looks into the theories regarding leadership, organizational culture, and organizational socialization and how they can influence organizational culture in Chinese organizations. Chalofsky (2008) links work-life programs with OC and suggests that organizational culture is the essence of workplace community.

Lucas, Kline (2008), in a Canadian case study, tried to understand the influence of organizational culture on group dynamics of organizational change and learning. Certain group and cultural phenomenon when manifested had significant influence on group members' response to organizational change and their capacity to learn. Kralewski (2008) discussed 'practice culture' of medical groups to demonstrate that it is difficult to manage patient care when there is wide disagreement among clinicians about norms of behavior. Based on the review of literature we find that OC as a concept has achieved widespread importance in organizational studies across various contexts. OC has been conceptualized in different forms and has been found to relate to several other phenomenon of organizations, both as an antecedent and as a consequence. It has also been found to be related to the individual level, organization and intra-organizational level, industry level and environment level variables. We find that inspite of several frameworks available to enhance our understanding of $\mathrm{OC}$; there is a need to develop a comprehensive model which takes into account various levels of influences on it. We also suggest a behavioral point of view of OC and propose a conceptual framework.

\subsection{Proposing a Conceptual Framework}

It is suggested that organizational culture is a constant negotiation of 'sources of behavior' and the 'manifestations of behavior' in the organizational and environmental context. We describe first our understanding of how culture develops.

\subsubsection{Evolution of OC}

The shared patterns of values, beliefs, assumptions (sources of behavior) are evolved as a result of experimentation with behaviors at the time of inception of an 
organization. Behaviors are actions or reactions to stimuli, internal or external; hence, while coping with internal and external issues, the organization attempts different forms of behavior and receives positive or negative feedback. As a result, it perceives different behaviors as successful or unsuccessful to a varying degree and classifies them as desirable, suitable or otherwise. The behavior perceived as desirable for the effectiveness, success or survival of the organization is reinforced; behavior which is non-conforming is discouraged and blocked. The workable and generally accepted solutions reduce the initial uncertainty faced by all members of the organization, which is a traumatic experience (Schien, 1985). These experiments are repeated to test the validity of behaviors, which once established, is accepted by most participants of the organization; to the limits that it gets transformed into assumptions, values and beliefs. Psychological contracts are created and are relatively stable, acting as stabilizer of individual behavior (Witte, Muijen, 1999).

The individual beliefs and values of participants, more so, of the people with influence, is likely to affect the perceived desirable behaviors and perceived success of organization during the initial struggle and stabilizing period. Founders often start with a theory of how to succeed; they have a cultural paradigm in their heads based on their experiences in the culture in which they grew up (Schien, 1983). With the passage of time, these assumptions, values and beliefs become the 'sources of behavior' and guide and direct subsequent 'manifestation of behavior' and there is a convergence of norms. This is in line with O'Reilly \& Chatman's (1996) view that culture is "a system of shared values defining what is important, and norms, defining appropriate attitudes and behaviors, that guide members' attitudes and behaviors"; and Schien's $(1985,1992)$ definition of culture as "a pattern of shared basic assumptions that the group learned as it solved its problems of external adaptation and integral integration, that has worked well enough to be considered valid and, therefore, to be taught to new members as the correct way to perceive, think, and feel in relation to those problems" further arguing that values and behavior were more superficial representations of this underlying structure.

Using this view, we can argue, then, that OC is a vehicle through which an organization encompasses the behavior variables and the sources of behavior; and influences through their interaction, behavior outcomes in the organizational 
context. Once culture is formed, though intangible and invisible, this reflection of an organization becomes obvious, and is experienced as its culture to an insider, stakeholder and an outsider who comes in contact with the organization. Literature does not discuss if there is a difference in how an insider or stakeholder or an outsider perceive and experience the culture of an organization. Culture researchers have been more concerned with the evolution of social systems over time (Pettigrew, 1979; Schien, 1985, 90); importance of a deep understanding of underlying assumptions (Kunda, 1992); individual meaning (Geertz, 1973; Pondy et al, 1983) and the insider's point of view of the organization (Denison, 1996). Since no organization can exist in isolation and is accountable to its internal as well as external associations, organizational culture is also likely to encompass the external environment which in turn will influence the behaviors and their outcomes in the environmental context.

\subsubsection{Dynamics of OC}

Traditional definitions assume that culture is enduring, and relatively stable; and once formed it could be learned by whoever is or becomes a part of the organization. But we know that organizations display what can be thought of as "learning disabilities," or what Argyris might call "defensive routines" that get in the way of the kind of second-order learning (Argyris and Schon, 1996). Parker (2002) demonstrates that because organizational members do not see the past of the organization in the same way, they orient themselves to different futures. In addition, the struggle between organizations bent on normative control and individuals subjected to it is over the definition of reality (Kunda, 1992). According to the social information-processing view (Salancik and Pfeffer, 1978) and cognitive view (Weick, 1969), the definitions of the situation offered by others and people's past experiences in social context provide the selection mechanisms or norms and values through which people enact events.

a) Sources of Behavior: Individual level. Individuals possess certain values and beliefs as a result of their own backgrounds and demographics; it is less likely that they will accept the behavioral norms as established by the culture of the organizations in totality. Also, as new entrants or new generations take over, they will try to negotiate their own values based on past experiences, self-efficacy and 
schemas with those of the dominant culture of the organization. This in turn is likely to have an influence on the manifestation of behaviors like sense-making and collaboration and also on the behavioral outcomes like relationships and psychological contracts. Conversely, we could argue that, strength of relationships and satisfying psychological contracts could possibly alter individual behavior and in turn enhance an individual's self-efficacy and alter schemas. Karahanna et al (2005) integrated different levels of culture, national, professional, organizational and group, by explicitly recognizing that individual's workplace behavior is a function of different cultures simultaneously.

Proposition 1: The individual level sources of behavior, and hence the individual values and beliefs based on their past experiences, schemas and self-efficacy will negotiate with the dominant and current values and beliefs of an organization and thus influence the organizational culture.

b) Sources of Behavior: Organizational level. The organizations internal environment is affected by its structure, purpose and practices which are in turn to some extent guided by the founder or the existing leader. Thus, a general paradigm exists in the organization as a whole which guides the common values of the organization. However, different work groups within an organization may have different nature of tasks and hence need to perform different behaviors. As a result they may hold unique values in addition to or different from the generally accepted values and beliefs of the organization. These group values are called subcultures and have been discussed in detail in literature. Accordingly we suggest that,

Proposition 2: The organizational and intra-organizational level sources of behavior, and hence the values and beliefs based on the structure, leadership and group specific tasks will negotiate with the dominant and current values and beliefs of an organization and thus influence the organizational culture.

c) Sources of Behavior: Industry level. Although culture is unique to an organization or its subunits, industries exert influences that cause cultures to develop within defined parameters (Gordon, 1991). These macro-factors of the industry are likely to influence organizations to manifest behaviors in response to the competition, needs of customers, the nature of product or services and societal expectations, as per industry norms. These behaviors will be common and shared by the industry members and may also be different from organizations in other 
industries. Thus, an organization's values and beliefs are likely to be influenced by the behaviors forced upon them by virtue of the industry that they belong to.

Proposition 3: The industry level sources of behavior, and hence the values and beliefs determined by the nature of product or service, the competition and societal expectations will negotiate with the dominant and current values and beliefs of an organization and thus influence the organizational culture.

d) External Environment. The process of evolution of culture, as has been pointed earlier, involves the external and internal environment. As a result, behavior found useful for success of an organization under a set of conditions of the external and internal environment and a set of people as its constituents at a certain period of time is likely to differ with time and as environment changes.

As in the present context, the global economy witnessed a major turbulence with the meltdown of the U.S. economy and the related impact on several emerging economies and business depending on exports. The uncertainties associated with recession and recovery call for different set of organizational behaviors in order to survive and perform. In general, the environment poses certain requirement of behaviors to suit its needs.

Organizations also need to be prepared for adapting their behaviors in order to remain competitive under changing environment conditions. Besides, many organizations have their offices in different countries. With the advent of globalization and mergers and acquisitions across borders, understanding of national culture and imperatives for behavior has become vital.

As a result, external environment creates a need for new behaviors which negotiate with the current manifestation of behaviors and thus change the dominant values and beliefs of the organization. The assumption here is that all participants of an organization would like to see their organization succeed, and the meaning of success may change with environmental contexts.

Proposition 4: The external sources of behavior, and hence the values and beliefs derived from the national culture and general economic conditions will negotiate with the dominant and current values and beliefs of an organization and thus influence the organizational culture. 
As described above, and following from the four hypotheses stated, there seems to be a continuous interplay between the organizational culture, its subculture, the internal and external environment of the organization and the leadership and people with influence who guide behavior. As manifestation of behavior changes, so do behavior outcomes.

As described in the beginning, if organizational success demands a change of behavior and experimentation with behaviors gives rise to new forms of behaviors, they are likely to get accepted and become the norms, eventually bringing about a change in the values and beliefs at different levels according to the respective needs of these levels in an organization.

Proposition 5: The manifestation of behaviors, based on the outcomes of behaviors in various behavioral contexts are likely to shape the values and beliefs of the organization which in turn will negotiate with the individual and organizational level sources of behavior in an organization and thus influence the organizational culture.

Following the five hypotheses described above, OC is likely to be in a state of flux at all times. Author therefore suggests that culture is dynamic and is a continuous process of interaction between what is manifested as a behavior and the sources of that behavior. As organizations and its members strive to achieve optimum performance, they always try to negotiate between the manifested behavior and their sources in behavioral contexts which are inherently dynamic. It therefore follows that,

Proposition 6: Organizational Culture is dynamic and a result of the continuous negotiation of sources of behavior and the manifestation of behavior in an organization's behavioral context.

On the next page, I present a Conceptual Framework of Organizational Culture based on the above propositions (Fig 9). 


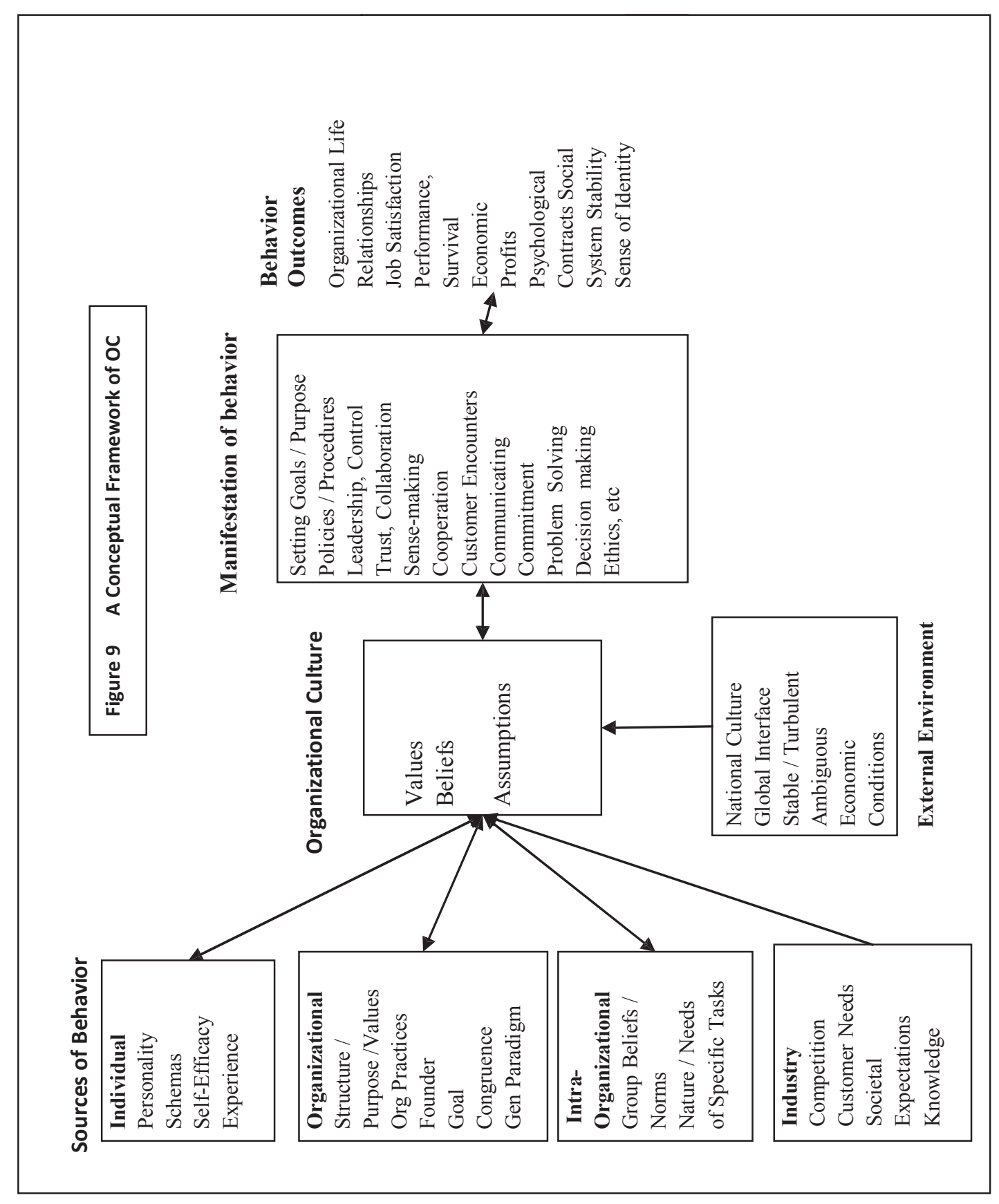




\subsection{Discussion}

Review of various studies has supported our view of understanding culture as dynamic and dependent on various internal and external environment conditions which invariably change with time, an assumption more valid in today's global village. These studies suggest that culture has time perspective, is related to performance and non-performance as well as to other variables related to performance and that in the highly ambiguous, uncertain and complex times, firms with cultures suited to their market environment will perform better (e.g. Pettigrew, 1979; Williamson,1980; Schien,1983; Martin, Siehl, 1983; Barley,1983; Wilkins,Ouchi,1983; Kotter \& Heskett,1992; Harris,1994; Barger,2007; Bryson, 2008; Taormina, 2008; Zheng et al, 2009). Pettigrew (1979) advocated longitudinal-processual study of organizations. Williamson (1980) demonstrated the existence of dominant, emergent and residual cultures. All of these suggest that as organizations evolve they will filter behavior norms suited to contemporary requirements.

Therefore, in order to survive and succeed, as new groups take charge, and as old behaviors become dysfunctional, new behaviors will be required which will challenge the values, beliefs and assumptions of the organization and a new culture will be negotiated on a continuous basis. Using the above arguments, author have presented the behavioral model of OC. Researchers of systemic change initiatives have paid little direct attention to the values, beliefs and underlying assumptions that support or impede these new behaviors (Detert et al, 2000). In absence of giving way to new behaviors, the sources of behavior would be criticized of exercising normative control. It has been pointed that culture serves as organizational control mechanisms, informally approving or prohibiting some patterns of behavior helping the top management to control behavior in accordance with their objectives (Martin et al., 1983). Most traditional OC definitions thus imply that $\mathrm{OC}$ is something developed and retained by organizations such that it is relatively stable and enduring. Hence, cultural change intervention is sought through the help of external agents. How do existing definitions of culture, then, explain the context of changing environments? If OC is affected by different levels of sources of behavior as described in a model and as evidenced by several studies carried out in the past decades, how can culture be stabled and enduring?

Literature addresses this perplexity through the concept of organizational climate. Tagiuri and Litwin (1968) defined climate as the values of a particular set of characteristics (or attributes) of the environment which are experienced by the occupants and influence their behavior i.e. there is emphasis on how the 
social environment is experienced by the actors while culture theorists like Schien argue how the social environment is created by the actors (Denison, 1996). This implies that while the organization experiences changing environments (climate), the culture (basic assumptions) created remains unaltered, a premise on which organizations across the world need external change agents. Author argues that since beliefs are formed through experiments of behavior, a consistent requirement of change in behavior would automatically lead to formation of new beliefs.

Eventually, this will alter the underlying assumptions of the founders who had an important role in developing the culture of the organization. Even if they are resilient to this change, they may withdraw to enable the new generation to devise new behaviors to compete in the changing environment. This is likely to induce change in the culture of the organization. Hence, while some elements of culture may still be unaffected, other elements of culture may change by environment which is always changing. Author had tried to contribute to the dynamic aspects of culture using a behavioral model and have indicated that new behaviors will affect a change in culture.

Authors of literature on climate and culture have attempted to understand this process of reciprocal evolution, but they have often been more successful at explaining one process or the other, rather than both at the same time (Denison, 1996). Concepts for understanding culture in organizations have value only when they derive from observation of real behavior in organizations, when they make sense of organizational data, and when they are definable enough to generate further study (Schien, 1996). Since organizational culture studies cannot be complete without differentiating it from climate, author present below our understanding of the two concepts.

The climate research has its roots in Lewin's (1951) expression of relationship between individuals and their social environments in terms of a simple equation

$$
B=f(P, E)
$$

where in $\mathrm{B}=$ behavior, $\mathrm{E}=$ the environment, and $\mathrm{P}=$ the person. According to Lewinian field theory, the social world can neatly be divided into Bs, Ps and Es. This assumes that managers are the agents providing for a climate and employees work in that climate and there is little scope for contribution of the individuals to the social context or the environment. Author suggests organizational culture (OC) can be represented in a rather complex equation as below:

$$
\mathrm{OC}=\mathrm{f}(\mathrm{B}, \mathrm{V}, \mathrm{E})
$$


wherein $\mathrm{B}=$ behavior, $\mathrm{E}=$ the environment, and $\mathrm{V}=$ the values and beliefs. Our assumption is that Bs, Vs and Es are not independent but interdependent and have interaction effects; Vs have more influence on the internal environment and Es relate more to external environment which is dynamic and in times as now, both are turbulent, both influence the Bs and assist in reciprocal evolution of the organizational culture and indulge in cultural negotiation, a term coined by Williamson (1980). After all, the organizations are not only made up of individual interactions but are also a determining context for those interactions (Ashforth, 1985; Barley, 1986; Golden, 1992; Poole, 1985; Poole \& McPhee, 1983; Riley, 1983; Schneider \& Reichers, 1983). Although culture as a process and more critical views have increased in popularity emphasizing the need for greater reflexivity in organizational research (Alvesson, 2002; Weick, 1999; Hawkins, 1997), where empirical studies are reported they still tend to reflect one point in time and thus fail to capture the process of cultural negotiation. Sound theory must take into account the history and the future of a system and relate them to the present (Pettigrew, 1979).

\subsection{Conclusion and Implications for Future Research}

Research that can contribute practical assistance to achieving a dynamic and broad contextual perspective is sparse throughout the literature on organizational culture (Bryson, 2008). This paper adds to the body of literature in two ways: 1). It presents organizational culture research carried out during the past three decades in order to provide future researchers with useful insights. 2) It provides a comprehensive framework and a behavioral perspective to understanding organizational culture and why and how it will change as an organization evolves through changing environment conditions, internal and external. Future research can examine each source of behavior of OC in detail and also the dynamics involved in the interchange between the manifestation of organization behavior and the source of behavior. Consequently, the proposed model has implications for practice as managers can have an overall assessment of the organizational culture by analyzing manifestations of organizational behavior and also by identifying sources of behavior. 


\title{
Chapter 6. Implications of Global Crisis: Integrate Sustainability with Organizational Culture ${ }^{1}$
}

\begin{abstract}
Sustainability is an issue of escalating importance as a result of structural changes of organizations which are consolidating, downsizing, merging and outsourcing as well as due to the increasing complexity and unpredictability of the external environment. Understanding, assessing and managing organizational culture can help create both stability and adaptability for organizations, thus helping supportive integration of the sustainability strategy into appropriate organizational behavior. This paper draws from review of literature on the concepts of sustainability and organizational culture in the present context of economic turmoil. The findings suggest that organizational culture moderated by leadership and trust play an important role in sustainability of organizations. A model is thereby proposed depicting the role of organizational culture, leadership and trust towards sustainability of a firm. It is also suggested that organizations can be visualized as manifestations of cultures and future organizations need to integrate sustainability with their organizational culture in order to be prepared for the uncertain socio-economic times.
\end{abstract}

1. This paper has been published in 2010. Rao, Indu. Integrate Sustainability with Organizational Culture: Leadership and Trust as Moderators. Khoj. Indian Management Research Journal published by - MAEER's MIT School of Management Vol 1. Issue 1, journal listed in EBSCO 


\subsection{Introduction}

"The current socioeconomic system is in a state of turmoil unlike any in recorded history, thereby calling for adjustments of major importance for the meaningful development of organizations" (Darling J.R. \& Heller V.L., 2009). After the explosion of liberalization, globalization, and ICT, major world economies are faced today with the phenomenon of turbulence and confusion. We hear about innumerable company-closures and countless employee lay-offs. The developed and developing nations have all been affected due to interdependence of business. The organizations of today are faced with the question of sustainability due to dual pressure of internal and external climate. On the one hand, turnover intentions, employee morale, reduced commitment levels and loyalty are a concern, while on the other hand, global economic slowdown, interdependence, costs, expectations from stakeholders and safety issues, all have a combined effect on operations of a firm. We agree with Peters and Waterman (1982), "If you are not confused, you are not paying attention."

How do organizations sustain and adapt themselves when the world economy peaks in 2006 and falls abysmally in 2007-08 and a credit crisis of one nation spreads jitters across all others which are interdependent like never before? Confusion abounds as do proposed panaceas. With a speck of optimism emerging in 2009, this paper revisits management literature and reasserts the importance of organizational culture, something less tangible, less blatant but perhaps more powerful than other market factors (as in Porter,1980) listed previously as essential ingredients required for the sustained success of organizations (Cameron,Quinn,1999).

\subsection{Literature Review}

Empirical research has produced an impressive array of findings demonstrating the importance of culture to enhancing a firm's performance (Denison, 1990). Organizational Culture (OC) is the key to organizational excellence and the function of leadership is the creation and management of culture (Schien, 1992). Quinn L. \& Dalton M. (2009) link the field of leadership to sustainability and call for a more in-depth investigation into the roles leaders and leadership play in the successful implementation of sustainability practices. Literature also suggests that the essential ingredient of collaborative effort is trust. High performance teams are characterized by high mutual trust among members. Leaders succeed in bringing about change because they are trusted by constituents to reflect their values and aspirations (Costigan et al., 1998). 
The concepts used in this paper, that of culture, trust, leadership and sustainability, as is the case with most social science concepts, are difficult to be contained in one single definition. A vast and diverse literature exits to explain the meaning and measurement of culture, trust and leadership; but the concept of sustainability continues to remain elusive in social sciences. Not only is there a failure to obtain a concise and universal definition (Simon B. \& Stephen M., 1999), non-availability of a generalized set of indicators or measuring instruments makes it further difficult to conduct sustainability studies. Yet, scholars agree as we do, that achieving sustainability for organizations is the need of the hour which makes it one of the most relevant concepts in contemporary times and needs further analysis from behavioral perspective. We address this gap by analyzing the concept of sustainability and mapping it with behavioral concepts in order to derive a conceptual model for sustainability of an organization.

\subsubsection{Organizations as 'Cultures'}

While numerous definitions and dimensions exist in literature, organizational culture emphasizes a set of values to regulate and shape employee's behaviors to respond to changes in the external environment (Schien, 1985; Geertz, 1973). Broadly, two schools of thought exist about organizational culture whether it represents something an organization 'is' or 'has'. Accordingly, researchers have analyzed the concept of $\mathrm{OC}$, both as a root metaphor, i.e. organizations as expressive forms, and manifestations of human consciousness (Cameron 1999; Smircich, 1983), and as an attribute, i.e. possessed by an organization and observable. This is because some researchers are concerned by what appears to them to be more fundamental issues of meaning and the processes by which organizational life is possible which is in line with the view that an organization 'is' culture while others give high priority to the principles of prediction, generalizability, causality, and control drawing from the view that an organization 'has' culture (Smircich, 1983). Both approaches share the conception of organizations as organisms; existing within an environment that presents imperatives for behavior.

We subscribe to the view that organizations can be thought of as cultures and that culture influences everything an organization does. The implications of this insight can only prove to be more useful today. After all, organizations are social entities formed by individuals whose interactions result in design of structures and processes. In order to timely adapt and redesign activities in response to the fluctuating environmental conditions, it is the organizational culture which can be harnessed to support the people and help organizations in achieving both operational and strategic goals and thus achieve sustainability. Handy (1997) argues that in order to survive, organizations need to be treated as 'communities' 
not owned by anyone and people as 'citizens' not employees. "Our use of old words to describe new things can hide the future from our eyes."(Handy.1997, p 26) Apparently, he implies that future organizations in order to be sustainable need to change the way they think, feel and perceive which again refers to the organizational culture.

Schien's (1985) model also suggests that basic assumptions are unconsciously learned and held and determine how group members perceive, think and feel. Values and beliefs are consciously embedded in individuals and they use these to justify and evaluate actions and outcomes. Artefacts are the symbols, myths and stories specific to an organization. All these levels together comprise the organizational culture and are "exploitable cultural levers, extremely powerful determinants of organizational life as well as intuitively incorporated into the actions of skilled executives who use them to manage people, formulate strategy and induce organizational change" (Brown,1992).

\subsection{Sustainability of Organization}

We do not necessarily subscribe to the need to define sustainability in order to practice it, but the exercise of definitions is one useful way to examine several perspectives and to understand competing views. While exploring definitions of sustainability by Lynam \& Herdt (1989), Pearce \& Turner (1990), Fresco \& Kroonenberg (1992), sustainability emerges as the dynamic equilibrium between inputs and outputs, modified by external events and climate (Simon B., Stephen M., 1999). Sustainable development is one that meets the needs of current generations without compromising on the needs of the future generations to meet their needs and aspirations (WECD, 1987). The Bellagio principles for sustainable development addressed some broad issues as need for a clear definition, a focus on holism and the importance of time and spatial scales.

Sustainability, in the present context, encompasses a much broader meaning. It is proposed as a normative concept in which ethical belief systems converge to limit the moral "free space" of organizations (Gladwin et al., 1995). It goes beyond the traditional, differentiated view of corporate citizenship that treats social and environmental activities as add-on functions of the organization (Hart, 1997). The goal of sustainability is to "meet the basic needs of all and extend to all the opportunity to fulfill their aspirations for a better life (Srivastava, 1995). In fact, the future organizations are faced with the challenge of developing a sustainable global economy which the planet can support indefinitely (Hart, 1997). Each organization should choose its own specific ambition and approach regarding sustainability, matching the organization's aims and intentions, and aligned with 
the organization's strategy, as an appropriate response to the circumstances in which it operates (van Marrewijk, M., Were, M. 2003).

\subsection{Organizational Culture and Sustainability}

Research on sustainability has predominantly focused on how companies manage their relations to external stakeholders, while implicitly assuming that managers and employees accept and adopt the sustainability strategy unchallenged (Morsing M., Oswald D., 2009). However, it does not ask how such organizational support is achieved, integrated, and coordinated into organizational systems, processes and structures, in order to fulfill the sustainability promise. The decline of some of the world's most successful companies in recent times have forced us to rethink our understanding of sustainability such that it becomes a part of the culture of an organization and reflects in everyday business practices.

While sustainability requires the full integration of social and environmental issues into the vision, values and operations of the organization (Srivastava, 1995, p 938), organizational culture emphasizes a set of values to regulate and shape employee's behaviors to respond to changes in the external environment (Schien, 1985; Geertz, 1973). Thus, organizational culture could prove a vital point of investigation to understand how a culture of sustainability can be nurtured. This implies that there is a growing need to explore informal and organizational cultural aspects of integrating sustainability into business practices.

Over the years, OC has been used to study several organizational phenomenon like performance, organizational climate, causal ambiguity and competitive advantage, distribution and control, job satisfaction, commitment, turnover intentions and organizational commitment, employee motivation, employee behavior ,organizational change and learning, leadership, human resource practices, decision making, organizational change and effectiveness, information systems and innovation uptake and improvement initiatives like TQM (Gordon, et al, 1992; Eli Sopow, 2006; Florencia et al, 2007; Klien et al, 1995; E. S. Williams, 2007; Lucas C. \& Klien 2008; Schien, 1992; Weese 1995; Rossman et al, 1988 and Detert et al (2000). Given the relatedness of OC to the various organizational performance factors as listed above, it is likely that organizational culture may find usefulness for the emerging concept of sustainability.

Organizations tend to develop a dominant organizational culture over time as they adapt and respond to challenges and changes in the environment (Schien, 1985, Sathe, 1983). Barney (1986) explored if organizational culture can be a source of sustained competitive advantage and suggested that a firm having a valuable, rare 
and imperfectly imitable culture enjoys a sustained competitive advantage, which, under a narrow set of conditions, is a source of sustained superior financial performance. Studies have established that change initiatives are unsuccessful unless the improvement strategies are embedded in a culture change (Cameron, Freeman, 1991). Organizational success depends on the extent to which the organizational culture matches the demands of the environment. Organizational cultural strength refers to the power or pre-eminence of the culture in affecting everything that happens in an organization.

Deal and Kennedy (1982) asserted that a strong culture has almost always been the driving force behind the continuing success in American business. They are associated with homogeneity of effort, clear focus, and higher performance in environments where unity and common vision are required. The extent to which an organization needs a strong dominant culture or balanced eclectic culture is a matter of circumstance and environment, i.e. it could be influenced by the type of industry the firm is operating in and the general global economic environment. Cultural congruence eliminates many of the complications, disconnects and obstacles that can get in the way of effective performance (Cameron and Quinn, 1999). Hence we propose that sustainability of an organization will depend on the culture type, cultural strength and cultural congruence.

Proposition 1: Sustainability is related to the Culture Type. A Culture of Flexibility and Discretion is likely to be positively related to sustainability.

Proposition 2: Cultural Strength and congruence are likely to be positively related to sustainability.

\subsection{Leadership, Organizational Culture and Sustainability}

A central aspect of leadership is the embracement of processes in which noncoercive influence is used to direct and coordinate the activities of a group towards its objectives (Selznick, 1957). Schien (1983) describes the role of the founder of the business in creating organizational culture as the members learn to cope with external adaptation and internal integration. By exploring the noncoercive aspects of leadership, rather than looking at the individual manager's skills and competence, and with a focus on organizational culture, we direct our attention to the creation of an environment that facilitates development of an internal environment that enables the implementation of sustainability practices. Transactional leadership motivates followers primarily through contingent reward-based exchanges (Burns,1978), the focus is on setting goals, clarifying the link between performance and rewards, and providing constructive feedback to 
keep followers on task (Bass,1985). Transformational leadership involves developing a closer relationship between leaders and followers; one based more on trust and commitment than on contractual agreements (Dong I Jung, Bruce J Avolio, 1999).

A critical basis for change toward sustainability is a leader's introduction and discussion of sustainability principles in order to create a remarkably different concept of business, one that can restore and protect while still allowing for innovation, profitability, and meaningful work. Leaders interested in pursuing a sustainability agenda should pay attention to how the concept is framed and introduced into the organization; they should build capacity in their systems (educational, communication, rewards, performance, etc.) and culture to support sustainability (Quinn L., Dalton M.,2009). Research findings by Patricia et al (2009) suggest that five reflexive abilities (combination of emotional and intellectual capacity) of systemic thinking; embracing diversity and managing risk, balancing global and local perspectives; meaningful dialogue and developing a new language and emotional awareness should be developed as core competencies. These abilities may enable leaders to develop new ways of thinking and new business models which will ensure the sustainability of their business.

This, we believe, can be transcended to the followers when the leader is perceived as representing the followers' perceptions and values. Walumbwa et al (2005) have argued that leadership is most effective when there is a match between the perceptions and values stressed by leaders and the cognitive structures held by followers. This is in line with transformational leadership as such leaders help followers to see the importance of transcending their own self-interest for the sake of the mission and vision of their group and /or organization (Jung, Avolio, 1999). Also, a culture of flexibility, adaptability and dynamism would logically support leadership to perform in such a situation. The congruence between followers' cultural values and a transformational leader's attempts to build identification with a collective vision is expected to enhance self-confidence, self efficacy and selfesteem, such leaders are expected to have a strong influence on followers' level of identification, motivation and goal achievement (Klien et al,1995), thus helping them learn and adopt the new business models and ways of thinking as suggested by their leaders towards sustainability of their business. We therefore propose that transformational leadership supported by culture of flexibility and adaptation will have a positive influence on sustainability of a firm.

Proposition 3: Leadership Style is related to Sustainability. Transformational Leadership is likely to be positively related to sustainability. 


\subsection{Trust, Organizational Culture, Sustainability}

The construct of Trust since the mid-1990s has been posited as being the basis of quality interpersonal relationships and a source of competitive advantage for organizations. Trust or the lack of it explains why we don't optimally capitalize on intellectual assets for competitive advantage (Oren Harari, 2002). Hwee Hoon Tan, Augustine K H Lim (2009) found that trust in coworkers' works through the mechanisms of trust in organizations to affect important outcomes of organizational commitment and performance. Amongst the most prominent factors of trustworthiness are the trustee's ability, benevolence and integrity (Mayer et al, 1995). The leader, supervisor, co-workers, suppliers, clients can all serve as a referent for trust.

Trust has also found to emerge as a dominant theme within the culture that influences the group's learning to change (Driver, 2003). Effective organizational learning is necessary for implementing the drive towards sustainability. As organizations attempt to cope with an environment that is changing at an everincreasing rate, they struggle to learn the changes required (Schein, 1992). New methods of solving problems or learning often do not get integrated or institutionalized by the organization if groups have difficulty learning. Organizations display "learning disabilities" or "defensive routines" that hinder the learning and development required. Edmondson (1999) found that the most salient factor influencing team learning was psychological safety (a climate in which group members believe that they can speak openly about mistakes without fear of negative repercussions). The organizational change requires that both, trust in competence and trust in intentions, become a part of the culture (Lucas, Kline, 2008). Hence, trust in organizations is expected to play an important role in sustainability of firms.

The human and the innovation oriented organizational culture from Quinn's (1985) competing values model encourages commitment, participation, teamwork, structural flexibility and problem solving and these values have been attributed to positively cultivate higher trust in the workplace (Argyris,1964). High subordinates' trust relates positively to the extent to which employees perceive that they are empowered, from empowerment to work, trust must first be nurtured so that employees will have no fear of experimenting with new ways of doing things (Chan, Taylor, Markham, 2008). Thus, psychologically empowered employees are motivated to reciprocate the organization with their behavior by choice while implementing interventions of sustainability. We, therefore, propose that sustainability is related to trust. 
Proposition 4: Sustainability is related to Trust in Organizations. Trust with respect to various referents of the firm as well as at individual level (trust in competence and trust in intentions) is likely to be positively related to sustainability.

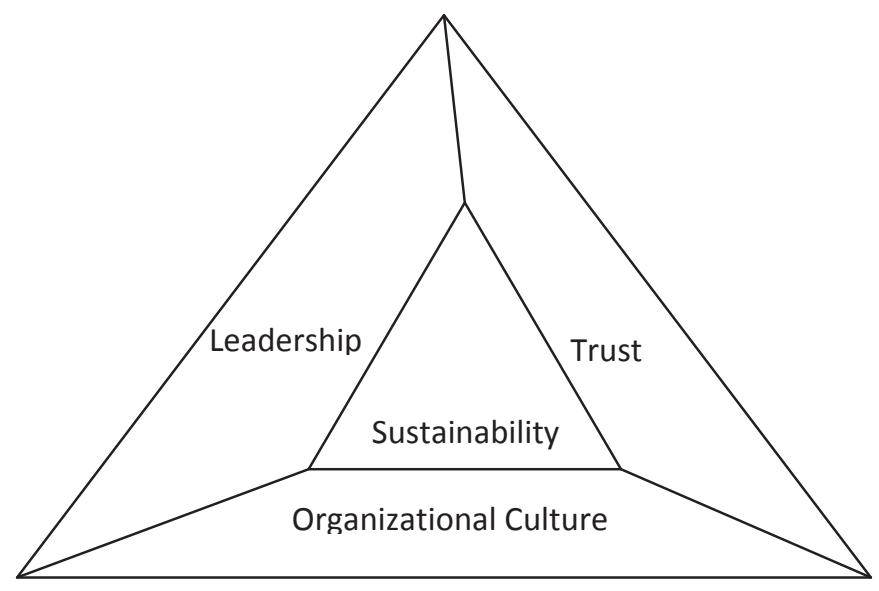

Fig A Conceptual Framework of Sustainability

\subsection{Leadership and Trust as Moderators}

A moderator variable is one that influences the strength of a relationship between two other variables, and a mediator variable is one that explains the relationship between the two other variables. In our model, we suggest that an appropriate organizational culture will be positively related to sustainability of the organization; however the leadership style and the trust factor will act as moderators and influence the strength of this relationship. If we remove the effect of the mediator variable, the relation between the predictor variable and the dependent variable disappears (Baron, \& Kenny, 1986). Since OC is an organization wide phenomenon and composed of several other dimensions, it may not be right to assume that removing the leadership style or the trust factor would lead to a system collapse and the relationship between culture and sustainability will disappear. Hence we have considered them as moderators not mediators. "In the more familiar analysis of variance (ANOVA) terms, a basic moderator effect can be represented as an interaction between a focal independent variable and a factor that specifies the appropriate conditions for its operation." (Baron, \& Kenny, 1986 p. 1174). 
Accordingly, we argue that in the presence of a strong leadership and high trust amongst various referents of the organization, an appropriate organizational culture is likely to enhance sustainability of an organization. Thus, leadership might be a moderator variable, in that the relation between $\mathrm{OC}$ and sustainability could be higher for strong leadership and less for a weak leadership. In most professional organizations of the modern world, leadership changes more often than it used to happen earlier and systems are in place where individuals perform their roles objectively, we therefore, argue that it may not be valid to consider leadership and trust as mediators to explain why there is a relation between organizational culture and sustainability. Organizational Culture envelops the entity of the organization as a whole and one could argue that it is also composed of the factors influenced by leadership and trust. This is the reason why we have preferred to use these two variables as moderators. In quantitative analysis, one could argue that this interdependence will lead to the problems of multidimensionality. Nonetheless, the concepts of organizational culture, leadership and trust are very crucial for the sustainability of organizations and need to be given more practical considerations.

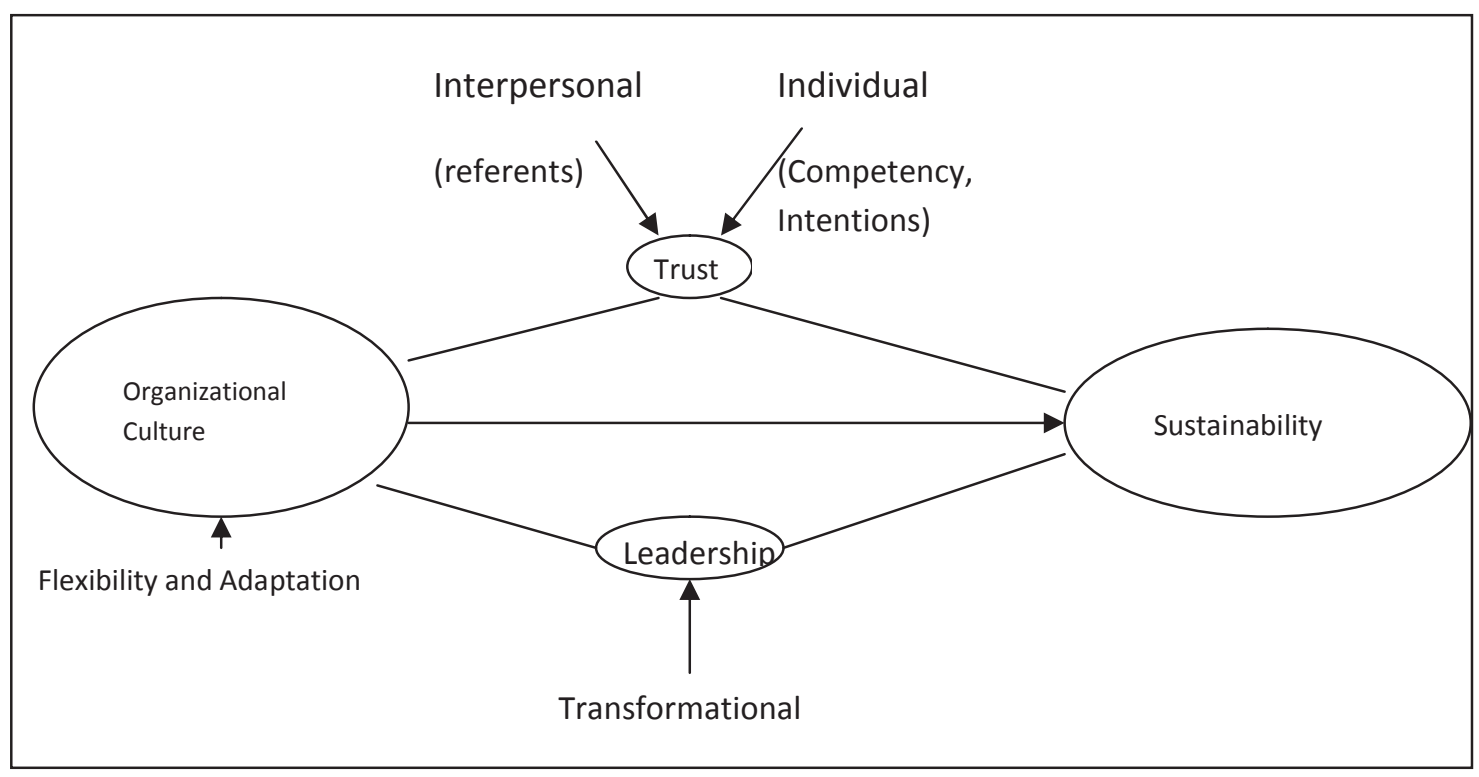

Proposition 5: The configuration of trust amongst various referents of the organization and leadership styles, both moderate the relationship between organizational culture and sustainability. 


\subsection{Conclusion}

Sustainability is rooted in something deeper, something beyond superficial explanation (Denison D., Colleen L., Ward, J.L., 2004) and is difficult to be explained by terms like capabilities, competence building, competence leveraging, decision making, closing strategy gaps between the perceived and the desired states of any of the firm's elements (Lewis D., 2002). The question is who is responsible for developing all this and leadership or CEO or top management may be the answer. However, in the current business scenario, neither the external conditions, nor the internal profile of an organization is constant. Hence there is a need for the organization to nurture a strong and appropriate organizational culture which promotes flexibility, adaptability and is moderated by the right leadership and trust amongst various referents of the organization. There is a need create a remarkably different concept of business- which can restore and protect interests for all stakeholders of the business and yet allow for innovation, flexibility and profitability. Organizations need to develop a culture wherein sustainability principles are introduced and discussed and understood.

\subsection{Implications for Future Research and Practice}

Organizations are increasingly trying to work out means to ensure their sustainability in present uncertain times. Also, more research is being carried out to develop theories and paradigms for sustainability. The model proposed could add value in understanding how the principles of sustainability can percolate through the organization. Empirical research can be carried out to examine the validity of the model. Further exploration of the concept of organizational culture and to enhance its utility in contributing to the sustainable development of organizations is suggested. 


\title{
Chapter 7. Results of Organizational Cultural Assessment using OCAI $^{1}$
}

\begin{abstract}
Developing international networks with industrial clusters requires an understanding of their organizational forms, more so if they operate in the informal or unincorporated sectors. The diamond manufacturing industry cluster located in a western state of India is one such example of an agglomeration of CPD units (entrepreneurial firms engaged in cutting and polishing of diamonds) and has grown to become the largest producer of cut and polished diamonds in the world in a span of two decades. The cluster thrives in the atmosphere of secrecy and informality that envelops the diamond trade and has for long been labeled as an informal or unorganized sector. Interestingly, 11 out of every 12 diamonds set in jewelry anywhere in the world are cut and polished in the CPD units of this cluster in Surat, Gujarat. The diamond cutting and polishing hub which was earlier in Antwerp in Belgium has now shifted to Surat in India. We conduct a micro-level organizational study. Primary survey data is collected from 589 employees of a relatively large sized CPD unit. The results of empirical study shed light on the demographic and organizational characteristics of the successful informal sector firms of the diamond industry. With the growing importance and size of the informal sector in international business, we hope to contribute to this emerging stream of literature.
\end{abstract}

1. This chapter is based on my paper accepted in the Cross Divisional Paper (CDP) session for the 2012 Academy of Management Annual Meeting in Boston, Massachusetts. Paper \#17691, titled "Organizing the Un-Organized? Exploring Organizational Forms of Informal Sector Firms". It was accepted for presentation as a Cross Divisional Paper and included in the CDP session titled "Operating in the Informal Economy: Information Asymmetry, Structure, and Choice scheduled for presentation on Aug 62012 from 3:00PM to 4:30PM. 


\subsection{Introduction}

While much has been written about functional frameworks, relational networks, firm strategies and firm growth in industrial clusters, literature on organizational forms of such firms, more so from the informal sector, is scarce. With growing importance of the informal sector's contribution to world business, we identify a cluster composed of informal sector firms which occupies a significant prominence in the related industry and attempt to study their organizational forms.

The Indian diamond industry resembles a close-knit community composed of tens of thousands of entrepreneurial firms which export cut and polished diamonds worth USD 20 billion annually employing more than a million people with little formal education. The cluster has for long been labeled as informal or unorganized sector but the collective output of its firms makes for a 95 percent market share of net global exports of polished diamonds and 20 percent of India's exports. The CPD units (firms engaged in cutting and polishing of diamonds) of the diamond industry appear to be individual entities like entrepreneurial firms but are more complementary than competitive within such geographically concentrated clusters.

The entrepreneurial firms of the Indian diamond cluster not only contribute to the country's economy but also are globally competitive. With modest beginnings in the informal sector of an emerging economy, they have moved up the value chain and created success stories in the global markets. In global supply chains, as in case of the industry under study, it appears that the informal sector entrepreneurial firms help build economically and organizationally viable clusters in certain geographical locations which also determine the direction of world trade in the related industries.

Traditionally, informal sector firms have not been of interest to organizational and business streams of literature. This we believe is not only due to lack of availability and access to comprehensive data but also due to small economic significance attached to them. However, the so-called unorganized sector firms may be more organized than we thought and if some of them demonstrate success in terms of growth, productivity and increased market shares at global level as in the case of the Indian diamond industry, it calls for further investigation into their organizational life. Our interest in this paper is to explore such new forms of organizing. 


\subsection{Literature Review}

The international entrepreneurship literature has examined identification and exploitation of opportunities for international exchange and how the opportunities are identified (Ellis, 2011). Cultural studies have been conducted to predict opportunity and necessity entrepreneurship rates using the World Values Survey data (Hechavarria \& Reynolds, 2009). A number of case-based studies have recently emerged to address how firms enter new markets (e.g., Chandra, Styles, \& Wilkinson, 2009; Crick \& Spence, 2005; Ellis, 2000; Komulainen, Mainela, \&Tähtinen, 2006; Sharma \& Blomstermo, 2003; Wong \& Ellis, 2002).

There is a rich, descriptive database documenting the rise of entrepreneurial firms in global markets from developed as well as developing economies. However, micro-level organizational data, more so for firms operating in industries comprised of informal firms in the emerging markets is scarce. Consequently, there is dearth of organizational studies with empirical evidence.

The informal sector firms (ISFs) were identified as "unincorporated entities without separate complete accounts but units of production operating at a low level of organization, based mostly on casual employment, kinship or personal / social relations rather than contractual arrangements with formal guarantees" (ICLS $\left.{ }^{1}, 1993\right)$. The meaning and definition of informal sector has changed with time (App A, B). Basically ISFs engage in production of goods and services with the primary objective of generating employment and incomes to the persons involved. But they are also a key form of organization of production of goods and service, both in rural and urban areas (ICMISIE, 2009).

However, organizational studies are seldom carried out in such firms, the informal economy has traditionally been the subject of economics and labor-related areas (de Soto, 1989; 2000) and neglected in the management literature and subsequent research. This is due to high mobility and turnover, seasonality, lack of recognizable features for and reluctance to share information (ADB, 2007). But entrepreneurship exists in both the corporate and the unincorporated sectors. Recently, there is a renewed interest in informal work arrangements or informal labor markets which stems from the fact that informal work arrangements have

1. In January 1993, the Fifteenth International Conference of Labour Statisticians (15th ICLS) adopted an international statistical definition of the informal sector, which was subsequently included in the revised international System of National Accounts (SNA 1993). 
Not only persisted and expanded but have also emerged in new guises and at unexpected places (ILO, 2002).

We try to address this gap, the globally-distributed industry specifically the diamond cutting and polishing industry; largely resident in the unorganized sector and composed of numerous the CPD units is identified for our purposes. An organizational survey is conducted to shed light on the organizational forms. Primary data is collected, documented and analyzed in this chapter.

Drawing insights from OB literature, organizational culture has strong relationship to several organizational variables and can be a source of sustained competitive advantage and firm performance if it is valuable, rare and imperfectly imitable (Barney 1986). Three levels of organization's culture, basic assumptions, values and beliefs and visible artifacts (Schein,1996) are extremely powerful determinants of organizational life, and are intuitively incorporated into the actions of skilled executives who use them to manage people, formulate strategy and induce organizational change (Brown, 1992). Firms with cultures suited to their market environment perform better (Kotter \& Heskett, 1992).

Due to lack of formal rules and procedures in such informal sector entrepreneurial firms, we believe that the firm's culture may play an important role in influencing what the firm does. We therefore explore organizational culture of a large sized CPD unit using a validated culture assessment instrument from scholarly literature and draw conclusions about its dominant characteristics, organizational leadership, management of employees, organizational glue, strategic emphases and criteria of success, as perceived by the members of the unit. Exploring culture of the entrepreneurial firm may help us understand the shared patterns of basic assumptions, values and beliefs held by their members and thus help gain insights into their organizational life.

Organizational culture translates into organizational behavior (Rao, 2011). However, organizational culture of a firm cannot be captured well without knowledge of the industrial context (Reynolds, 1986). Within an industry, firms share the industry driven cultural elements which are influenced by industry characteristics and are based on assumptions about the competitive environment, customer requirements and societal expectations Gordon (1991). Although culture is unique to a firm or its subunits, industries exert influences that cause cultures to develop within defined parameters. An initial exploratory study of the Indian diamond industry (Rao \& Von Glinow, 2012) and an in-depth case study a large sized firm nested within the industry (Rao \& Bhatnagar, 2009) were therefore conducted. 


\subsection{Research Method}

An organizational analysis of a large successful firm of the Indian diamond cluster was designed as below.

\subsubsection{Selection of the Firm.}

As there is a lack of comparative data to list the more successful firms in this industry, the CPD unit was identified after analysis of inputs obtained from the exploratory study and of those received from responsible actors in the industry. Triangulation was achieved after consulting the Chairman, GJEPC (Gems and Jewelry Export Promotion Council ) at Mumbai, an official body working under the ministry of commerce, Government of India; the Director of IDI (Indian Diamond Institute) at Surat and members of local diamond associations. This CPD unit has been in existence for 40 years, strength of employees is 1500 and exports $\$ 400$ million worth of cut and polished diamonds annually. The firm resembles a family owned business. The difference is that it continues to be a part of an industry cluster which has for long been labeled as unorganized or informal sector. The firm therefore imbibes cultural elements of the industry to which it belongs.

\subsubsection{Selection of the Instrument.}

As explained in chapter 2, section 2.3 , we identify a validated culture assessment instrument to draw cultural profiles for a large sized CPD unit of the industrial cluster under study. The Organizational Culture Assessment Instrument (OCAI) is selected for the purpose. It is based on a theoretical model, Competing Values Framework. This framework was developed from research conducted on the major indicators of effective organizations and was formulated on the basis of very fundamental assumptions about how organizations work and how they are managed.

The organizational effectiveness indicators were analyzed by Quinn \& Rohrbaugh (1983) and organized into four main clusters along two major dimensions. One dimension differentiates an effectiveness criterion that emphasizes flexibility, discretion and dynamism from criteria that emphasize stability, order and control. The first continuum ranges from organizational versatility and pliability on one end to organizational steadiness and durability on the other end. The second continuum ranges from organizational cohesion and consonance on the one end to organizational separation and independence on the other. 


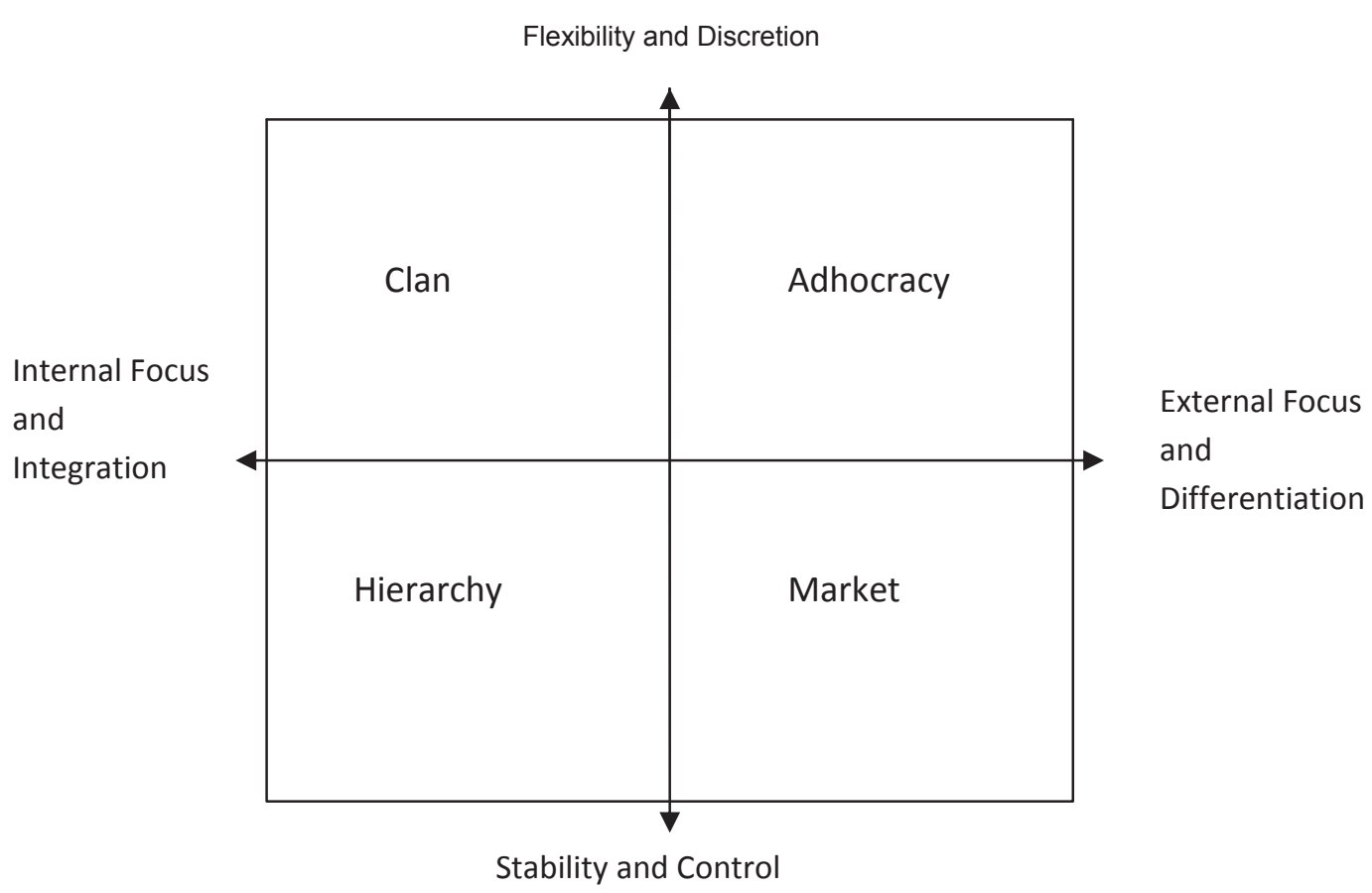

The four quadrants represent core values competing and opposing each other, justifying the name competing values. The quadrants are called clan, adhocracy, hierarchy and market and are indicative of the organizational values which have also become associated with the similar organizational forms as developed in organizational science. The indicators of effectiveness represent what people value about an organization's performance. So, if we collect responses from the employees of the CPD units on the 24 items of the instrument (appendix D), we can have insights of their perceptions about what values prevail in the firm. Analysis of these responses shed light on the organizational culture and organizational forms.

\subsubsection{Translation and Validation of the Instrument.}

The Organizational Culture Assessment Instrument (OCAI) was translated from English to Gujarati language with the help of 6 experts who were well versed with both the languages. An initial draft was prepared and circulated amongst all the six team members. After reviewing the same and making several corrections, a final draft of the Gujarati questionnaire was prepared. The validation of the Gujarati version was done by administering both the versions of the instruments to 30 experts which included Faculty and Graduate students from a technical 
engineering college and who were equally conversant with Gujarati and English language. The comments were reviewed by the team of six experts and the revised translated version was used for collection of data from the CPD unit under study.

\subsubsection{Sample and Data Collection.}

The data was collected personally by the researcher from the artisans, supervisors, managers and owner of the CPD unit. 630 questionnaires were administered but some contained missing data and hence 589 responses were considered for analysis for the 24 variables (appendix D). These 24 variables are categorized into six organizational dimensions of Dominant Characteristics, Organizational Leadership, Management of Employees, Organizational Glue, Strategic Emphases and Criteria of Success. Each of the four items under these six categories represents values which symbolize the clan, adhocracy, and market or hierarchy culture. We also collected data on the demographic variables of age, gender, level of education and the job profiles of the respondents. Further, we try to assess if there is any difference between the responses of the owner, the family member and the employees with respect to the six dimensions of the Organizational Culture Assessment Instrument OCAI. The results are presented below.

\subsection{Demographic Profile of the Sample}

We collected a sample representative of all employees of the CPD unit. 58.1 percent respondents were below the age of 35 years and 91.3 percent below the age of 45 years. 62.3 percent were employed for 10 years or less and 91.7 were employed for less than or equal to 20 years. 44 percent of respondents had an experience of up to 10 years, 78.3 percent had total experience of up to 20 years and 95.8 percent had experience of up to 30 years .It is amazing that 60.2 percent respondents received education only primary education i.e. grade 5 in school and 92.8 percent studied up to grade 12 in school, some five percent went for an under graduate study and only 2 percent received graduate level education. The percent of female employees was less than 1 percent; this is a male dominated industry. 86.8 percent of employees were artisans actually doing the cutting and polishing of diamonds in the manufacturing process, $1.2 \%$ was supervisors looking after the artisans (workers) and only $1.5 \%$ were managers. Only $3.6 \%$ were administrative staff and the rest for other support services including technical, medical, security, sanitation services. Data shows that overheads in CPD units are very low as shown in even the large sized CPD unit (Fig. 11). 
Figure 11 Demographic Profiles of the CPD Unit
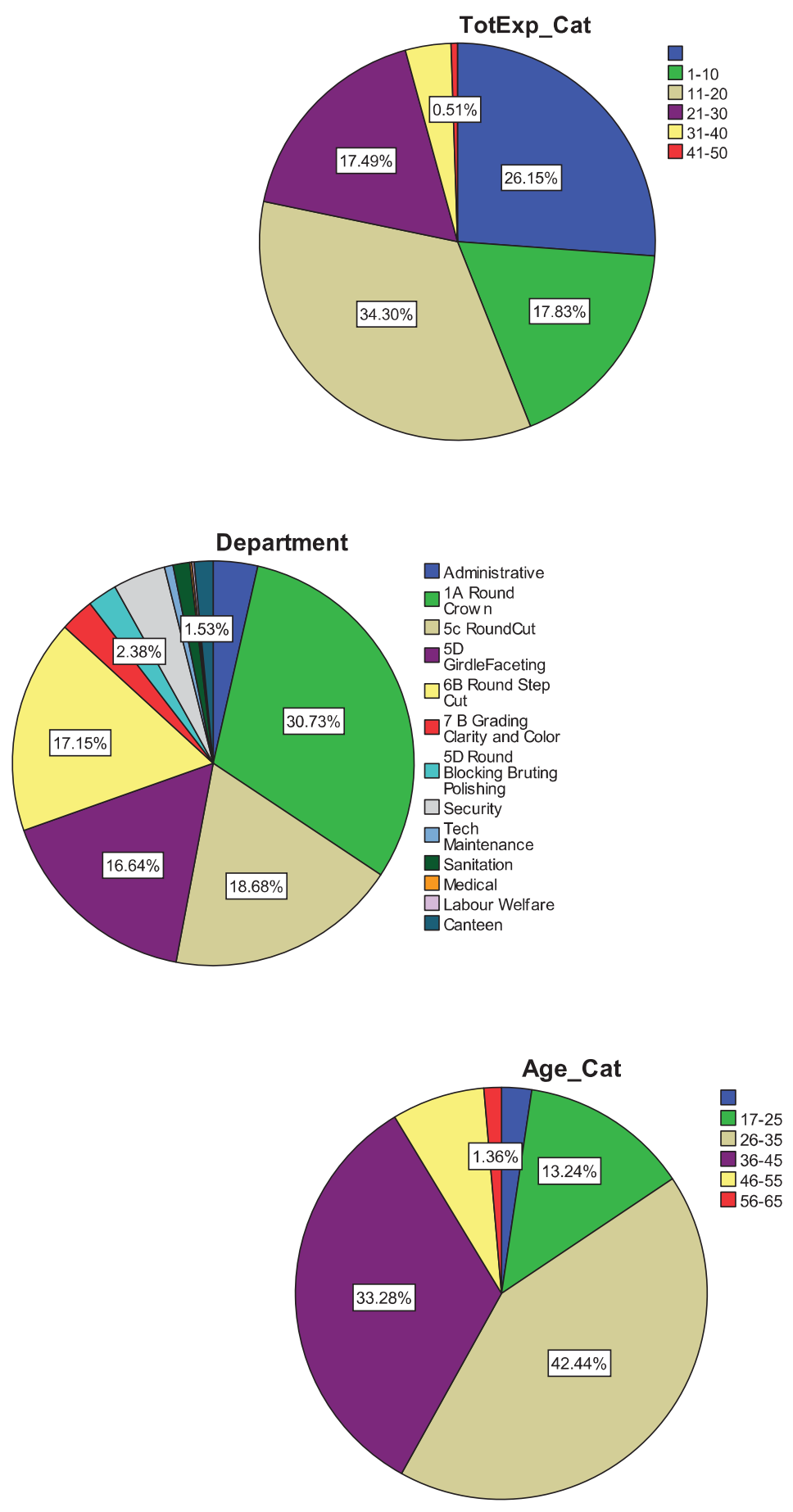

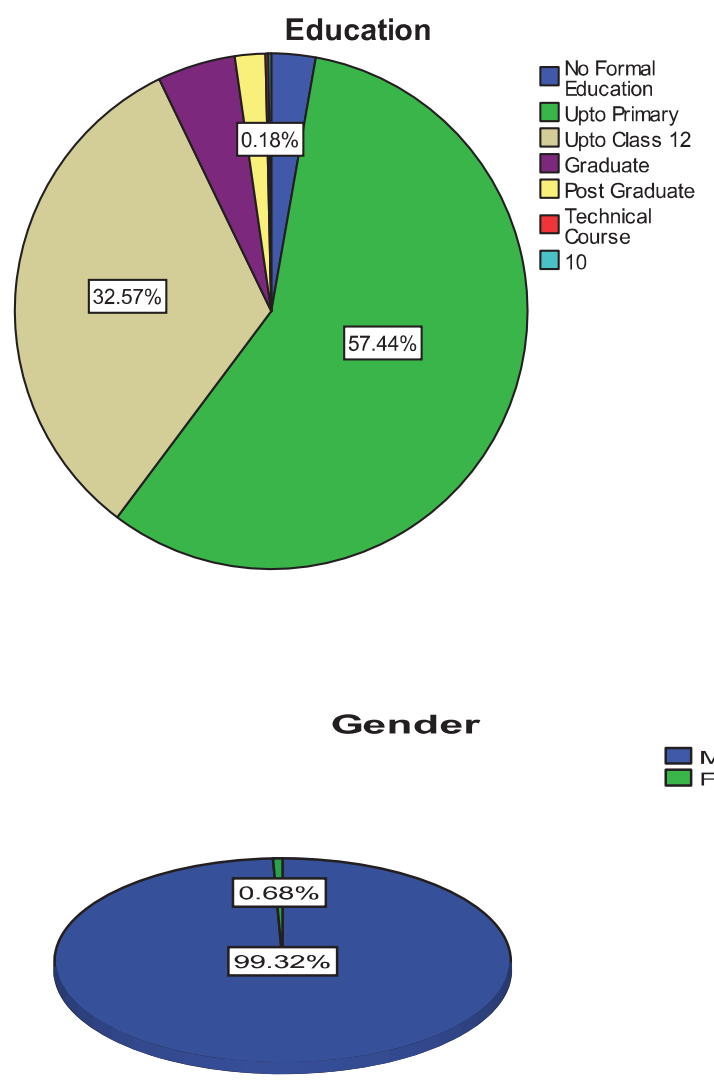

$\square$ Male

JobProfile

$\square$ Artisan

$\square$ Supervisor

and

$\square$ Others

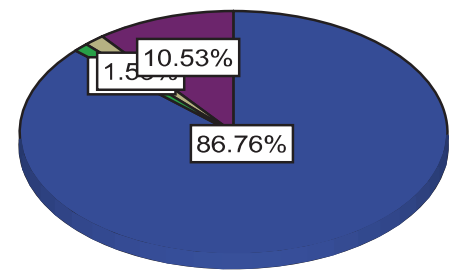




\subsection{Results: Cultural Profiles}

Table 4 Cultural Perceptions along six dimensions of OCAI

\begin{tabular}{|c|c|c|c|}
\hline & Expected & Results & \\
\hline Dominant Characteristics & CLAN & $*$ & Hierarchy (45\%) \\
\hline Organizational Leadership & CLAN & $*$ & Market (35\%) \\
\hline Employee Management & CLAN & $\checkmark \cdot$ & $38 \%$ \\
\hline Organizational Glue & CLAN & $\checkmark \cdot$ & $37 \%$ \\
\hline Strategic Emphases & CLAN & $\checkmark \cdot$ & $34 \%$ \\
\hline Criteria of Success & CLAN & $\checkmark$ & $41.5 \%$ \\
\hline
\end{tabular}

Given the informal nature of the firms, and lack of literature support, we began with an assumption that perceived culture across all dimensions will be dominated by the clan type. But contradictory to our expectation, the dominant characteristics and organizational leadership turned out to be hierarchy and market respectively (Table 4).

We then plotted the cultural profiles for the

1) Overall firm culture as aggregate of all responses from employees (Fig 12)

2) Overall firm culture as perceived by the first and next generation leaders (Fig 13)

3) Individual Cultural Profiles for the six dimensions of the OCAI (Fig 14)

4) A Comparative Cultural profile across all dimensions of the OCAI (Fig 15) 
Figure 12 Overall Cultural Profile

OverallCulturalProfile

Flexibility and Discretion

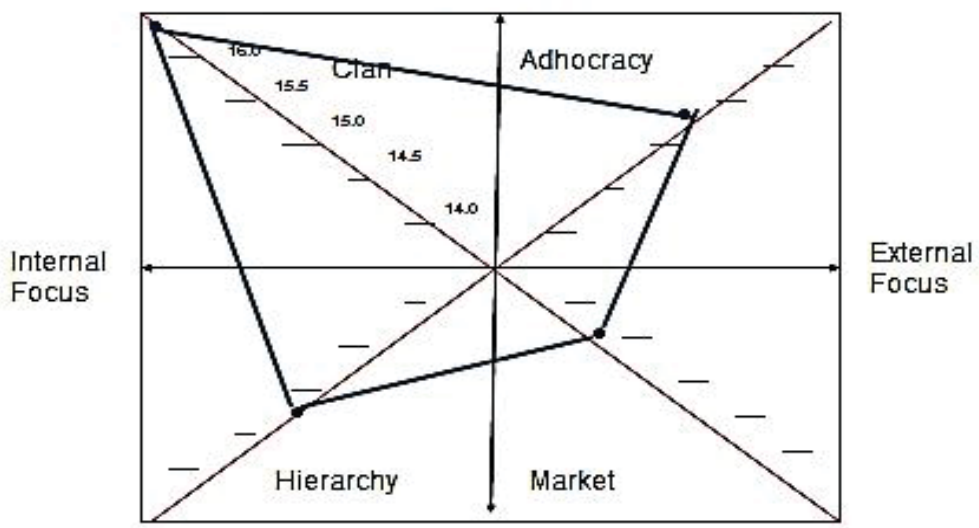

Stability and Control

Figure 13 Leader's Cultural Profile

Leader'sCultural Profile

Flexibility andDiscretion

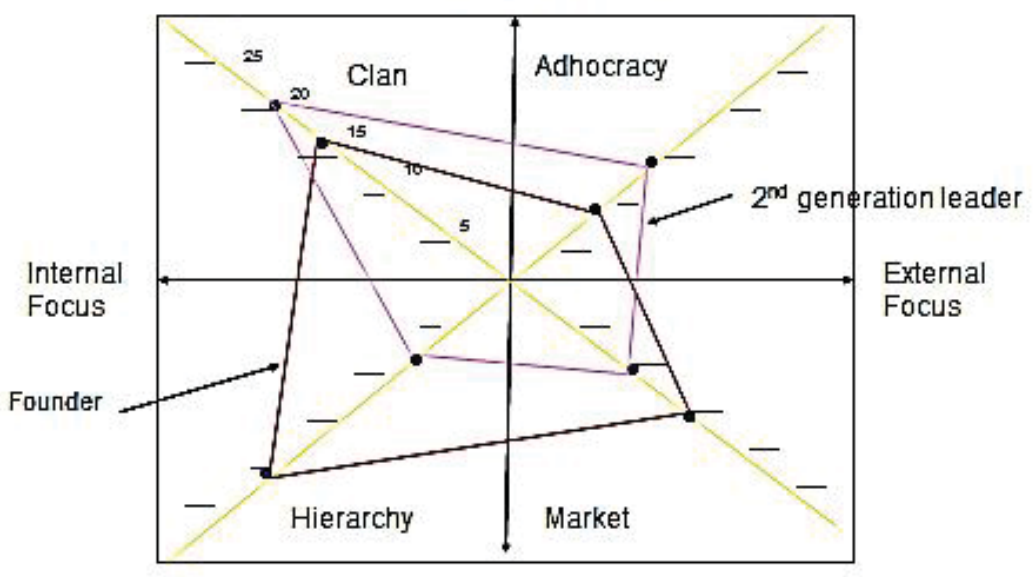

Stability and Control 
Figure 14 Dimension-wise Cultural profiles
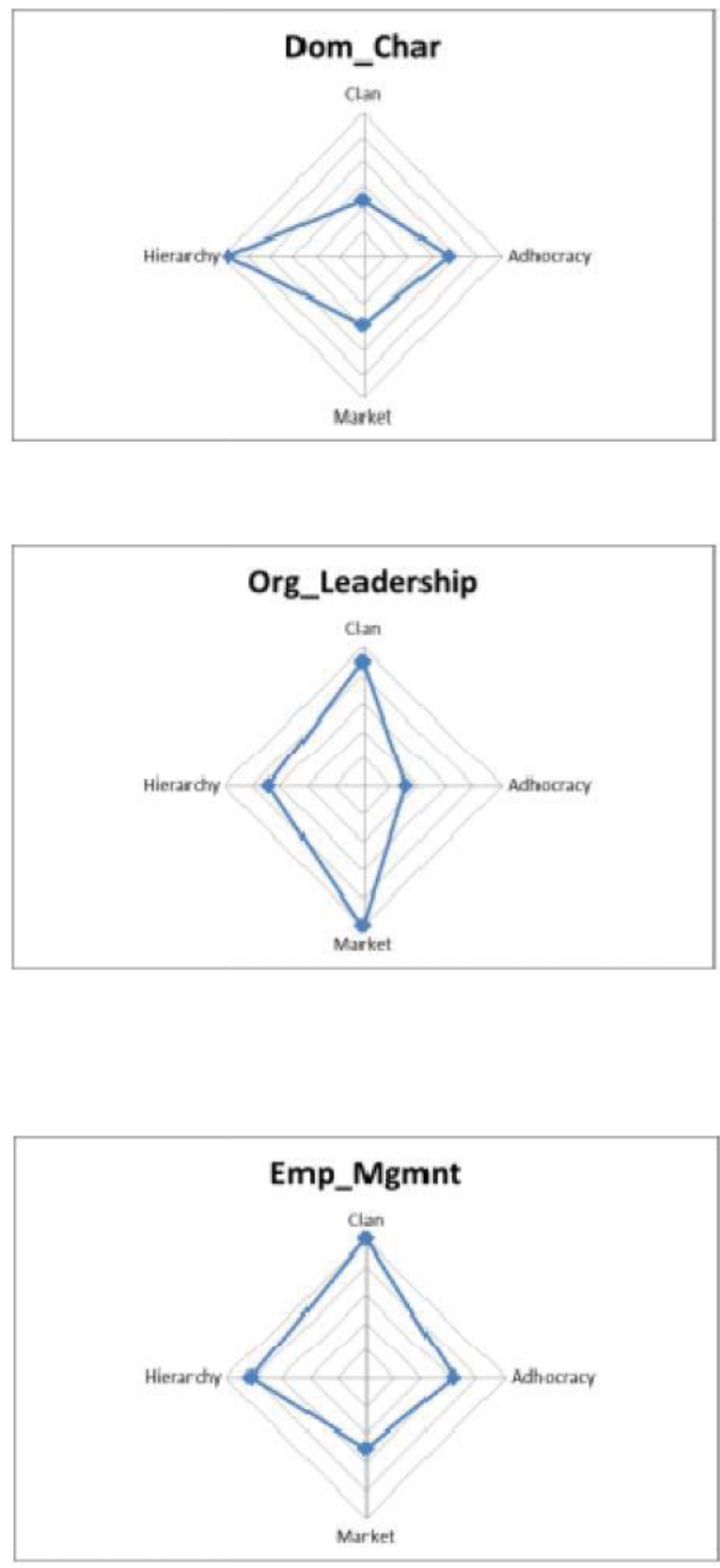

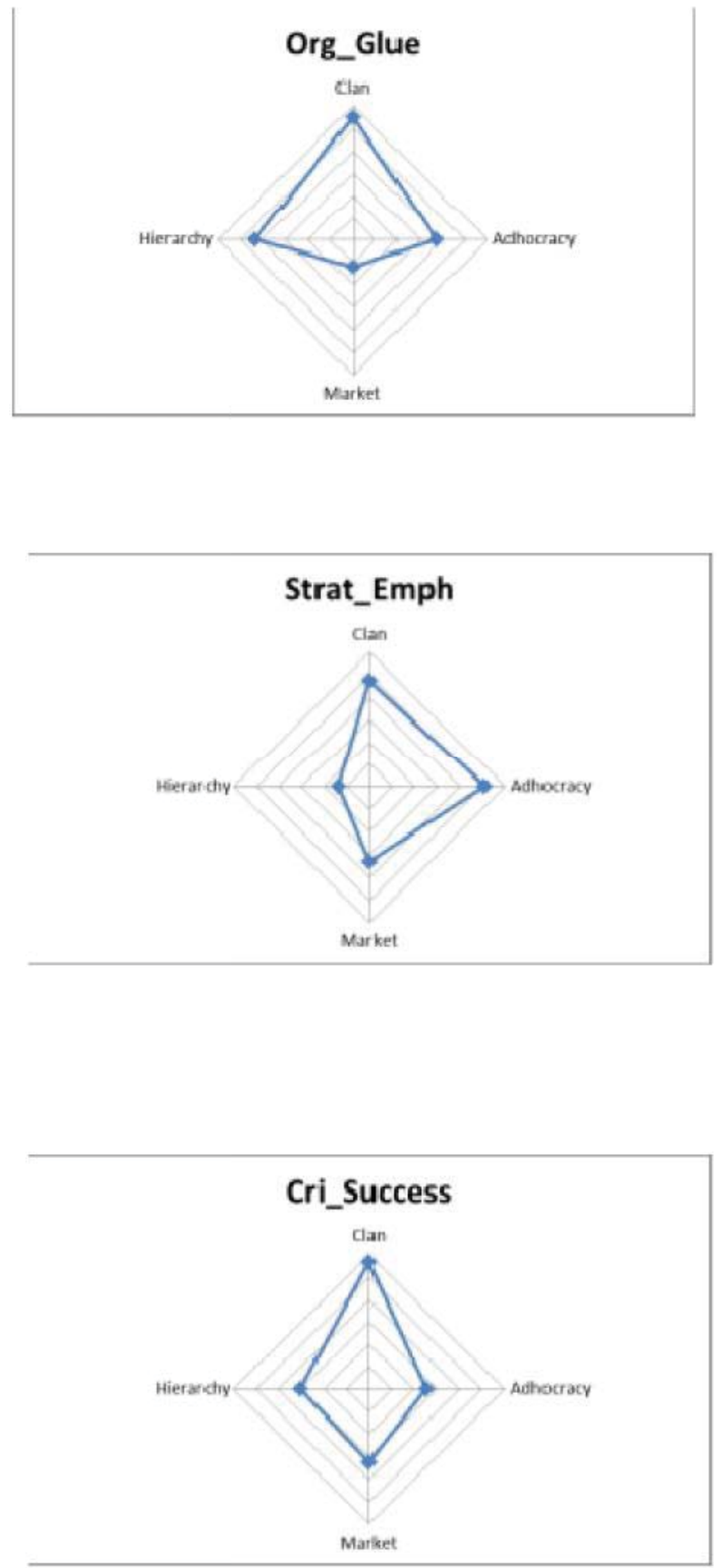
Figure 15 Comparative Cultural Profiles

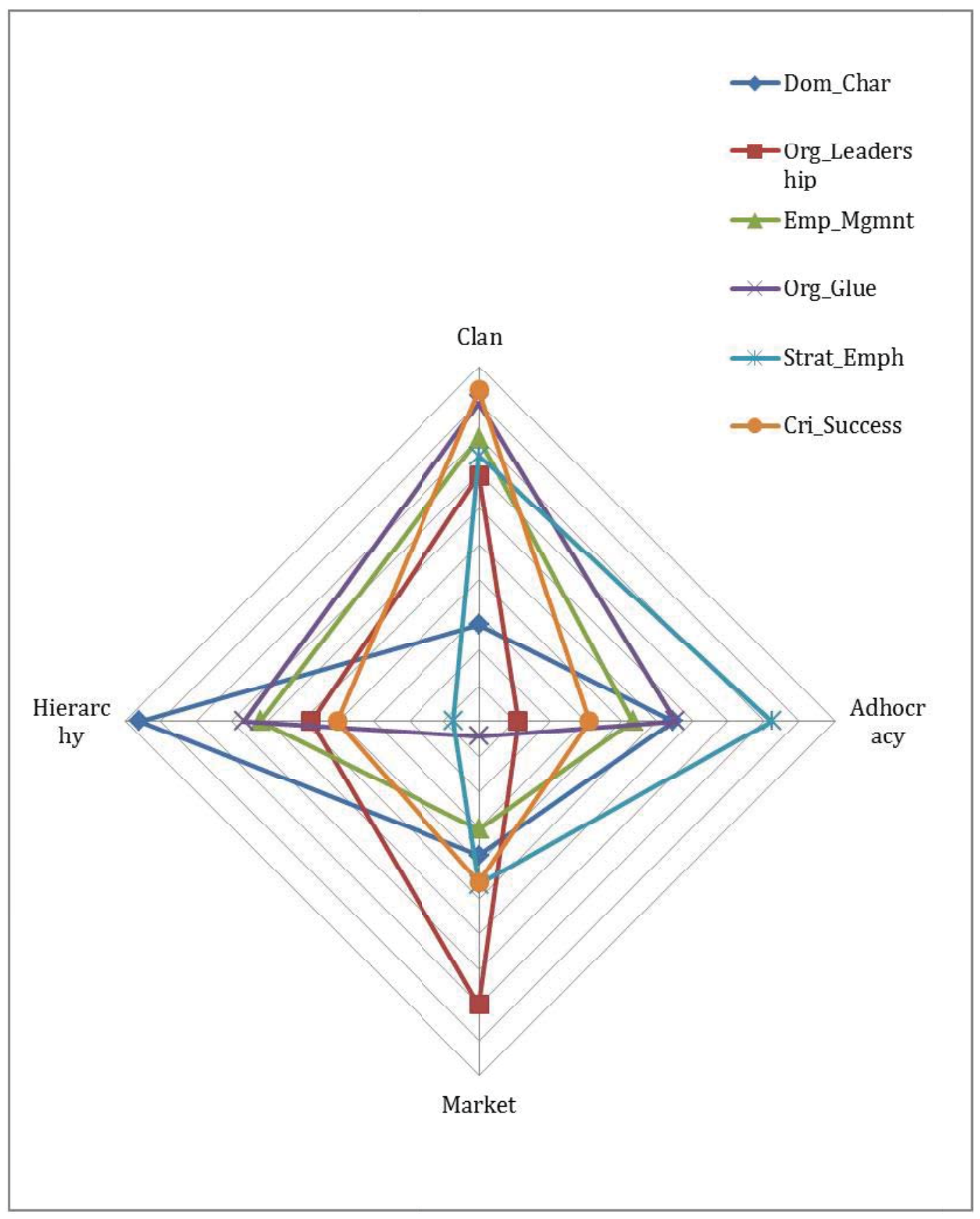




\subsection{Discussion}

The dominant overall cultural type is CLAN (Fig 12) and is significantly different from the Adhocracy and Market cultural types. The second most observed cultural profile is HIERARCHY which is also significantly different from the observed values of Adhocracy and Market cultural types but not so from the Clan cultural type. Given the informality of the firms and the family owned nature of business, it was expected that Clan culture would dominate, however, despite absence of formal rules and structures, it is noteworthy that there exists hierarchy in the informal sector firms. We looked for differences in cultural types across the six dimensions of the OCAI. Results are presented in Fig $14 \& 15$. The HIERACRCHY culture type was found to be the dominant characteristics of the CPD unit and also significantly different from all other culture types and this was a very interesting result for us showing that the so-called unorganized or informal sector firms may in fact be highly organized and structured.

The organizational leadership as observed by the OCAI is Market culture which is again significantly different from the other three culture types. This throws light on the entrepreneurial capabilities of the owner-leaders of the CPD unit. The leadership is operates the firm as economic market mechanism, and the major focus of markets is to conduct transactions with other constituencies to create competitive advantage. Profitability, bottom line results, secure customer bases are primary objectives of the firm and core values are competitiveness and productivity.

The organizational glue which holds the CPD unit together is Loyalty and Mutual Trust and is a highly significant result. The criteria of success appears to be again CLAN culture type which means that the organization defines success on the basis of the development of human resources, teamwork, employee commitment and concern for people.

a) CLAN * Age* Education. We observed some interesting patterns while analyzing for interaction effects. The perception of CLAN culture diminished with increase in age of employees. Those with graduate level education scored higher on the CLAN culture. However, interaction effect was not prominent as in either case, for low levels of education and for higher levels of education, the CLAN culture generally decreased with age. It is observed that only younger employees between the age group less than 45 years possess higher level of education up to graduation, those older than 45 years were educated not beyond grade 12 in schools.

b) CLAN * Age* Gender. This univariate analysis reveals that with the age of employees, the CLAN score increased in case of females while it decreased in case of males. Also, females are very few and only in the age category of less than 35 
years which shows that the diamond cluster may have been male dominated before but started recruiting females lately and also that they were well taken care of and hence the higher score on CLAN culture. It also contradicts with the scores of males counterparts with increase in age.

c) CLAN*Job Profile*Years of Experience in the CPD Unit.

The tests across Job Profile gave us insights about the experience of artisans (workers), supervisors and managers. While artisans scored relatively low on CLAN culture, managers scored higher while the supervisors who are responsible for directly supervising the artisans rated much lower on CLAN score. The high score on the graph is due to the administrators who perceive that the culture of their CPD unit is more CLAN type. With increasing length of stay in the firm, the CLAN score generally except for managers for whom it was like a V-shape. It is interesting to note that though some artisans had served for a longer duration in the CPD unit up to 40 years, the supervisors were those with relatively less experience in the firm, less than 20 years.

\subsection{Conclusion}

OCAI has been used in variety of industries but mostly in case of formal firms. However, at this time, organization-level data for firms operating in industries comprised of informal sector firms in the emerging markets is scarce. In this study we have attempted to bridge this knowledge gap by describing the culture of ISFs and also by developing empirical evidence and organizational level data using a well-accepted instrument from literature.

Based on the items on OCAI receiving the highest scores, the ISF is a very controlled and structured place. Formal procedures generally govern what people do (Hierarchy). The leadership is generally considered to exemplify a nononsense, aggressive, results-oriented focus (Market). The management style is characterized by teamwork, consensus, and participation (Clan). The glue that holds company together is loyalty and mutual trust. Commitment to this organization runs high (Clan). The company emphasizes human development. High trust, openness, and participation persist (Clan). The company defines success on the basis of the development of human resources, teamwork, employee commitment, and concern for people (Clan). Smaller units were not underpinned by the larger ones, and were happy to be operating from their native places, the location of their respective villages where they shared their life with the members of the family and kith and kin. 


\section{Chapter 8. Conclusions ${ }^{1}$}

\subsection{Introduction.}

As stated in chapter 1, our preliminary research objectives and their subobjectives were:

Objective \#1: To understand and describe the organizational culture of ISFs in the Indian Diamond Industry.

a. First describe the industry context of the diamond industry

b. Describe a firm within the diamond industry, and

c. Develop an organizational culture profile of the firm along cultural dimensions.

Objective \#2: To develop an initial theory of ISFs

We followed a grounded theory approach, where in research findings are grounded in data. We began with field visits to collect exploratory data about the context of the informal firms of the Indian diamond industry. In order to meet our objective 1a, in chapter 3 we present an overview of the Indian diamond industry and cultural aspects with respect to its history, evolution, different stakeholders, networking and transacting. To meet objective $1 \mathrm{~b}$, we have reported in chapter 4 , an in-depth case study of a 40 year old firm engaged in cutting and polishing of diamonds in India and sheds light on the values and beliefs held by its members. The case was written in the context of 2008 economic crisis and how the organization had sustained itself by surviving the recession. Following this preliminary collection of data, and as our research focus was narrowed down on the firm-level culture, we reverted to literature on organizational culture. Chapter 5 is a review of literature on organizational culture of firms. It develops a conceptual model to explain how organizational culture translates to organizational behavior and thus asserts as to why understanding of organizational culture of the ISFs helps us in understanding ISFs.

1. This chapter draws from chapters from chapters 1-7 and summarizes their findings. 
Drawing from real-world case study of the diamond unit (chapter 4) and the context of the recession of 2008, as well as the insights about organizational culture (chapter 5) we produced an article on sustainability of organizations which is a conceptual paper (chapter 6). The ideas in chapter 6 are a result of having observed the unit under study in chapter 4 . Through chapter 6 , we attempt to make a theoretical contribution about integrating sustainability with organizational culture, leadership and trust as moderators. Through chapter 7, we meet the objective 1c. This chapter produces results of an empirical investigation of organizational culture of the CPD of the case study in Chapter 4. We use the OCAI (organizational culture assessment instrument) to measure the salience of four cultural arche-types, i.e. Clan, Hierarchy, Market and Adhocracy. We study these arche-types with regards six dimensions of organizational leadership, management of employees, strategic emphasis, criteria of success and organizational glue.

Thus, in chapter 5, we established the importance of studying organizational culture (OC) to understand organizational life. In chapters 3, 4 and 7, we specifically addressed our first objective (\#1a; \#1b; and \#1c) to understand and describe organizational culture of the ISFs (informal Sector firms) of the Indian diamond industry. The findings of chapter 5 confirmed that a firm's industrial context has an important influence on the firm's culture, thus supporting our data collection of the industrial context as our first agenda item in objective 1a. In accordance with this objective, chapter 3 of the thesis describes the context of the Indian Diamond Industry and the emergence of informal sector firms within the industry. Next, to understand the firm level aspects (objective $1 \mathrm{~b}$ ); we studied the case-history of a firm, Venus, to describe a firm in the Indian diamond industry (chapter 4). Chapters 5 and 6 are conceptual chapters presenting our ideas on organizational culture and its importance in organizations. Following this description, in chapter 7, we conducted a survey and collected quantitative data to plot cultural profiles of this firm, using the survey instrument OCAI and reported results (objective \#1c).

We now provide a summary of conclusions below.

\subsection{Insights from the Study of ISFs in Indian Diamond Industry (Objective 1)}

The study of the informal sector firms in the diamond industry provides useful insights. The cultural survey provides us with organizational characteristics of a large CPD unit. Although we have chosen one large CPD firm as our focal case, we have visited dozens of small and medium sized ISFs, during the data collection phase. Based upon these observations, we believe that informal economy thrives 
on a culture which cultivates entrepreneurship and facilitates its growth while at the same time contributing significantly to the economy.

The analysis of the findings from the exploratory study of the Indian diamond industry and that of the case study of a large CPD unit leads to multiple significant findings. We found that informal sector firms are not just local firms but also have global reach. They acquire diamond rough from global sources, and supply the finished diamonds to the global diamond industry. These Informal Sector Firms, which have made it big on the global front, have flourished like a close-knit community.

Within this community large sized firms, like Venus, the firm described in the above case, lead this CPD community at the forefront. As the volume of their business increases, they pass on (sub-contract) business to others smaller firms within to the same community. However, this sub-contracting is not a formal process. There are no formal contracts or processes. Instead it relies on existing clan relationships where the leading firm passes on work to people that they already know and trust.

Despite little formal education, professionalism exists where verbal commitments are honored and met, and a high order of integrity is exhibited. It is, as many respondents remarked, a part of their societal culture. Our OCAI survey (chapter 7) showed the dominance of the "Clan" Culture quadrant in the CPD ISFs. The six dimensions associated with the clan culture show that the networking of IFs in the diamond industry IFs, works on a culture of loyalty, trust and mutual respect.

The people involved take pride in their work and in what they have achieved. A sense of belonging to the community is a big motivating factor. People try their best to be known and respected by others in the clan, by adhering to the norms of behavior established by their clan and culture. Values of simplicity, sincerity to work, diligence, loyalty and discipline were observed in all CPD firms in the industry, down the line from the large, to medium, and small sized CPD units.

We found that in the broader context of the Indian diamond industry, there is lack of formal systems like: documentation of the diamond packets exchanged or subcontracted: of the financial transactions between parties in the industry; or that of the recording of employee details or number of units worked on, etc. However, these firms made them feel proud of their ability to conduct a business of global dimensions based primarily on mutual trust within their community.

The community or clan feeling appeared so strong that the mere thought of being ousted from the group and the diamond business on account of not delivering on verbal commitments, or due to any symptoms of dishonesty, became a driver to 
behave within the societal and cultural norms. If any ISF was non-compliant with the cultural norms, it could not expect any help from the societal institutions in this informal sector. This makes the entrepreneur responsible for his actions. Across all sizes of the CPD units, we found that the unit owners were sensitive to the family concerns of their employees. This in turn helped employees to remain loyal and devoted to their work.

Another interesting observation, at least in the smaller units, was that after the workers and the artisans learned the art of cutting and polishing a diamond, they were likely to start their own CPD unit and employ others known to them through personal references. This finding is similar to observations with other clan-like cultures e.g. Prato (Kumar, van Dissel and Bielli, 1998) where an enterprise may spawn new enterprises with strong ties with these new firms, because these firms were started by people who were originally members of the parent firm. A culture of individual responsibility which goes together with the entrepreneurial spirit is demonstrated by these ISFs. This often drove the individuals to start their own CPD units. The ISFs have their organizational cultures more in tune with their societal cultures.

The respondents frequently remarked about the importance of culture; and how their "culture" made their businesses unique and successful. These remarks also confirm that the firm owners and their sub-contractors and employees were proud of the uniqueness and strength of their culture, and passionate about maintaining it. An enterprising spirit was present in all firms, large or small. Everyone understood the importance of what they were doing irrespective of the place they were operating in on the value chain. The large network of these thousands of ISFs was held together by a common goal of doing and improving the business of diamond cutting and polishing. They worked together by understanding and conforming to the informal systems that were traditionally in place.

Most unit owners mentioned that they had a dream of making Surat the world's largest diamond cutting and polishing center. They were able to achieve this goal. This achievement gave them a sense of fulfillment. At the same time, these individuals also contributed to their society by getting involved in social, religious and other human endeavors. The smaller units, as it seemed, were not overshadowed or underpinned by the larger ones. They were content to be operating from their native places, the locations of their respective villages where they shared their life with the members of the family, and kith and kin. However, the mention of the names of larger firms did evoke a sense of respect and their own determination to grow. 
Results from the OCAI cultural survey reveal some interesting facts (Table 5)

Table 5 The Cultural Profile of the ISF

\begin{tabular}{|c|c|c|c|c|}
\hline & Clan & Hierarchy & Market & Adhocracy \\
\hline Dominant Characteristics & & $45 \%$ & & \\
\hline Organizational leadership & & & $35 \%$ & \\
\hline Employee Management & $38 \%$ & & & \\
\hline Organizational Glue & $37 \%$ & & & \\
\hline Strategic emphases & $34 \%$ & & & \\
\hline Criteria of Success & $41 \%$ & & & \\
\hline
\end{tabular}

1. The percentages above reflect the maximum score (e.g. 37\%) for a cultural type (e.g. Clan) with respect to an organizational dimension (e.g. organizational glue)

It is important to note, that, with, a strong "clan" orientation, and the dimensions of company culture being characterized by loyalty, trust, teamwork, and consensus we were anticipating that the dominant culture orientation will be a "Clan" cultural archetype. However, the dominant cultural type was found to be "Hierarchy," and the leadership was rated as being one of "Market Type". The item with loyalty and mutual trust as the organizational glue had the highest rating. This data provides evidence that not only trust is a major factor holding together the ISFs but also provides interesting evidence that the ISFs are very structured and controlled places.

Moreover a market-orientation by the leadership shows that the leadership of these firms could be aggressive and results-oriented. The ISF cultural profile also emphasizes human development as a core strategy and defines their success based on concern for people and human resource development. Furthermore, their management style is characterized by teamwork and consensus. These findings can stimulate many studies on leadership, strategy, and governance of informal firms.

The finding that Hierarchy is the dominant characteristic of the IF is an interesting finding. However, within these firms, the hierarchy is not a typical bureaucratically prescribed hierarchy. It is a traditional clan type hierarchy where social relations, not bureaucratic prescription define the hierarchical structures. Clan relations define a person's place in the clan's hierarchy. This finding 
confirms that a clan structure includes hierarchy and systematic ways of organizing, except that unlike a formal organization, this hierarchy is based upon relationships and traditions. It is not bureaucratically prescribed. This second way of characterizing hierarchy, could be an important contribution to the Competing Values Framework (CVF) and to our understanding of governance mechanisms and ways of organizing.

Of the 24 items on the scale, six items were rated highest along the cultural dimensions of the OCAI. The overall profile in Chapter 7 suggests that a CLAN culture was dominant in the company. The organizational glue which kept people together in the absence of formal policies and structures was Mutual Trust and Loyalty. It was also evidenced that the management of employees emphasized fostering teamwork, consensus and participation. Surprisingly, despite an overall dominant Clan culture and the informality surrounding the diamond business in this industry, the Dominant Characteristics (one of the six elements in the OCAI survey) of the CPD unit were rated as Hierarchy. Leadership was rated as being no-nonsense, aggressive, and result-oriented. The Strategic emphasis was on promoting competitiveness and productivity.

Consolidating, we list here the six key observations about ISFs that were discovered by the OCAI survey we conducted.

1. The CPD-ISF was found to be a very controlled and structured place. Formal procedures generally governed what people do (Hierarchy).

2. The leadership was generally considered to exemplify a no-nonsense, aggressive, results-oriented focus (Market).

3. The management style was characterized by teamwork, consensus, and participation (Clan).

4. The glue that held the company together was loyalty and mutual trust. Commitment to this organization ran high (Clan).

5. The company emphasized human development. High levels of trust, openness, and participation continue to persist (Clan).

6. The company defined success on the basis of the development of human resources, teamwork, employee commitment, and concern for people (Clan).

7. We observe that while the overall cultural profile was "clan" dimensions dominated, there was also a strong sense of hierarchy. This suggests that "Hierarchy" and "Clan" are not orthogonal as implied by the word "competing" in CVF by Cameron and Quinn (1983). Instead, a strong sense of Hierarchy can co- 
exist in a clan culture, especially in traditional societies such as India. While the traditional culture creates a strong sense of clan-type behavior, it also includes a high level of reverence and deference to hierarchical authority to authority of higher or privileged positions in the social hierarchy. These seemingly contradictory observations suggest a modified interpretation for ISFs, of the Cameron and Quinn's Competing Values Framework. In this modified interpretation a strong sense of Hierarchy co-exists within a Clan behavior. Perhaps this is a characteristic of traditional Asia societies which are based on a strong sense of hierarchical deference to authority, however within a clan type behavior pattern. Thus we may need to modify the CVF with type-of-society (traditional Asian cultural vs. modern Western) being a moderating influence on the organization's cultural profile.

\subsection{Towards an Initial Theory of the Informal Firm ( Objective 2)}

We drew from the extant theories of the informal economy (appendix B) to identify the theories that describe or explain informal economy (sector) firms. From the extant literature, we identified four theories of the informal economy firms: the dualist approach, structuralist school, the legalist school and the neo-classical view. The meaning of informal sector (appendix A) and the meaning of informal economy (appendix C) were also referred for the purpose of objective 2 .

To develop an initial theory of ISFs, we first tested these theories against empirical findings from the Indian CPD firms, and then, further augmented them by the additional empirical findings from Chapters $4 \& 5$ and from the OCAI survey reported in chapter 7. Godfrey (2011), while focusing on the illicit-legal and bureaucratic vs. non-bureaucratic dimensions, proposed a four quadrant framework of the formal-informal economy (Fig 16).

This framework spurred an agenda for studying firms operating in both informal and formal economies. While, organizations in the formal economy (Quadrant I) have typically been studied exhaustively in management literature, organizations in Quadrant II and III are organizations, such as the Underworld, Italian Mafia, and terrorist organizations, that deal in illicit products or services; and are outside the scope of our study. We are dealing with organizations dealing primarily with legitimate products and processes. Thus we stay in the left-hand column of Figure 8.1 below. Informal and semi-formal firms in quadrant IV have received little attention by scholars. These organizations are subjects of this study. 
Product or Processes

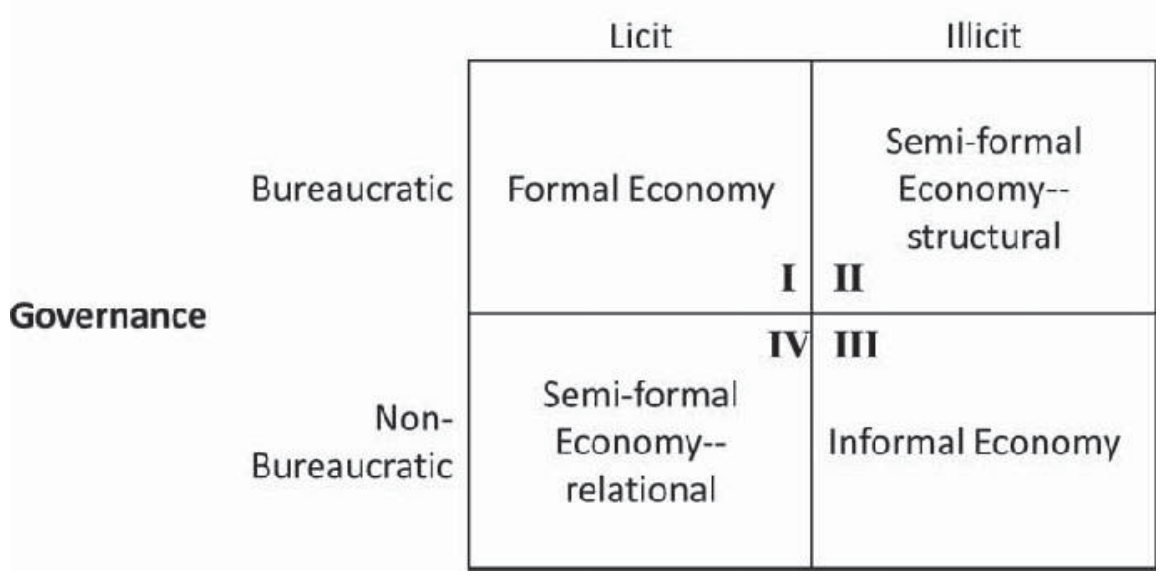

Firms in our study, in the Indian Diamond CPD industry, fall in the fourth quadrant (QUADRANT IV) of the above model, that is, semi-formal firms dealing with legal products and services but operating based on trust and relational governance. Most scholars, who have ventured to study such organizations, have been working to understand trust, and relational vs. transactional governance in these organizations (e.g. Barney \& Hansen, 1994; Dyer \& Singh, 1998; Lazzarini et al, 2004; Poppo \& Zenger, 2004). These researchers report that informally governed transactions, operating within legal activities and processes, provide firms with substantial advantages in times of uncertainty and change (Godfrey, 2011).

Based upon our empirical studies, we found that such firms, in absence of the formal procedures, are governed mainly by their organizational culture. As reported in our cultural assessment survey (OCAI) in chapter 7, trust and loyalty are influential elements in their cultural profiles. It is the existence of trust and loyalty relationships, and not formal procedures and organizational structures that keep these firms performing at high levels of reliability and efficiency.

The four initial theories in Appendix B, dualist, structural, legalist and neoclassical explain the existence of the IFs. Appendix A and B list the various meanings attributed to the informal economy and informal firms by various scholars. Drawing from the extant literature on informal economy, we can show that the ISFs in the Diamond Cutting and Polishing (CPD) industry in India meet the characteristics of IS criteria mentioned above. We learn that these theories and characteristics in are not mutually exclusive. Instead ISFs show most of these 
characteristics. Thus a comprehensive theory of ISFs is needed to integrate and include all these theories and characteristics.

The dualist school assumes that there is surplus labor that cannot be absorbed in the formal economy. It suggests that these two economies, formal and informal, are separate. The structuralist school considers the formal and informal economies as linked, and part of the overall economic structure. The structuralist view of interlinked formal and informal economies is also supported in our research because the informal firms are part of the global supply chains of the diamond industry which comprises of both formal (eg, the de Beers, BHP Billiton, Alrosa, and Rio Tinto) and informal firms (like the ones we see in Indian diamond industry).

Our study thus shows that the informal economies are not separate from the formal economy but an integral part of the overall economy. The idea that these firms are initiated mainly to utilize surplus labor (the dualist school) may be nominally correct from the economist's stance. This is because at the time of inception of this industry, which coincided with the timing of the independence from the British rule for India, the newly independent country was left by their erstwhile colonial masters with extreme poverty and joblessness. A large number of people were looking for gainful employment. So there is some truth in the economist's assertion that these firms provide employment to surplus labor.

But this "economic rationality" misses out on the more interesting social and behavioral genesis of the formation of these firms (Dan Ariely, 2012). From a behavioral perspective, the actors who initiated the industry and laid the initial foundations were enterprising individuals, or entrepreneurs, not just working-fora-wage employees or labor. Finally unleashed from their colonial legacy, these entrepreneurial individuals eventually organized themselves into firms and later into a network of firms based on mutual trust and loyalty.

The legalist school of thought suggests that the IFs try to circumvent the legal framework of economy to avoid taxation and bureaucracy of the formal systems. This theoretical observation also may only be partially true. The avoidance of legal systems is not entirely intentional. Often, in the early stages of their life, these small firms are unaware of the legal systems. But as they grow in size, as the case study of Venus shows, they adopt the legal frameworks and comply with the current regulations.

Our proposition here is that firms are basically governed by the values and the culture that is formed at the time of inception. Even as these firms grow larger, and become compliant with the formal economy regulations, their relatively stable, 
basic assumptions, values and beliefs that is, their organizational culture (Stinchcombe, 1965; Johnson, 2007), continue to give a unique character to these ISFs. The levels of formality-informality for different organizational processes structures, and governance could be just a part of firm's culture that has pragmatically evolved based on the social norms, and what works or does not work.

While the motives for different organizational actions (behaviors) are sustainability and profitability of firms, the compliance with legal regulations are not a conscious strategy for existence and survival. Further in the overall national context and governance, societal benefits supersede the compliance -non-compliance behaviors. This may not suggest that unintentional non-compliance at the early stages of their life is the optimal strategy for a firm. On the other hand disregard or ignorance of the regulations may explain the nimbleness of these firms and thus helpful to understanding why the IFs continue to exist the way they do.

The neo-classical theory considers IFs as a response to the economic environment. It highlights the dynamic and entrepreneurial spirit of IFs. It further suggests that IFs create markets, and transform the legal, social, economic institutions. Earlier we had suggested that IFs arise due to the long suppressed entrepreneurial aspirations of the founders of these firms.

As found in our study, in the Indian diamond industry did emerge as a response to the economic and political environment and the IFs have been able to provide jobs and livelihoods to millions of people and also helped in contributing to the foreign exchange reserves of the country. But at the same time they arose because of their unique cultural make-up. Both conditions, their cultural heritage, as well as the economic-political conditions, were necessary for the IF's inception and growth.

This could be the reason that, although the government ministry controlling the industry tracks data only at the country level (the import of rough diamonds and export of polished diamonds); it does not interfere with a system which is working so well to provide a thriving industry, even if it is informal.

\section{3a Our View of the Informal Firm}

It is important to note here is that the ISFs are not just economic arrangements, they are also social organizations, which are born, and which grow just like any other formal social organization. So, for purposes of theory construction (and so that we can borrow existing theory, vocabulary and concepts from organizational theory), we need to first acknowledge that they are organizations (firms) that have 
unfamiliar but still, organized ways of doing business. We draw from both the economic and behavioral schools of thought to develop a new initial theory of the IF.

Our study of the diamond industry does not suggest that the formal and informal economies are separate (the dualist school) but that they are linked with each other (consistent with the structuralist school). However, we also look at the contextual conditions at the time when the industry was incepted in India. The origins of the Indian CPD firms are just after Indian independence, in 1950s. This coincides with the timing of the Independence of the state of India from the British colonial rule in 1947. In the post-colonial rule, a new country was left bankrupt with extreme poverty and joblessness. What added to this plight was the large population in India. Economists may call this as surplus labor; another perspective is that people were trying to find income and work to support their families, their kith and kin. Some communities and societies which were more enterprising went outside their national boundaries to search for work. The diamond trade (the CPD firms) did so.

The state of Gujarat, where the diamond industry is concentrated in India, has a long coast line and was traditionally the point of international trade and exchange in India. Perhaps this ALSO assisted in the movement of some entrepreneurs to places like Antwerp. They took a share of polishing the smaller rough diamonds from the relatively formal firms, back to India, and began to supply finished diamonds to the Antwerp diamond merchants.

As a part of their supply-chains, the Indian entrepreneurs brought some work back to their native places so that they could have better control over their quality, and to provide work for more. The business acumen, technology upgrades, diligence, the community support, and most importantly mutual trust and loyalty relationships laid the foundation of an enterprising culture which was unique, and hard to emulate.

Barney (1986) suggests that an organizational culture that is rare, invaluable and inimitable is a source of competitive advantage. The IFs of the Indian diamond industry then, have organized themselves through the mechanism of their culture which becomes a source of their competitive advantage and helped them capture 95 percent of the global business of cutting and polishing of diamonds over the next 50-60 years. This is why we have focused on studying organizational culture of these firms during our research study.

Thus, we can say that the formation and growth of ISFs is a result of combination of several factors that include: 1. Individuals and their motivations; 2 . The existing 
economic environment; 3. The societal environment. 4. The national context (political environment). 5. The Industry Environment. Accordingly, based on these several contextual factors, the actors of the ISFs sub-consciously chose and install processes, forms of governance, and structures for their firms that yield best results for their firm. The motivations for the formation of these firms were not, as suggested by the legalist school, compliance or non-compliance with the legal framework. The motivations were social: to provide enough for the families and friends of those engaged in this business and the communities they were a part of.

We call these firms, Informal Firms because they do not look like the formal firms that we normally study in business schools. Nonetheless, as evidenced in our results, the dominant characteristic of an ISF is hierarchy, which may be different from a bureaucratic hierarchy, because it is not based on formal systems of governance.

Therefore, while our theory of the Informal sector firms draws from concepts from the theories of the informal economy, it also includes the organizational concepts of trust, leadership, organizational glue, strategic emphasis and as related to their dominant cultural types. We have reproduced in the section 8.2, the Table 5, which describes how different elements of the organizational culture look like in our chosen competing values framework (arche-types of clan, adhocracy, market and hierarchy). The data in this table above shows the percentage of respondents which perceived a specific cultural arche-type to be dominant in the firm as a result of our survey. In Fig 17, we present a framework which suggests that the ISF culture develops as a result of the influence of the social, economic, political and industry environments and the entrepreneurs themselves who lead or are a part of the ISF.

The processes of the ISF may then be both formal and informal to ensure that the firm continues to perform within the constraints of its environment. The existence of ISFs, as suggested by the legalist school, may not be primarily for the purpose of saving tax or the avoiding regulations or to circumvent the formal economy.

The ISFs generally start very small. Often they may not fall under the regulatory compliance umbrella. Being only semi-literate the players are often unaware of the regulations. However, as they grow in size, these ISFs may begin to formalize some of their processes. As our data shows, the leaders are result oriented and the firms are structured and well-organized. As compliance with regulations ensures their longer term survival, they begin to implement and use regulation-compliant processes and governance. 
Figure 17 Our View of the Informal Firm

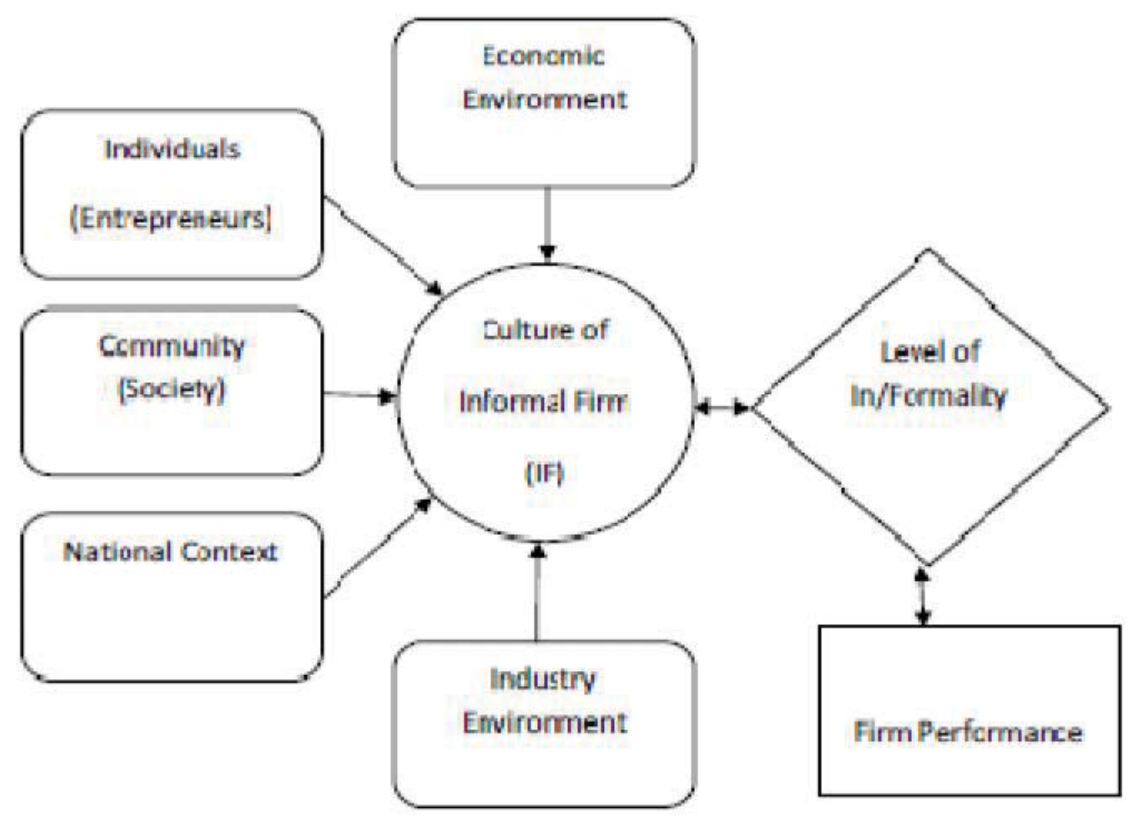

We also propose here a definitional clarity about the Informal firm. The level of the informality, we believe is not a dichotomous variable, a firm must be assessed along different dimensions for the level of informality (Table 6) The firm is a system, a set of components that are organized (components are related to one another) to serve the system's purpose. A system consists of its structure (the components of the system and relationships between them); its processes; its boundaries, and its purpose. 
Table 6 Levels of Formality / Informality

\begin{tabular}{|l|l|l|l|l|}
\hline $\begin{array}{l}\text { Components/Level } \\
\text { of Formality }\end{array}$ & $\begin{array}{l}\text { Extremely } \\
\text { Informal(1) } \\
\text { (Adhocracy) }\end{array}$ & $\begin{array}{l}\text { Informal (2) } \\
\text { (CLAN) }\end{array}$ & $\begin{array}{l}\text { Formal (3) } \\
\text { (Market) }\end{array}$ & $\begin{array}{l}\text { Extremely } \\
\text { Formal (4) } \\
\text { (Hierarchy) }\end{array}$ \\
\hline Structure & & & & \\
\hline Processes & & & & \\
\hline Governance & & & & \\
\hline Boundaries & & & & \\
\hline Purposes & & & & \\
\hline
\end{tabular}

Formality vs. informality is a continuum, not a dichotomy. Informality can be defined as five aspects: informal vs. formal structures; informal vs. formal processes; informal vs. formal governance; informal vs. formal boundaries; and informal vs. formal purposes. The informal firms themselves seem to have fluid structures, processes and boundaries. Moreover within an informal sector, like that of the Indian diamond industry, the structure of the firms within the sector is relatively informal; the inter-firm processes are typically informal; the boundaries of the sector -- except for the fact that all people in the sector belong to the same community (clan) are informal; and the purposes of the sector/community/clan are informal.

The firms can occupy different cells with regard to the five components mentioned in the Table 6. Further these levels of formality/informality can be perceived differently by the insiders/outsiders of the firm.

The OCAI helps us to classify the perceptions of the members of the firm as insiders' view. The insiders' view (Table 5) rates the dominant characteristics as "Hierarchy" which by definition would likely be extremely formal, at least in terms of the structures and processes. The leadership is characterized by Market culture, so we can mark it along the formal cell of the Table 6 . Both these observations would go against the outsider's view which generally rates the firms of the Indian diamond industry as informal or unorganized.

The organizational glue, the criteria of success, management of employees and strategic emphases are reported as being CLAN-type in our survey. This would suggest that the purposes and the boundaries of the firm in our study are informal. 
We can summarize our findings as follows. IFs are an important link in the structure of global supply chains and are so, due to their unique organizing capabilities governed by their organizational culture of trust and loyalty; emphasizing human development, but at the same time being results oriented and structured.

The IFs provide livelihoods to the local people, as well as revenue to the governments; hence they may not be forced to comply with the existing regulations of the institutions. In this context, we can agree with the neo-classical view that IFs may contribute to transforming the legal, social and economic institutions where they operate.

The core features, core values, and the organizational culture of IFs are shaped by the conditions in which the IFs were founded. They are likely to be different from those of a developed economy MNE or firms of the organized corporate sector. Moreover, organizations, while being created, are shaped by their environments (Stinchcombe 1965). These historically determined cultural elements can stay with the organizations "for decades or even centuries as fundamental features of the organization" (Johnson, 2007). The organizational imprinting theory (Stinchcombe, 1965) recognizes these influences on a firm. In the absence of documented mechanisms, IFs are driven by their historically driven values, as manifested in their organizational culture. This culture is stable over time and sustains these culturally driven organizational forms.

\subsection{Contributions of the Study}

That these unorganized, globally-dispersed companies appear to gel or 'fit' into a more 'organized' framework, in the value creation chain challenges our current thinking on organizing and managing for competitive advantage. Despite their global scope, neither theorists nor empiricists have studied these unorganized organizational forms in the diamond industry, nor charted their best practices. This dissertation is a first such attempt to study these new organizational forms, as represented by the ISFs of the diamond industry cluster in India.

\section{4 a. Contribution to Practice}

Firms dealing with ISFs need to understand that these so-called unorganized sector IFs may in fact be highly organized. It should be recognized that informal sector firms are not just local firms but also have global reach. Dealing with these firms as unorganized, chaotic entities could be a costly operating mistake. 
These firms could not have built a global business without a highly sophisticated form of organization. However the basis of this organization is not formally defined and prescribed procedures, structures, and governance. Instead the firms dealing with these ISFs need to understand trust, relationships, and loyalty as the basis of organization. The Informal Sector Firms which have made it big on the global front have flourished like a close-knit community of entrepreneurs. Despite little formal education, professionalism exists where verbal commitments are honored and met, and a high order of integrity is exhibited, and it is all a part of their societal culture.

The networking of IFs as observed in the diamond industry, works on a culture of trust and mutual respect. The people involved take pride in their work and in what they have achieved. A sense of belonging to the community is a big motivating factor and people try their best to be known and respected by adhering to the norms as established by their culture.

\section{4 b Contribution to Scholarship}

This study sheds light on the organizational culture of the informal firm. It helps us understand the leadership styles, strategic emphases and organizational glue in the informal sector firm. Overall, this study contributes an understanding of the organizational culture, cognitive categories of organizational forms, and of other organizational dimensions of an ISF and thus addresses an important research gap.

Another contribution of this study is that, we have translated, validated and tested an existing instrument which has typically been used in developed countries and formal sector firms in a new context in a firm in a relatively unsophisticated emerging economy. By doing so, we have contributed to the growing literature on Emerging Markets, Informal Economy, Organizational Forms, Indian Diamond Industry and of course the informal economy firms.

\subsection{Limitations of the Study}

We acknowledge that the informal economy and the informal sector firms (ISF) are a widespread phenomenon across space (industries, regions and countries) and time. Therefore, it is premature to generalize a theory of the ISFs. Having said that, we know very little about the organization of the IF and of the values (the organizational culture) that govern their organization. Therefore, this initial study in this new area of research provides a starting point. Nonetheless, it is only a single country, single industry study, and its findings are limited to a particular context. We have taken an example of an industry that is globally successful. 
Our original intention was to highlight the organizational culture of the globally successful ISFs in the Indian diamond industry. However, this also becomes a limitation for generalizing. Finally, all data is based on perceptions. This is usually a criticism for most behavioral studies but is also a widely accepted method of data collection, particularly for new research frontiers like the one of informal economy.

\subsection{Implications of the Study and Directions for Future Research}

This preliminary study on the multifaceted diamond industry opens up whole new directions for future research. Our study suggests that industries and firms of the Indian CPD informal sector possess a close knit community culture which helps them to develop, grow, compete and also to survive the difficult times. This may or may not be case for other informal sector firms. Given the cultural and social diversity of firms, the informal sector is also likely to be differentiated and heterogeneous. Therefore these results, we do not claim can be generalized. Nevertheless, this preliminary step in analyzing globally distributed work here is to recognize the entrepreneurial firms in the informal sector as an existing and potentially powerful driver of the economy.

The informal entrepreneurial firms we studied are likely to play a significant role in international business. The countries with more of such IFs may draw higher FDI as they provide for the structural support to the firms which have moved up from the lower band to the upper band as well as a cost structure to the industries they are a part of. While many in the corporate business and the world economy in general continue to struggle with the aftermath of the recession, the IFs we studied have shown sufficient resilience to bounce back.

This study also shows that informal sector firms are growing large and that more such firms can emerge from anywhere across the world in any industry, they have certain advantages of both local and global knowledge. As the world shrinks, there is space for both the formal and informal sector firms to become global players.

We believe this study will have significant implications for theory as it explores new forms of organizing. There are several unexplored dimensions a large scope to learn from their innovative operations and value systems. Study of the people management practices is likely to add to the body of literature on human resource management. Clearly there are implications for practice for SMEs in all developing countries. 


\section{Bibliography}

Acquaah, M. 2007. Managerial social capital, strategic orientation and performance. Strategic Management Journal, 28(12), 1235-1255.

Adiga, A. 2004. Uncommon Brilliance. Time Asia Magazine May-June 2004.

Alexander, J.C. 1990. Analytic debates: Understanding the relative autonomy of culture. In Alexander J.C. \& Seidman, S. (Eds). Culture and Society: Contemporary Debates: 1-27. Cambridge: Cambridge University Press.

Apressyan, R.G.1997. Business ethics in Russia. Journal of Business Ethics. 16(14), 1561-1570.

Alvesson, M. 2002. Understanding Organizational Culture. Sage.

Argyris, C.1957. Personality and Organization: The Conflict between System and the Individual. Amsterdam: Harper.

Argyris, C. 1964. Integrating the Individual and the Organization. Wiley, NY

Ariely, Dan. 2012. Predictably Irrational: The Hidden Forces that Shape Our Decisions. HarperCollins

Arogyaswamy, B. \& Byles, C. 1987. Organizational culture: internal and external fits. Journal of Management, Vol. 13, 647-59.

Asea, P.K. 1996. “The Informal Sector: Baby or Bath Water?” Carnegie-Rochester Conference Series on Public Policy, Vol. 45, pp. 163-71.

Ashforth, B. 1985. Climate formation: Issues and extensions. Academy of Management Review, Vol. 10, 837-847.

Asian Development Bank. 2007, Key Indicators of Developing Asia and Pacific Countries. Manila

Asian Development Bank. 2007. Measuring the Informal Sector. Regional Technical Assistance Report. Project Number 41144

Bain \& Company Report. 2013. The Global Diamond Report 2013

Banerjee, A. 2014. Home To The Stocks. The Gujarati zeal for business will provide the national blueprint for economic drive. http://www.outlookindia.com/article/Home-To-The-Stocks/290792 June 2, 2014

Bangasser, P E. 2000. ILO and the Informal Sector: An Institutional History. ILO, 2000

Barger, Bonita B. 2007. Culture an overused term and international joint ventures. Journal of Organizational Culture, Communication and Conflict. Vol. 11(2), 1.

Barley, S. 1986. Technology as an occasion for structuring: Observations on CT scanners and the social order of radiology departments. Administrative Science Quarterly, Vol. 31, 78- 108. Barnard, C.I. 1938. The functions of the executive. Cambridge, MA: Harvard University Press. 
Barney, J. 1986. Organizational culture: can it be a source of competitive advantage? Academy of Management Review, Vol. 11 No.3, pp.656-65

Barney, J.B., \& Hansen, M.H. 1994. Trustworthiness as a source of competitive advantage. Strategic Management Journal, 15, S175-190.

Baron, R. M., \& Kenny, D. A. 1986. The moderator-mediator variable distinction in social psychological research: Conceptual, strategic, and statistical considerations. Journal of Personality and Social Psychology, 51, 1173-1182.

Bartlett, C.A. \& Ghoshal, S. 1990. Managing across borders: The transnational solution. Boston: Harvard Business School Press.

Bass, B. M. 1985. Leadership and performance beyond expectations. New York: Free Press.

Bebbington, A., Lewis, D., Batterbury, S., Olson, E. \& Siddiqi, M. S. 2007. Of texts and practices: Empowerment and organizational cultures in world bank-funded rural development programmes. Journal of Development Studies, Vol. 43(4), 597-621.

Bettinger, C. 1989. Use corporate culture to trigger high performance. Journal of Business Strategy, Vol. 10 (2), 38-42.

Blanchard, O.J.1997. The Economics of Post-Communist Transition. Oxford University Press.

Bloor, G. \& Dawson, P. 1994. Understanding professional culture in organizational context. Organization Studies. Vol. 15(2), 275.

Boisot, M., \& Child, J.1996. From fiefs to clans and network capitalism: Explaining China's emerging economic order. Administrative Science Quarterly, 41(4), 600-628.

Bourantas, D., Anagnostelis, J., Mantes, Y. \& Kefalas, A.G. (1990). Culture gap in Greek management. Organization Studies, Vol. 11(2), 261-283.

Bright, K. \& Cooper, C. L. 1993. Organizational culture and the management of quality. Journal of Managerial Psychology, Vol. 8(6), 21

Brown, A. 1992. Organizational culture: The key to effective leadership and organizational development. Leadership and Organization Development Journal, Vol. 13(2), 3-6.

Brutan G. D., Ireland, R.D. \& Ketchen Jr D.J. 2012. Toward a Research Agenda on the Informal Economy. Academy of Management Perspectives.amp.2012.0079

Bryson J. 2008. Dominant, emergent, and residual culture: the dynamics of organizational change. Journal of Organizational Change Management, Vol. 21(6), 743-757.

Buch K. \& David K. W. 2001. Analyzing and realigning organizational culture. Leadership and Organizational Development Journal, Vol. 22(1), 40- 44.

Burns, J. M.1978. Leadership. New York: Harper \& Row. 
Cameron and Quinn.1999. Diagnosing and Changing Organizational Culture: Based on the Competing Values Framework. Addison-Wesley Publishing Company, Inc.

Cameron, K. S., \& Freeman, S. J. 1991. Cultural congruence, strength, and type: Relationships to effectiveness. Re-search in Organizational Change and Development. 5: 23-58

Campbell, John P., David A. Bownas, Norman G. Peterson, and Marvin D. Dunnette. 1974. The Measurement of Organizational Effectiveness: A Review of Relevant Research and Opinion. NPRDC TR 75-1, Navy Personnel Research and Development Center, San Diego, CA.

Castells, M. \& Portes, A. 1989. World Underneath: The Origins, Dynamics, and Effects of the Informal Economy. In Alejandro Portes, Manuel Castells and Lauren A. Benton, Eds., The Informal Economy: Studies in Advanced and Less Advanced Developed Countries. Baltimore: Johns Hopkins University Press.

Chakraborty, S.K. 1997. Business ethics in India. Journal of Business Ethics, 16(14), 1529-1538.

Chalofsky N. 2008. Community. Organization Development Journal. Chesterland: Vol. 26(1),11.

Chan Yuen H, Taylor Robert R, Markham Scott .2008. The Role of Subordinates' Trust in a Social Exchange-driven Psychological Empowerment Process. Journal of Managerial Issues, 20(4), 444-467,421-422.

Chandra, Y., Styles, C., \& Wilkinson, I. 2009. The recognition of first time international entrepreneurial opportunities: Evidence from firms in knowledge-based industries. International Marketing Review. 26(1): 30-61.

Charmaz, K. 2003. Objectivist and Constructivist methods. In Strategies of Qualitative Enquiry. Norman K. Denzin, Yvonna S. Lincoln. $2^{\text {nd }}$ ed

Charmaz, K. 2000. Grounded theory: Objectivist and constructivist methods. In N. Denzin \& Y. Lincoln (Eds.), Handbook of qualitative research (2nd ed., pp. 509-535). Thousand Oaks, CA: Sage.

Charmaz, K. 2001. Qualitative interviewing and grounded theory analysis. In J. Gubrium \& J. Holstein (Eds.), Handbook of interview research: Context and method (pp. 675-694). Thousand Oaks, CA: Sage.

Charmes, J. 2000. The Contribution of Informal Sector to GDP in Developing Countries: Assessment, Estimates, Methods, Orientations for the Future. Presented at the 4th Meeting of the Delhi Group on Informal Sector Statistics; Geneva: 28-30 August 2000

Chen, M., Vanek J. and Marilyn C. 2004. Mainstreaming Informal Employment and Gender in Poverty Reduction: A Handbook for Policy-makers and Other Stakeholders. London: Commonwealth Secretariat.

CITEE. 2009. Informal Sector: Definitions and its Implications for Growth. Centre for International Trade, Economics \& Environment

Coase, Ronald H. 1937. "The Nature of the Firm, " Economica N.S., 4: 386-405 
Costigan Robert D, Selim S Ilter, J Jason Berman. 1998. A Multi-dimensional study of trust in organizations. Journal of Managerial Issues, 10(3), 303-317.

Creswell, J.W. 2011. Research Design: Qualitative, Quantitative, and Mixed Methods Approaches

Crick, D., \& Spence, M. 2005. The internationalization of "high performing" UK high-tech SMEs: A study of planned and unplanned strategies. International Business Review, 14(2): 167-185.

Critchley, B. 1993. Managing organizational culture - is it just an illusion? Leadership and Organization Development Journal, Vol. 14(1)

Croft, A.C. 1990. The case of the missing corporate culture. Public Relations Quarterly, Vol.35(1), 17-20.

Darling John R, Victor L Heller. 2009. Organization Development in an Era of Socioeconomic Change: A Focus on The Key to Successful Management Leadership. Organization Development Journal, 27(2), 9-26.

Daymon, C. 2000. Culture formation in a new television station: A multi-perspective analysis. British Journal of Management, Vol. 11(2), 121-135

de Soto, Hernando. 1989. The Other Path: The Invisible Revolution in the Third World. HarperCollins. ISBN 0060160209

de Soto, Hernando.2000.The Mystery of Capital: Why Capitalism Triumphs in the West and Fails Everywhere Else. Basic Books. ISBN 0465016146

Deal, T., \& Kennedy, A. A. 1982. Corporate culture: Rites and rituals of organizational life. Reading, MA: Addison- Wesley.

DeCastro, J., \&. Bruton, G. D. 2012. Understanding the role of social ties in informal firm success in emerging economies. Presented at Academy of Management Conference, Boston

Denison D.,Colleen L.,Ward J.L. 2004. Culture in Family-Owned Enterprises: Recognizing and Leveraging Unique Strengths. Family Business Review. Vol 17,1.

Denison, D. R. 1996. What IS the difference between organizational culture and organizational climate? A native's point of view on a decade of paradigm wars. Academy of Management Review, Vol. 21, 619-654.

Denison, D. R. 1990. Corporate culture and organizational effectiveness. New York: John Wiley \& Sons.

Denzin N K and Lincoln Y. S. (eds). 1994. Introduction: Entering the field of qualitative research. In N. K. Denzin N K \& Y. S. Lincoln (eds), Handbook of Qualitative Research, pp. 1-17. London: Sage. 
Detert J.R., Roger G S., John J M. 2000. A framework for linking culture and improvement initiatives in organizations. Academy of Management. The Academy of Management Review. 25(4), 850-863

Detert J.R., Schroeder R.G. \& Mauriel J.J. 2000. A framework for linking culture and improvement initiatives in organizations. Academy of Management Review, 25(4), 850-863.

Dong I Jung, Bruce J Avolio. 1999. Effects of leadership style and followers' cultural orientation on performance in group and individual task conditions. Academy of Management Journal. 42(2), 208-218

Driver, M. 2003.Diversity and learning in groups. The Learning Organization., Vol. 10 pp.149-66.

Dyer, J.H., \& Singh, H. 1998. The relational view: Cooperative strategy and sources of interorganizational competitive advantage. Academy of Management Review. 23, 660-679.

Dyer, W. G. Jr. 1985. The cycle of cultural evolution in organizations. In R. H. Kilmann, M. J.Saxton, \& R. Serpa (Eds.), Gaining Control of the Corporate Culture, 200-229. San Francisco: Jossey-Bass.

E.S. Williams, K.V. Rondeau, L.H. Francescutti. 2007. Impact of culture on commitment, satisfaction, and extra-role behaviors among Canadian ER physicians. Leadership in Health Services, 20(3), 147-158.

Edmondson, A.C. 1999. "Psychological safety and learning behavior in work teams", Administrative Science Quarterly, Vol. 44, pp. 350-83.

Eisenhardt K. M. 1989. Building Theories from Case Study. The Academy of Management Review, $14(4): 532-550$

Eli Sopow. 2006. The impact of culture and climate on change programs. Strategic Communication Management, 10(6), 14-17.

Ellis, P. D. 2000. Social ties and foreign market entry. Journal of International Business Studies, 31(3): 443-469.

Ellis. 2011. Social ties and international entrepreneurship: Opportunities and constraints affecting firm internationalization. Journal of International Business Studies. 42, 99-127

Farrell, D. 2004. The Hidden Dangers of the Informal Economy. McKinsey Quarterly 2004(3): 2637

Fitzgerald, T.H. 1988. Can change in organizational culture really be managed? Organizational Dynamics, Vol. 17, 4-15.

Fleet, D., Van, R. \& Griffin W. 2006. Dysfunctional organization culture: The role of leadership in motivating dysfunctional work behaviors. Journal of Managerial Psychology. Vol 21(8), 698-708. 
Florencia M., David W Palmer, Patricia C. Borstorff. 2007. An exploratory analysis of the relationship between organizational culture, regional culture, causal ambiguity and competitive advantage in an international setting. Journal of International Business Research, 6(1), 61-75.

Gaitonde, Aruna. 2013. Indian diamond cutting and polishing sector. Rough and Polished. http://www.rough-polished.com/en/analytics/77889.html

Geertz, C.1973. The interpretation of cultures. New York: Basic Books.

Giacomo Becattini.1991.Italian Industrial Districts: Problems and Perspectives. International Studies of Management and Organization Vol 21 No 1 pp 83-90

Gladwin, T.N., Kennelly, J.J., Krause, T. 1995. Shifting paradigms for sustainable development: implications for management theory and research. Academy of Management Review, Vol. 20 No.4, pp. 874-907.

Glaser, B. 1978. Theoretical sensitivity: Advances in the methodology of grounded theory. Mill Valley, CA: Sociology Press.

Glaser, B. 1992. Basics of grounded theory analysis: Emergence vs. forcing. Mill Valley, CA: Sociology Press.

Glaser, B., \& Strauss, A. 1967. The discovery of grounded theory: Strategies for qualitative research. Chicago: Aldine.

Godfrey Paul C. 2011: Toward a Theory of the Informal Economy, The Academy of Management Annals, 5:1, 231-277

Golden, K. A. 1992. The individual and organizational culture: Strategies for action in highly ordered contexts. Journal of Management Studies, Vol. 29, 1-21.

Gordon, George G. 1991. Industry Determinants of Organizational Culture. Academy of Management Review, Vol. 16(2): 396-415.

Gordon, George G., and Nancy DiTomaso. 1992. Predicting corporate performance from organizational culture. Journal of Management Studies. 29: 783-798.

Gotwon, G., Ditomaso, N. 1992. Predicting corporate performance from organizational culture. Journal of Management Studies. Vol. 29(6), 783-798.

Guba, E., \& Lincoln, Y.1994. Competing paradigms in qualitative research. In N. Denzin \& Y. Lincoln (Eds.), Handbook of qualitative research (pp. 105-117). London: Sage.

Handy, C. 1997 Looking Ahead : Implications for the present. Harvard Business Review, Jan-Feb.

Hansen, G.S. \& Wernerfelt, B. 1989. Determinants of firm performance: The relative importance of economic and organizational factors. Strategic Management Journal. Vol.10, 399-411. 
Harris, L. C., Ogbonna, E. 2002. The Unintended consequences of culture interventions: A study of unexpected outcomes. British Journal of Management. Vol. 13(1), 31.

Harris, S.G.1994. Organizational culture and individual sense making: A schema-based perspective. Organization Science. Vol. 5(3), 309-321.

Hart, K. 1973. Informal Income Opportunities and Urban Employment in Ghana. Journal of Modern African Studies Vol 11 61-89.

Hart, S.L. 1997. "Beyond greening: strategies for a sustainable world", Harvard Business Review, pp.67-76.

Hawkins, P. 1997. Organizational culture: Sailing between evangelism and complexity. Human Relations, Vol. 50(4), 417-40.

Hayes, N., Lemon, N. (1990). Stimulating positive cultures: The Concorde Informatics case. Leadership and Organization Development Journal (UK), Vol. 11(7), 17-21.

Hechavarria, Diana M. \&Paul D. Reynolds. 2009. Cultural norms \& business start-ups: the impact of national values on opportunity and necessity entrepreneurs. The International Entrepreneurship and Management Journal 5, 4: 417

Hofstede, G. 1986. The usefulness of the 'organizational culture' concept. Journal of Management Studies, Vol. 23(3), 253-277.

Hofstede, G., Neuijen B., Denise D. O. \& Sanders G. 1990. Measuring organizational cultures: A qualitative and quantitative study across twenty cases. Administrative Science Quarterly, Vol. 35(2), 286-316.

Hofstede.1986. Cultural differences in teaching and Learning. International Journal of Intercultural Relations.10, 301-320.

Hosmer, L.T. 1994. Strategic planning as if ethics mattered. Strategic Management Journal, 15, 17-34.

Hudson, R., \& Wehrell, R. 2005. Socially responsible investors and the micro-entrepreneur: A Canadian case. Journal of Business Ethics, 60(3), 281-292.

Hwee Hoon Tan, Augustine K H Lim. 2009. Trust in Coworkers and Trust in Organizations. The Journal of Psychology, 143(1), 45-66.

ICMISIE. 2009. Interregional Cooperation on the measurement of Informal sector and Informal Employment http://www.unescap.org/stat/isie/index.asp last updated 24th November 2009

ICRA.2006. A Report on "Indian Gems and Jewellery Sector Analysis 2006-07” www.icra.in

ILO and Delhi Group. 2007. Draft Chapter 5 Informal Sector Establishment Surveys Manuel on Surveys of Informal Employment and Informal Sector. 
ILO. 1972. Employment, Incomes and Equality: A Strategy for Increasing Productive Employment in Kenya. Geneva: ILO.

ILO. 1972. International Labor Organization Report Employment, Incomes and Equality: A Strategy for Increasing Productive Employment in Kenya. Geneva: ILO.

ILO. 1993. Report of the Fifteenth International Conference of Labor Statisticians, Geneva, 19-28 January. Doc. ICLS/15/D.6 (rev.1), Geneva.

ILO. 2002. Women and Men in the Informal Economy: A Statistical Picture. Geneva.

ILO. 2011. Statistical Update on Employment in the Informal Economy. ILO Department of Statistics, June, 2011

Jackson, T., Kotze, E. 2005. Management and change in the South African National Defence Force: A cross-cultural study. Administration \& Society, Vol. 37(2), 168-198.

Jermier, J. M., Slocum Jr., John W., Fry, Louis W. \&Gaines, J. (1991). Organizational sub-cultures in a soft bureaucracy: Resistance behind the myth and façade of an official culture. Organization Science. Vol. 2(2), 170-194.

Johanson, J. \&Vahlne, J.E. 2009. The Uppsala internationalization process model revisited: From liability of foreignness to liability of outsidership. Journal of International Business Studies. Vol. 40 pg 41-43

Johnson, S., D. Kaufmann, and A. Shleifer. 1997. The Unofficial Economy in Transition. Brooking Papers of Economic Activity, 0:2, pp. 159-221

Johnson, V. 2007. What Is Organizational Imprinting? Cultural Entrepreneurship in the Founding of the Paris Opera. American Journal of Sociology v. 113 no. 1 p. 97-127

Jones, G. 1983. Transaction costs, property rights, and organizational culture: An exchange perspective. Administrative Science Quarterly, 28(3), 454-467.

Jung Dong I, \& Bruce J Avolio. 1999. Effects of leadership style and followers' cultural orientation on performance in group and individual task conditions. Academy of Management Journal, 42(2), 208-218.

Kale, S. H., Barnes, J. W. 1992. Understanding the domain of cross national buyer-seller interactions. Journal of International Business Studies, Vol. 23(1), 101-132.

Kanbur, \& E. Ostrom (Eds.). Linking the formal and informal economy (pp. 93-120). Oxford, England: Oxford University Press.

Karahanna, E., Evaristo, J. R., Srite, M. 2005. Levels of culture and individual behavior: An integrative perspective. Journal of Global Information Management, Vol. 13(2), 1-20.

Khanna, T., \& Rivkin, J.W. 2001. Estimating the performance effects of business groups in emerging markets. Strategic Management Journal, 22, 45-74. 
Khavul, S., Bruton, G. D., \& Wood, E. 2009. Informal family business in Africa. Entrepreneurship: Theory \& Practice, 33(6), 1219-1238

Klein, A. S., Masi, R. J., \& Weidner, C. K., II. 1995. Organization culture, distribution, and amount of control, and percep- tions of quality. Group and Organization Management, 20: 122148.

Komulainen, H., Mainela, T., \&Tähtinen, J. 2006. Social networks in the initiation of a high-tech firm's internationalization. International Journal of Entrepreneurship and Innovation Management, 6(6): 526-541.

Kotter, J. P. \& Heskett, J. L. 1992. Corporate culture and performance. New York: The Free Press.

Kralewski, J.E., Kaissi, A.D.,Bryan E. 2008. Culture as a management tool for medical groups. Physician Executive, Vol. 34(5), 12-18.

Kroeber, A. L., \& Kluckhohn, C. 1952. Culture: A critical review of concepts and definitions. New York: Vintage Books.

Kumar K., van Dissel, H., and Bielli. P. 1998. The merchant of Prato-revisited: toward a third rationality of information systems. MIS Quarterly. Vol 22 Issue 2, 1998, 199-226

Kunda,G. 1992.Engineering Culture. Philadelphia: Temple University Press.

Kurian V. 2002. No Problems here : Success, Complacency and Suspicion in the Indian Diamond Industry".

Kwan, P. \& Walker, and A. 2004. Validating the competing values model as a representation of organizational culture through inter-institutional comparisons. Organizational Analysis. Vol. 12(1), p21-37.

Lazzarini, S. G., G. J. Miller, and T. R. Zenger. 2004. Order with some law: complementarity vs. substitution of formal and informal arrangements. Journal of Law, Economics and Organization 20:261-298.

Lee, S., Jean K. \& Yu K. 2004. Corporate culture and organizational performance. Journal of Managerial Psychology. Vol. 19(4), 340-359.

Lewin, K. 1951. Field Theory in Social Science. New York: Harper \& Row.

Lewis D. 1996. The organizational culture saga - from OD to TQM: a critical review of the literature. Part 1 - concepts and early trends. Leadership \& Organization Development Journal, Vol. 17 Issue. 1, pp.12 - 19

Lewis D. 2002. Five years on - the organizational culture saga revisited. Leadership and Organization Development Journal Vol 23, 5. 280-287

Lewis, D.S. 1994. Organizational change: relationship between reactions, behavior and organizational performance. Journal of Organizational Change Management, Vol. 7(5), 41-55. 
Li, J.L., Zhou, K.Z., \& Shao, A.T. 2009. Competitive position, managerial ties, and profitability of foreign firms in China: An interactive perspective. Journal of International Business Studies, 40, $339-352$.

London, T., \& Hart, S.L. 2004. Reinventing strategies for emerging markets: Beyond the transnational model. Journal of International Business Studies, 35(5), 350-370.

Lucas C. \& Theresa K. 2008. Understanding the influence of organizational culture and group dynamics on organizational change and learning. The Learning Organization. Vol. 15(3), 277.

Lund, D.B. 2003. Organizational culture and job satisfaction. Journal of Business and Industrial Marketing. Vol. 18(3), 219-236.

Maignan, I. \& Ferrell, O.C. 2001. Antecedents and benefits of corporate citizenship: an investigation of French businesses. Journal of Business Research, Vol. 51(1), 37-51.

Maloney, William. 2004.Informality Revisited. World Development Vol. 32 (7)

Marcoulides, G. A., Heck, R. H. 1993. Organizational culture and performance: Proposing and testing a model. Organization Science. Vol. 4(2), 209-225.

Martin, J. \& Siehl, C. 1983. Organizational culture and counter culture: An uneasy symbiosis. Organizational Dynamics, 12(2), 52-64.

McKinsey Global Institute. 2006. Driving Growth: Breaking Down Barriers to Global Prosperity. Harvard Business School Press

Meyerson, D.E. \& Martin J. 1987. Culture change: An integration of three different views. Journal of Management Studies, Vol.24, 623-647.

Miles, M., \& Huberman, A. M. 1984. Qualitative data anal-ysis. Beverly Hills, CA: Sage Publications.

Mintu-Wimsatt, A., Gassenheimer, J. B. 1996. Negotiation differences between two diverse cultures. European Journal of Marketing, Vol. 30(4), 20.

Mintzberg, H.1979. An emerging strategy of "direct" re-search. Administrative Science Quarterly, $24,580-589$.

Morsing M., Oswald,D. 2009. Sustainable leadership: management control systems and organizational culture in Novo Nordisk A/S. Corporate Governance, 9(1), 83-99.

Moser, Caroline N. 1978. Informal Sector or Petty Commodity Production: Dualism or Independence in Urban Development? World Development, Vol. 6, 9-10.

Murphy, M. G., Davey, K. M. 2002. Ambiguity, ambivalence and indifference in organizational values. Human Resource Management Journal. Vol. 12(1), 17-32.

New York: Free Press 
Nicholson, N., Rees, A. \& Brooks-Rooney, A. 1990. Strategy, innovation and performance. Journal of Management Studies, Vol. 27(5), 511-534.

Nichter, S., \&. Goldmark, L. 2009. Small firm growth in developing markets. World Development, 37(9), 1453- 1464.

Nwabuzor, A. 2005. Corruption and development: New initiatives in economic openness and strengthened rule of law. Journal of Business Ethics, 59(1/2), 121-138.

Ogbonna, E., Harris, L. C. 2002. Organizational culture: A ten year, two-phase study of change in the UK food retailing sector. Journal of Management Studies. Vol. 39(5), 673-706.

Oren Harari. 2002. The Trust Factor. Public Management, 84(8), 6-9.

Ouchi, W.G. 1981. Theory Z. How American Business Can Meet the Japanese Challenge. Addison-Wesley, Reading, MA.

Parker, H. 2011. Toward a definition of popular culture. History and Theory, 50(2), 147-70

Patricia Hind, Andrew Wilson, Gilbert Lensen. 2009. Developing leaders for sustainable business. Corporate Governance, 9(1), 7-20.

Personal Discussion. 2008. Indu Kaveti and Mary Ann Von Glinow with the Directors of Venus Jewel, a large sized CPD, in Surat and Mumbai, India

Peters, T., Waterman, R.1982. In Search of Excellence: Lessons from America's Best-run Companies. Harper \& Row, New York.

Petrock, F. (1990). Corporate culture enhances profits. HR Magazine, Vol. 35(11), 64.

Pettigrew A. M. 1979. On studying organizational cultures. Administrative Science Quarterly, Vol. 24(4), 570-581.

Pettigrew, A. M. 1990. Conclusion: Organizational climate and culture: Two constructs in search of a role. In B. Schneider (Ed.), Organizational Climate and Culture: 413-434. San Francisco: Jossey-Bass.

Pierre A. B., Robert A. C., Richard E. P. 2006. Dysfunctional culture, dysfunctional organization: Capturing the behavioral norms that form organizational culture and drive performance. Journal of Managerial Psychology. Vol. 21(8), 709-732.

Piore, Michael J. \& Charles F. Sabel 1984. The Second Industrial Divide. New York: Basic books, 354 pp. Journal of Peace Research 24: 206

Pondy, L., Frost, P., Morgan, G., \& Dandridge, T. 1983. Organizational Symbolism. Grenwich, CT: JAI Press.

Poole, M. S. 1985. Communication and organization climates. In R. D. McPhee \& P. K. Thompkins (Eds.), Organizational Communication: Traditional Themes and New Directions. Beverly Hills, CA: Sage. 
Poole, M. S., \& McPhee, R. D. 1983. A structural analysis of organizational climates. In L.Putnam \& M. Pacanowsky (Eds.), Communication and Organizations: An Interpretive Approach, 195-220. Beverly Hills, CA: Sage.

Poppo, L., \& Zenger, T. 2004. Testing alternative theories of the firm: Transaction cost, knowledge-based, and measurement explanations for make-or-buy decisions in information services. Strategic Management Journal, 19, 853-877.

Porter, Lyman W. 1996. Forty years of organization studies: Reflections from a micro perspective. Administrative Science Quarterly, 41(2), 262.

Porter, Michael.1980 Competitive Strategy. New York : Free Press

Portes, A., Schauffler R. 1993. Competing perspectives on the Latin American informal sector. Population and Development Review Vol 19, 33-60.

Poupart, R., Hobbs, B. 1989. Changing the corporate culture to ensure success: a practical guide, National Productivity Review, Vol. 8(3), 223-238.

Quinn Laura, Maxine Dalton. 2009. Leading for sustainability: implementing the tasks of leadership. Corporate Governance, 9(1), 21-38.

Quinn, R.E. \& Rohrbaugh, J. 1983. A spatial model of effectiveness criteria: Towards a competing values approach to organizational analysis. Management Science, 29, 363-377.

Quinn, R.E., McGrath, M.R. 1985, "Transformation of organizational culture: a competing values perspective", in P. Frost (Eds), Organizational Culture, Sage Publications, Inc., Beverly Hill, CA

Rao, I \& Bhatnagar D. 2010. Surviving the Recession: Venus Jewel. A Case Study from the Indian diamond industry. Vikalpa: The Journal of Decision Makers, Vol 34 Issue 3 published by IIM A

Rao, I. 2010. Integrate Sustainability with Organizational Culture: Leadership and Trust as Moderators. Khoj. Indian Management Research Journal published by - MAEER's MIT School of Management Vol 1. Issue 1, journal listed in EBSCO

Rao,Indu. 2011. Behavioral Equivalence of Organizational Culture-A Conceptual Framework. GFJMR. Vol 2, Jan-June, 2011 ISSN 2229 -4651.

Rao, I \& Von Glinow, M.A. 2012. The Emergence of Informal Sector Firms in International Business: The Globally Distributed Indian Diamond Industry. Indore Management Journal. Vol 2 Issue 1 published by IIM Indore

Rashid, Md., Abdul Z., Sambasivan M., Azmawani A. R.(2004). The influence of organizational culture on attitudes toward organizational change. Leadership and Organizational Development, Vol. 25(2), 161-179.

Raskin, J. D. 2002. Constructivism in psychology: Personal construct psychology, radical constructivism, and social constructivism. In J. D. Raskin \& S. K. Bridges (Eds.), Studies in meaning: Exploring constructivist psychology (pp. 1-25). New York : Pace University Press. p. 4 
Reynolds, P. D. 2011. Informal and early formal financial support in the business creation process: Exploration with PSED II data set. Journal of Small Business Management, 49(1), 27-27-54.

Reynolds, Paul D.1986. Organizational culture as related to industry, position and performance: a preliminary report. Journal of Management Studies 23, 3: 333

Riley, P. 1983. A structural account of political cultures. Administrative Science Quarterly, Vol. $28,414-437$.

Rossman, G. B., Corbett, H. D., \& Firestone, W. A. 1988. Change and effectiveness in schools: A cultural perspective. Albany: State University of New York Press.

Ruighaver, A. B., Maynard, S.B. \& Chang, S. 2007. Organizational security culture: Extending the end-user perspective. Computers \& Security, Vol. 26(1), 56-62.

Saffold, G.S. III. 1988. Culture traits, strength, and organizational performance: moving beyond „strong“ culture. Academy of Management Review, Vol. 13(4), 546-58.

Salancik G. R. \& Jeffrey P. 1978. A social information-processing approach to job attitudes and task design. Administrative Science Quarterly, Vol. 23, 224-252.

Samuelson, R.J. 2001. The Spirit of Capitalism. Foreign Affairs published by the council of Foreign Relations. www.foreignaffairs.com

Saraph, J.V., Sebastian, R.J. 1993. Developing a quality culture. Quality Progress, Vol. 26(9), 73-8.

Sathe, V. 1983. "Implications of corporate culture: a manager's guide to action", Organizational Dynamics, No.Autumn, pp.5-23.

Saxenian, A. 2000. The origins and dynamics of production networks in Silicon Valley. In M. Kenney (Ed.), Understanding Silicon Valley (pp. 141-164). Stanford, CA: Stanford University Press.

Schein, E. H. 1996. Culture: The missing concept in organization studies. Administrative Science Quarterly, 41(2), 229.

Schein, E.H. 1983. The role of the founder in creating organizational culture. Organizational Dynamics, Summer, 13-28.

Schein, E.H. 1990. Organizational culture. American Psychologist, Vol. 45(2), 109-119.

Schien, E. H. 1985. Organizational Culture and Leadership. San Francisco:Jossey-Bass.

Schien, Edgar H.1983 “Organizational Culture”. Organizational Dynamics, 12:13-28

Schneider, B., \& Reichers, A. (1983). On the etiology of climates. Personnel Psychology. Vol. $36,19-39$. 
Schneider, F. and D. Enste. 2000. Shadow economies: size, causes and consequences. Journal of Economic Literature, American Economic Association. Vol 38, 77-114.

Schoonhoven, C. B., M. D. Burton, and P. D. Reynolds. 2009. "Reconceiving the Gestation Window: The Consequence of Competing Definitions of Firm Conception and Birth," in New Firm Creation in the United States: Initial Explorations with the PSED II Data Set. Eds. Paul D. Reynolds and Richard T. Curton. New York: Springer, 219-238.

Schwartz, H. \& Stanley M. D. 1981. Matching corporate culture and business strategy. Organizational Dynamics, Summer, 30-48.

Selznick, P. 1957, Leadership in Administration, Harper \& Row, New York, NY

Sethuraman, Salem V.1976. The Urban Informal Sector: Concept, Measurement and Policy. International Labour Review, Vol.114(1)

Sharma, D., \&Blomstermo, A. 2003. The internationalization process of Born Globals: A network view. International Business Review, 12(6): 739-753.

Sherwood, J.J. 1988. Creating work cultures with competitive advantage. Organizational Dynamics, Vol. 16, 5-26.

Simon B. \& Stephen M. 1999. Sustainability Indicators: Measuring the Immeasurable? Published by Earthscan, ISBN 185383498X,

Sinclair, A. 1993. Approaches to organizational culture and ethics. Journal of Business Ethics. Vol. 12(1), 63-73.

Sirmon, D. G., Lane, P. J. 2004. A model of cultural differences and international alliance performance. Journal of International Business Studies. Vol. 35(4), 306-319.

Smircich, L. 1983. Concepts of culture and organizational analysis. Administrative Science Quarterly, Vol. 28(3), 339-58.

Smith, S., Tranfield, D., Foster, M. \& Whittle, S. 1994. Strategies for managing the TQ agenda. International Journal of Operations and Production Management, Vol. 14(1), 75-88.

Spicer, A., McDermott, G.A., \& Kogut, B. 2000. Entrepreneurship and privatization in Central Europe: The tenuous balance between destruction and creativity. The Academy of Management Review, 25(3), 630-649.

Srivastava, P. 1995. "The role of corporations in achieving ecological sustainability", Academy of Management Review, Vol. 20 No.4, pp.936-60.

Stinchcombe, A. L. 1965. "Social Structure and Organizations". In March, J. G. Handbook of Organizations. Chicago: Rand McNally \& Co. pp. 142-193.

Strauss, A., \& Corbin, J. 1990. Basics of qualitative research: Grounded theory procedures and techniques. Newbury Park, CA: Sage. 
Strauss, A., \& Corbin, J. 1994. Grounded theory methodology: An overview. In N. Denzin \& Y. Lincoln (Eds.), Handbook of qualitative research (pp. 273-285). Thousand Oaks, CA: Sage.

Strauss, A., \& Corbin, J. 1998. Basics of qualitative research: Techniques and procedures for developing grounded theory (2nd ed.). Thousand Oaks, CA: Sage.

Stulhofer A. 1999. Between Opportunism and Distrust: Socio-Cultural Aspects of the Underground Economy in Croatia in Edgar L.Feige and Katarina Ott, eds., Underground Economies in Transition. Brookfield, VT :Ashgate p 44

Tagiuri R. \& Litwin G. 1968. Organizational Climate: Explorations of a Concept. Boston (Eds). Taormina. Robert J. 2008. Interrelating leadership behaviors, organizational socialization, and organizational culture. Leadership \& Organization Development Journal, Vol. 29(1), 85-102.

Thai, M., \& Turkina, E. 2012. Determinants of formal entrepreneurship versus informal entrepreneurship at the macro level. Presented at Academy of Management Conference, Boston.

The Boston Globe. May 15, 2011. "The MIT 150: 150 Ideas, Inventions, and Innovators that Helped Shape Our World". https://www.inventhelp.com/Alfred-Sloans-Concept-of-theCorporation.asp

Tokman, Victor. 1978. An Exploration into the Nature of the Informal-Formal Sector Relationship. World Development, Vol. 6 9-10.

Tourish, D., Pinnington, A. 2002. Transformational leadership, corporate cultism and the spirituality paradigm: An unholy trinity in the workplace? Human Relations, Vol. 55(2), 147.

Turner, J.H. 2004. Human institutions: A Theory of societal evolution. Lanham, MD: Rowman and Littlefield.

Van D.P. \& Sanders, G. 1993. Organizational culture as a missing link in quality management. International Journal of Quality and Reliability Management, Vol. 10(5), 5-15.

Van Maanen, J. 1988. Tales of the field: On writing ethnography. Chicago: Univ of Chicago Press.

Van Maanen, J., Barley, S.R.1985. Cultural organization: fragments of a theory. Frost. P.J., Moore

van Marrewijk, Were M. 2003. "Concepts and Definitions of Corporate Sustainability", Journal of Business Ethics, Vol. 44 pp.107-19

Wallace,M. \& Weese,W.J. 1995. Leadership, organizational culture, and job satisfaction in Canadian YMCA organizations. Journal of Sport Management, Vol. 9(2), 182-193.

Walumbwa F. O, Lawler J.J., Avolio B.J., Peng W., Kan S.2005.Transformational leadership and work related attitude: the moderating effects of collective and self-efficacy across cultures. Journal of Leadership \& Organizational Studies. Vol. 11, 2.

Webb, J.W., Tihanyi, L., Ireland, R.D., \& Sirmon, D.G. 2009. You say illegal, I say legitimate: Entrepreneurship in the informal economy. Academy of Management Review, 34(3), 492-510. 
Weber, Max. 1904 (1958). The Protestant Ethic and the Spirit of Capitalism. New York: Charles Scribner's Sons.

Weese, W. James. 1995. Leadership and Organizational Culture: An Investigation of Big Ten and Mid-American Conference Campus Recreation Administrations. Journal of Sport Management. Vol. 9 Issue 2, p119-134, 16p

Weick, K. 1999. Conclusion: theory construction as disciplines reflexivity: tradeoffs in the 1990s. Academy of Management Review, Vol. 24, 797-806.

Weick, K. 1969. The Social Psychology of Organizing. Reading, MA: Addison-Wesley.

Whipp, R., Rosenfeld, R. \& Pettigrew, A. 1989. Culture and competitiveness: evidence from two mature UK industries. Journal of Management Studies, Vol. 26(6), 561-85.

Wilkins, A., and Ouchi, W.G. 1983. Efficient cultures: exploring the relationship between culture and organizational performance. Administrative Science Quarterly, Vol. 28, 468-81.

Wilkins, A.L. 1983. The culture audit: a tool for understanding organizations. Organizational Dynamics, Autumn, 24-38.

Williams C.C. \& Nadin Sara. 2010. Entrepreneurship and the Informal Economy: An Overview. Journal of Developmental Entrepreneurship. Vol 15. No 4: 361-378

Williams, J.D., Sang-Lin H., Jerome D., Qualls, W.J. 1998. A conceptual model and study of cross-cultural business relationships. Journal of Business Research, Vol. 42(2), 135-143.

Williams, R. 1980. Problems in Materialism and Culture, Verso, London

Williamson, O.E. 1975. Markets and Hierarchies: Analysis and Antitrust Implications.

Witte, K., \& Muijen, J. 1999. Organizational culture: Critical questions for researchers and practitioners. European Journal of Work \& Organizational Psychology, 8(4), 583-595.

Wong, P., \& Ellis, P. D. 2002. Social ties and partner identification in Sino-Hong Kong international joint ventures. Journal of International Business Studies, 33(2): 267-289.

Yin, R.1981. The case study crisis: Some answers. Administrative Science Quarterly, 26, 58-65.

Zammuto, R. F., O'Connor, E. J. 1992. Gaining advanced manufacturing technologies" benefits: The roles of organization design and culture. Academy of Management Review, Vol. 17(4), 701728.

Zeitz, G., Johannesson, R., R, Jr., Edgar J. 1997. An employee survey measuring total quality management practices and culture. Group \& Organization Management, Vol. 22(4),

Zheng, Q.Q., Yang B. 2009. Toward a theory of organizational cultural evolution. Human Resource Development Review, Vol. 8(2), 151. 


\section{Appendix A. The Meaning of Informal Sector}

\section{Past}

The informal sector is the traditional economy that will wither away and die with modern, industrial growth.

It is only marginally productive.

It exists separately from the formal economy.

It represents a reserve pool of surplus labor.

It (the informal sector) is comprised mostly of street traders and very small-scale producers.

Most of those in the (informal) sector are entrepreneurs who run illegal and unregistered enterprises in order to avoid regulation and taxation.

Work in the informal economy is comprised mostly of survival activities and thus is not a subject for economic policy.
Present

The informal economy is 'here to stay' and expanding with modern, industrial growth.

It is a major provider of employment, goods and services for lower-income groups.

It contributes a significant share of GDP.

It is linked to the formal economy - it produces for, trades with, distributes for and provides services to the formal economy.

Much of the recent rise in informal employment is due to the decline in formal employment or to the informalization of previously formal employment relationships and contracts.

It (the informal sector) is made up of a wide range of informal occupations - both 'resilient old forms' such as casual day labor in construction and agriculture as well as 'emerging new ones' such as temporary and part-time jobs plus homework for high tech industries.

It (the informal sector) is made up of non-standard wage workers as well as entrepreneurs and self-employed persons producing legal goods and services, albeit through irregular or unregulated means. Most entrepreneurs and the self-employed are amenable to, and would welcome, efforts to reduce barriers to registration and related transaction costs and to increase benefits from regulation; and most non-standard wage workers would welcome more stable jobs and workers' rights.

Informal enterprises include not only survival activities but also stable enterprises and dynamic growing businesses, and informal employment includes not only selfemployment but also wage employment. All forms of informal employment are affected by most (if not all) economic policies.

Source: Chen, Martha, Joann Vanek and Marilyn Carr. 2004. Mainstreaming Informal Employment and Gender in Poverty Reduction: A Handbook for Policy-makers and Other Stakeholders. London: Commonwealth Secretariat. 


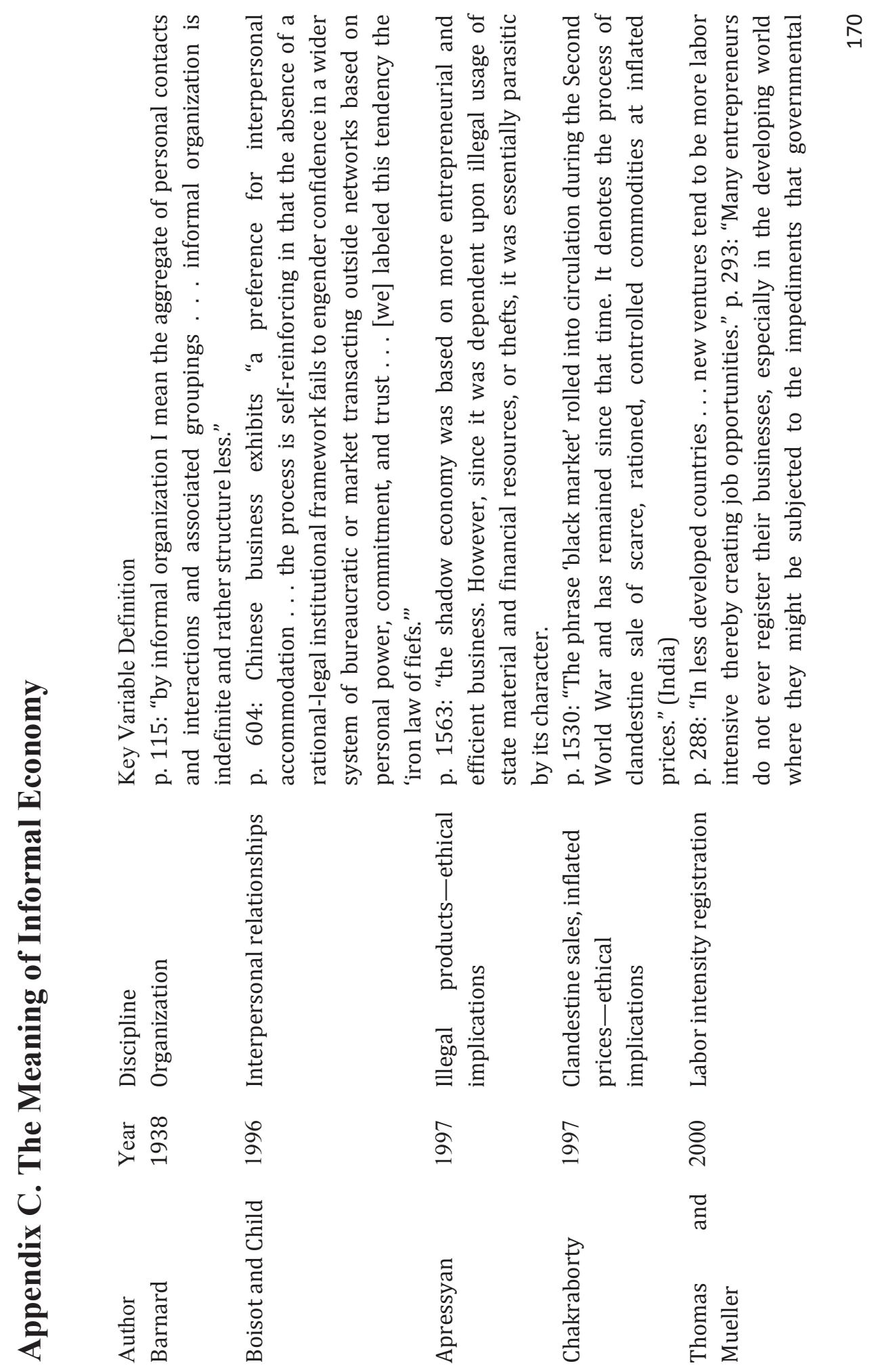




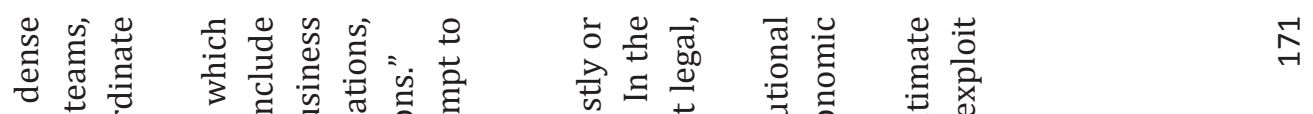

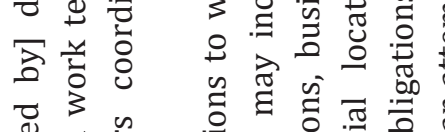

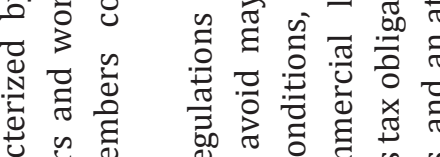

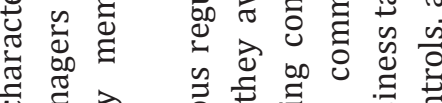

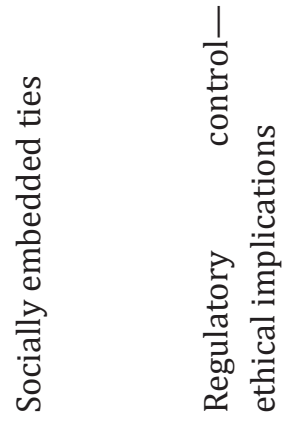

$\ddot{\text { ก }}$

$\ddot{\gamma}$ 苛

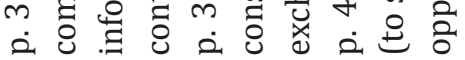

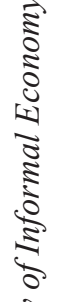

¿ั่ ڤัे

ซ్ $\quad \bar{\sigma}$

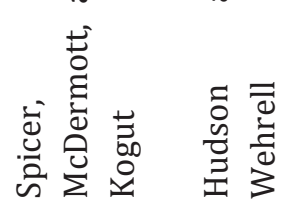

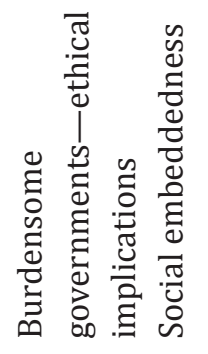

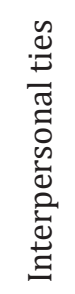

官

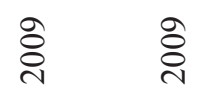

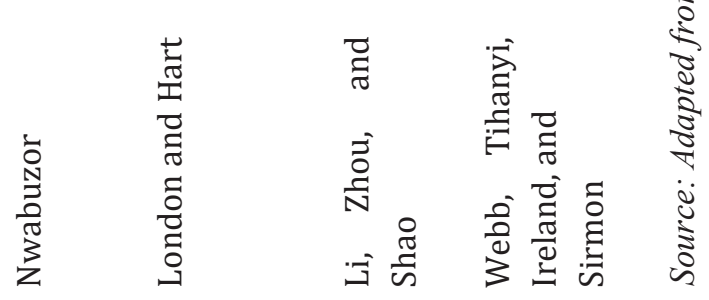




\section{Appendix B. Theories of Informal Sector}

Theories of the Informal Sector: Scholars have long tried to explain the existence and nature of the informal sector. In the following discussion we identify four key theoretical approaches to ISFs: the Dualist Approach; The Structuralist School; The Legalist School; and the Neo-Classical View. Our data indicate that these views are complementary - they are not substitutes for each other. Rather than being a complete theory in itself, each of the following four perspectives describe different aspects of the same phenomenon, that is, informal economy and Informal Sector Firms:

The dualist approach (ILO, 1972) considers the informal sector as comprising marginal activities, distinct and unrelated to the formal sector. Sethuraman (1976) and Tokman (1978) observe that informal activities emerge due to limited opportunities in the formal sector. They suggest that surplus labor, low economic growth, and high population growth act as catalysts for the under-privileged segment of the population to operate in the informal sector. These firms provide income for the poor and a safety net in times of crisis.

The structuralist school describes the informal sector as subordinated economic units (micro-firms) and workers that serve to reduce input and labor costs for large formal firms, thereby increasing the their competitiveness (Moser, 1978). Unlike the dualist model, the structuralist model views the formal and informal sectors as co-existing and inextricably linked and interdependent (Castells \& Portes, 1989). The focus of the structuralist perspective is on the nature of capitalist development, rather than on a lack of economic growth.

The legalist school posits that the informal sector is comprised of micro-entrepreneurs who choose to operate informally to avoid the costs, taxes, time and effort of formal registration (de Soto, 1989). This school believes that the ISFs will continue to produce informally so long as government procedures are cumbersome and expensive. The difficulties in creating legal businesses compel these relatively resource-poor firms to skip the formal-legal aspects of the process. Maloney, 2004, a neo-liberal economist, suggests that informal entrepreneurs deliberately avoid regulations and taxation and may deal in grey-market goods or even illegal goods and services. Informal entrepreneurs choose to operate in the underground or black economy illegally, or even criminally, so as to avoid taxation, commercial regulations, electricity and rental fees, and other costs of operating formally.

According to the neo-classical view (Schneider, 2000), the informal economy responds to the economic environment's demand for urban services and small-scale manufacturing. It adds a dynamic and entrepreneurial spirit to the industry and can lead to increased competition and higher efficiencies. The informal sector may also contribute to the creation of markets, increase financial resources, enhance entrepreneurship and transform the legal, social and economic institutions necessary for accumulation (Asea, 1996). 
Appendix D. OCAI Instrument

\begin{tabular}{|c|c|}
\hline Category/Content Dimension & Style (A = Clan; B = Adhocracy; C = Market; D = Hierarchy) \\
\hline 1. Dominant Characteristics & $\begin{array}{l}\text { A: Personal, like a family } \\
\text { B: Entrepreneurial, risk taking } \\
\text { C: Competitive, achievement oriented } \\
\text { D: Controlled and structured }\end{array}$ \\
\hline 2. Leadership style & $\begin{array}{l}\text { A: Mentoring, facilitating, nurturing } \\
\text { B: Entrepreneurial, innovative, risk taking } \\
\text { C: No-nonsense, aggressive, results oriented } \\
\text { D: Coordinating, organizing, efficiency oriented }\end{array}$ \\
\hline 3.Managementof employees & $\begin{array}{l}\text { A: Teamwork, consensus, and participation } \\
\text { B: Individual risk taking, innovation, freedom, and uniqueness } \\
\text { C: Competitiveness and achievement } \\
\text { D: Security, conformity, predictability }\end{array}$ \\
\hline 4. Organizational glue & $\begin{array}{l}\text { A: Loyalty and mutual trust } \\
\text { B: Commitment to innovation, development } \\
\text { C: Emphasis on achievement and goal accomplishment } \\
\text { D: Formal rules and policies }\end{array}$ \\
\hline 5. Strategic emphasis & $\begin{array}{l}\text { A: Human development, high trust, openness } \\
\text { B: Acquisition of resources, creating new challenges } \\
\text { C: Competitive actions and winning } \\
\text { D: Permanence and stability }\end{array}$ \\
\hline 6. Criteria for success & $\begin{array}{l}\text { A: Development of human resources, teamwork, concern for people } \\
\text { B: Unique and new products and services } \\
\text { C: Winning in the marketplace, outpacing the competition } \\
\text { D: Dependable, efficient, low cost }\end{array}$ \\
\hline
\end{tabular}




\section{Appendix E. The List of Variables Used in Analysis}

\begin{tabular}{|c|c|}
\hline $\begin{array}{l}\text { Variable } \\
\text { Name }\end{array}$ & Label \\
\hline A_Dom_Char & Venus is a very personal place. It is like an extended family. People seem to share a lot of themselves. \\
\hline B_Dom_Char & Venus is a very dynamic and entrepreneurial place. People are willing to stick their necks out and take risks. \\
\hline C_Dom_Char & Venus is very results oriented. A major concern is with getting the job done. People are very competitive and achievement oriented. \\
\hline D_Dom_Char & Venus is a very controlled and structured place. Formal procedures generally govern what people do. \\
\hline A_Org_Leader & The leadership in Venus is generally considered to exemplify mentoring, facilitating, or nurturing. \\
\hline B_Org_Leader & The leadership in Venus is generally considered to exemplify entrepreneurship, innovating, or risk taking. \\
\hline C_Org_Leader & The leadership in Venus is generally considered to exemplify a no-nonsense, aggressive, results-oriented focus. \\
\hline D_Org_Leader & The leadership in Venus is generally considered to exemplify coordinating, organizing, or smooth-running efficiency. \\
\hline A_Emp_Mgmnt & The management style in Venus is characterized by teamwork, consensus, and participation \\
\hline B_Emp_Mgmnt & The management style in Venus is characterized by individual risk-taking, innovation, freedom, and uniqueness. \\
\hline C_Emp_Mgmnt & The management style in Venus is characterized by hard-driving competitiveness, high demands, and achievement \\
\hline D_Emp_Mgmnt & The management style in Venus is characterized by security of employment, conformity, predictability, and stability in relationships. \\
\hline A_Org_Glue & The glue that holds Venus together is loyalty and mutual trust. Commitment to this organization runs high. \\
\hline B_Org_Glue & $\begin{array}{l}\text { The glue that holds Venus together is commitment to innovation and development. There is an emphasis on being on the cutting } \\
\text { edge }\end{array}$ \\
\hline C_Org_Glue & $\begin{array}{l}\text { The glue that holds Venus together emphasis on achievement and goal accomplishment. Aggressiveness and winning are common } \\
\text { themes. }\end{array}$ \\
\hline D_Org_Glue & The glue that holds Venus together is formal rules and policies. Maintaining a smooth running organization is important. \\
\hline A_Strat_Emph & Venus emphasizes human development. High trust, openness, and participation persist. \\
\hline B_Strat_Emph & $\begin{array}{l}\text { Venus emphasizes acquiring new resources and creating new challenges. Trying new things and prospecting for opportunities are } \\
\text { valued. }\end{array}$ \\
\hline C_Strat_Emph & Venus emphasizes competitive actions and achievement. Hitting stretch targets and winning in the marketplace are dominant. \\
\hline D_Strat_Emph & Venus emphasizes permanence and stability. Efficiency, control and smooth operations are important \\
\hline A_Cri_Success & $\begin{array}{l}\text { Venus defines success on the basis of the development of human resources, teamwork, employee commitment, and concern for } \\
\text { people. }\end{array}$ \\
\hline B_Cri_Success & Venus defines success on the basis of having the most unique of or newest products. It is a product leader and innovator \\
\hline C_Cri_Success & $\begin{array}{l}\text { Venus defines success on the basis of winning in the marketplace and outpacing the competition. Competitive market leadership is } \\
\text { key. }\end{array}$ \\
\hline D_Cri_Success & Venus defines success on the basis of efficiency. Dependable delivery, smooth scheduling, and low-cost production are critical \\
\hline Age & Age \\
\hline Gender & Gender \\
\hline JobProfile & Job Profiles \\
\hline Education & Level of Education \\
\hline ExpVenus & Experience (years) in the firm \\
\hline TotalExp & Experience(years) in the industry \\
\hline Department & Sub-unit of the CPD \\
\hline
\end{tabular}




\section{List of Publications and Presentations}

Publications:-

- $\quad$ Rao, I \& Von Glinow, M.A. 2012. The Emergence of Informal Sector Firms in International Business: The Globally Distributed Indian Diamond Industry. Indore Management Journal. Vol 2 Issue 1 published at IIM Indore

- Rao, I. 2011. Behavioral Equivalence of Organizational Culture-A Conceptual Framework. GFJMR. Vol 2, Jan-June, 2011 ISSN 2229-4651.

- Rao, I. 2010. Case Analysis of Tata Steelium: A Success Story in B2B Branding. Vikalpa: The Journal of Decision makers. Vol 35 Issue 2, 2010

- Rao, I. 2010. Integrate Sustainability with Organizational Culture: Leadership and Trust as Moderators. Khoj: Indian Management Research Journal published at - MAEER's MIT School of Management Vol 1. Issue 1

- Rao, I \& Bhatnagar, Deepti. 2009. Surviving the Recession: Venus Jewel-A Case from Indian Diamond Industry. Vikalpa : The Journal for Decision Makers, Vol 34,Issue 3 published at IIMA

\section{Conference Presentations:-}

- Rao, I \& Von Glinow, M.A. 2012. Organizing the Unorganized? Exploring Organizational Forms of Informal Firms of the Indian diamond Industry. Presented at the Academy of Management Annual Conference in Boston in August, 2012

- $\quad$ Rao, I, Newburry W. \& Gilbert R. 2012. Strategic Implications of Networks on Firm Performance in Public, Private and Not-For-Profit Sector: A Cross-National Study. Presented the Academy of International Business- South East Conference at Fort Lauderdale, October, 2012.

- Rao, I, 2011. An organizational Study of an informal firm of the Indian diamond industry. Presented at the Academy of International Business- South East Conference at Orlando.

- Rao, I \& Von Glinow, M. A. 2010. Implications of Global Crisis: Integrate sustainability with Organizational Culture. Leadership and Trust as Moderators. Presented at the Academy of International Business Annual Conference at Rio de Janeiro, Brazil, June, 2010.

- Rao, I. 2010. The Rise, Recession and Revival of Indian Diamond Industry. Presented at the Indian Academy of management Bi-Annual Conference at XLRI, Jamshedpur, Dec, 2010.

- Rao, I. 2010. The Behavioural Equivalence of Organizational Culture-A Conceptual Framework presented at the IMRC 2010 on Global Competitiveness through Human Resource Management at IIM, Bangalore, July, 2010.

- Rao, I. 2009. Implications of Global Crisis: Insights from Rise, Recession and Revival of Indian Diamond Industry. Presented at the 'India International Conference on Global Economic Crisis: Challenges \& Opportunities' the VII Academy of International Business-India Chapter Conference at IILM, New Delhi in Dec, 2009.

- Rao, I. \& Von Glinow. 2008. Organizing the Unorganized? GDW in India's Labor - Intensive, Unorganized Diamond Industry. presented at International Conference Globalization and Emerging Economies' of the Academy of International Business-India Chapter at IIM Indore, Aug, 2008

- Rao, I. \& Von Glinow. 2007. GDW in India's Labor - Intensive, Unorganized Diamond Industry. presented at Second International Conference on Management of Globally Distributed Work at IIM Bangalore, July, 2007. 